\author{
UNIVERSIDADE DE SÃO PAULO \\ FCF / FEA / FSP \\ Programa de Pós-Graduação Interunidades \\ em Nutrição Humana Aplicada - PRONUT
}

\title{
VALIDAÇÃO DE UM QUESTIONÁRIO SEMI-QUANTITATIVO DE FREQÜÊNCIA ALIMENTAR ONLINE PARA FERRO
}

KARINA OCHSENHOFER

Dissertação para obtenção do grau de MESTRE

Orientadora: Prof ${ }^{\text {a. }}$ Dr $^{\text {a. }}$ Célia Colli

São Paulo

2007 


\author{
UNIVERSIDADE DE SÃO PAULO \\ FCF / FEA / FSP \\ Programa de Pós-Graduação Interunidades \\ em Nutrição Humana Aplicada - PRONUT
}

\title{
VALIDAÇÃO DE UM QUESTIONÁRIO SEMI-QUANTITATIVO DE FREQÜÊNCIA ALIMENTAR ONLINE PARA FERRO
}

KARINA OCHSENHOFER

Dissertação para obtenção do grau de MESTRE

Orientadora: Prof ${ }^{\text {a. }}$ Dr $^{\text {a. }}$ Célia Colli

São Paulo

2007 


\title{
VALIDAÇÃO DE UM QUESTIONÁRIO SEMI-QUANTITATIVO DE FREQÜÊNCIA ALIMENTAR ONLINE PARA FERRO
}

\author{
Comissão Examinadora \\ Profa. Dra. Célia Colli \\ Orientadora / Presidente
}

Dissertação para obtenção do grau de MESTRE

$1^{\circ}$. Examinador

$2^{\circ}$. Examinador

São Paulo, 20 de abril de 2007. 


\begin{abstract}
A Deus ...
... pela vida, saúde e força !!!
\end{abstract}

Ao grande e único amor da minha, meu “Anjo Romano" ...

\title{
Marcos Rogério das Neves
}

... meu eterno namorado, noivo, esposo, companheiro, amigo, amante, pai, filho. Por me fazer mulher, florescer em mim uma pessoa melhor a cada dia, me ensinar os valores mais preciosos da vida e transmitir o sentimento maior, supremo e divino - O AM OR !!! 


\section{AGRADECIMENTOS}

À Profa ${ }^{\mathrm{a}}$ Dra . Célia Colli por ter aceito ser minha orientadora

Ao Programa de Pós-Graduação Interunidades em Nutrição Humana Aplicada (PRONUT)

Ao Projeto Integrado de Nutrição Humana Aplicada (PRINUTHA), na pessoa de sua coordenadora Denise Cavallini Cyrillo

Ao Departamento de Alimentos e Nutrição Experimental da FCF / USP, na pessoa de Fernando Salvador Moreno

A Edílson Feitosa dos Santo, Elaine Midori Ychico, Jorge Alves de Lima e Mônica de Alis

A Luciana Setaro, Alice Gomes Lichtenthäler, Clariana, Renatinha, Andréa Pólo Galante, Mariana Carballo, Malu, Lili, Alexandre, Cristiane e Tatiana

Aos colegas do Laboratório de Nutrição

À todos aqueles que contribuíram para a realização deste trabalho 


\section{RESUMO}

\section{OCHSENHOFER, K. Validação de um Questionário Semi-quantitativo de Freqüência Alimentar online para ferro}

Foi utilizado um Questionário Semi-quantitativo de Freqüência Alimentar (QSFA) anteriormente validado para obter dados de ingestão de macronutrientes e cálcio, agora para obtenção online de dados de ingestão de ferro e de cálcio. Para tanto, foram selecionadas mulheres de 19 a 59 anos de idade, que participaram espontaneamente de um evento do PRINUTHA (Projeto Integrado de Nutrição Humana Aplicada) no CEPE-USP (Centro de Práticas Esportivas da USP), para responderem a um Recordatório de 24 Horas (RH24). Nos quatro meses seguintes foram obtidos mais quatro $\mathrm{RH} 24$ 's por telefone ou por e-mail. No mês seguinte as participantes preencheram o QSFA online. Este Questionário foi validado para ferro e para cálcio, uma vez que o coeficiente de correlação dos dados obtidos pelos RH24's e pelo QSFA corrigidos pela energia resultaram em valores de $r_{c}=0,402$ para ferro e $r_{c}=0,605$ para cálcio.

Palavras-chave: validação, Questionário de Freqüência Alimentar, ingestão, ferro, cálcio, mulheres 


\title{
ABSTRACT
}

\section{OCHSENHOFER, K. Validation of an online Semi-quantitative Food Frequency} Questionnaire for iron

\begin{abstract}
A Semi-quantitative Food Frequency Questionnaire (QSFA), previously validated, was used to obtain the intake of energy, carbohydrates, proteins, fat and calcium, now to obtain the intake of iron and calcium online. Therefore, women between 19 and 59 years old, who participated from PRINUTHA (Integrated Project of Human Nutrition) at the CEPE-USP (USP's Sport Practice Center) was selected to answer a 24 Hours Recall (RH24). At the next four months four more $\mathrm{RH} 24$ 's was obtained per telephone ou e-mail. At the next month the participants full an online QSFA. This questionnaire was validated for iron and calcium, resulting in an energy adjusted correlation coefficient $r_{c}=0,402$ for iron and $r_{c}=0,605$ for calcium.
\end{abstract}

Key-word: validation, Food Frequency Questionnaire, intake, iron, calcium, women 


\section{SUMÁRIO}

\section{Pág}

1 - INTRODUÇÃO

2 - REVISÃO DA LITERATURA ……............................................ 03

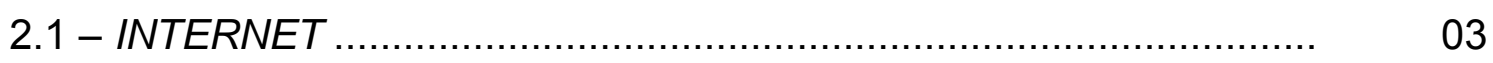

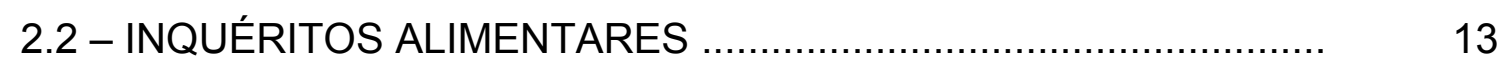

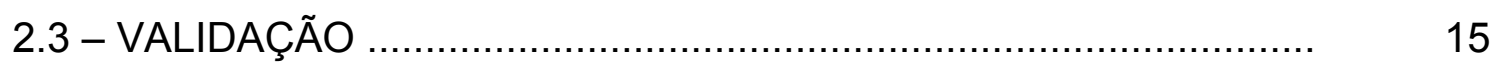

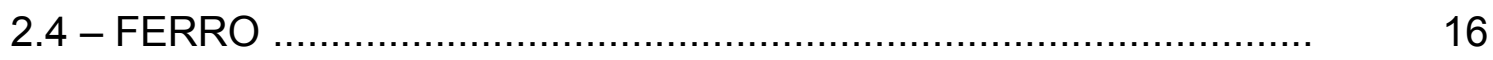

2.5 - AS DRI'S (DIETARY REFERENCE INTAKES) …..................... 18

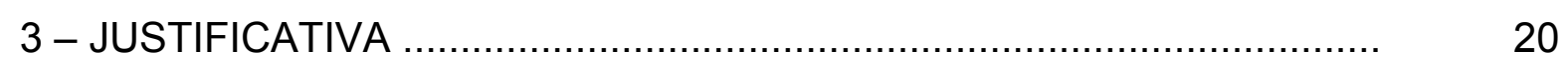

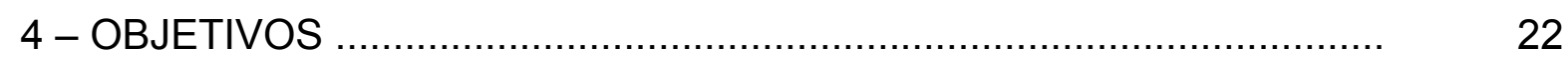

5 - CASUÍSTICA E MÉTODOS ......................................................... 23

5.1 - CASUÍSTICA ................................................ 23

5.2 - SELEÇÃO DA AMOSTRA ........................................ 24

5.3 - CARACTERIZAÇÃO DA AMOSTRA ............................. 25

5.4 - VALIDAÇÃO DO QSFA ........................................ 26

5.5 - ADEQUAÇÃO DA INGESTÃO DE FERRO E DE CÁLCIO ........... 28

5.6 - ANÁLISE ESTATÍSTICA .................................................... 29 
5.7 - ORIENTAÇÃO NUTRICIONAL ………………........................ 30

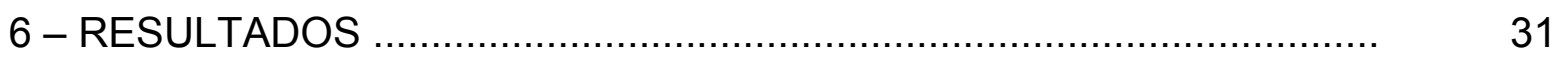

6.1 - ESTATÍSTICA DESCRITIVA ................................................... 31

6.2 - ESTATÍSTICA ANALÍTICA …………………….................... 38

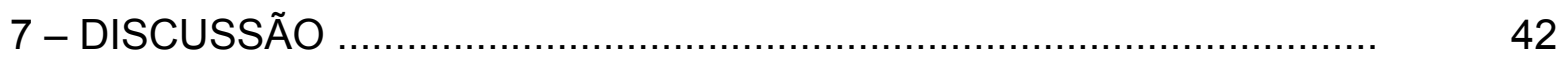

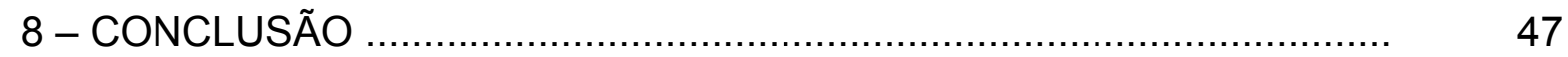

9 - REFERÊNCIAS BIBLIOGRÁFICAS …................................................. 48

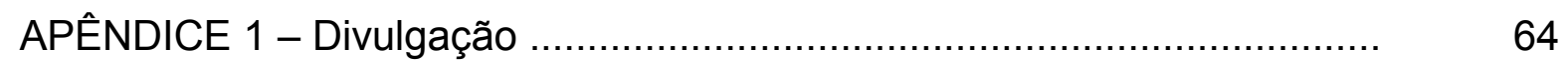

APÊNDICE 2 - Termo de Consentimento Livre e Esclarecido ...................... 65

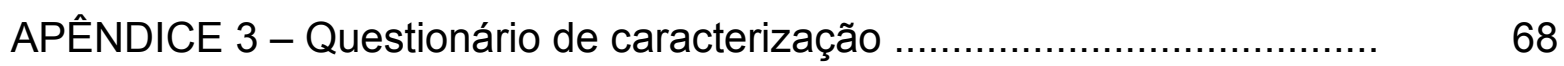

APÊNDICE 4 - Itens alimentares do software "Nutriquanti" ......................... 71

APÊNDICE 5 - Instrução para o preenchimento do QSFA online ............... 76

APÊNDICE 6 - Normas para o exame de Qualificação …………................ 81 


\section{FIGURAS E TABELAS}

Pág

Tabela 1 - Cronograma de desistência das mulheres durante as etapas do estudo, USP, São Paulo, 2005

Figuras 1 - Classificação da amostra ( $\mathrm{n}$ inicial $=100)$ de acordo com a faixa etária, o estado nutricional, a instrução, a ocupação e a prática de atividade física, USP, São Paulo, 2005. Distribuição percentual.

Figuras 2 - Classificação da amostra (n final $=40$ ) de acordo com a faixa etária, o estado nutricional, a instrução, a ocupação e a prática de atividade física, USP, São Paulo, 2005. Distribuição percentual.

Tabela 2 - Ingestão de nutrientes por mulheres $(n=40)$ de 19 a 59 anos de idade a partir de Recordatórios de 24 horas (média $n=5$ ) e QSFA ( $n=$ 1). Valor calórico, macronutrientes, ferro e cálcio, USP, São Paulo, 2005 ..

Tabela 3 - Distribuição de mulheres $(n=40)$ segundo a adequação da ingestão de ferro, segundo as DRI's (2003), a partir de RH24's ( $n=5$ ), USP, São Paulo, 2005

Tabela 4 - Distribuição de mulheres $(n=40)$ segundo a adequação da ingestão de cálcio, segundo as DRI's (2003), a partir de RH24's ( $=5$ ), USP, São Paulo, 2005

Figura 3 - Distribuição da ingestão de ferro por mulheres $(n=40)$ de 19 a 59 anos de idade, segundo as DRI's (2003), a partir de RH24's ( $n=5)$ e QSFA ( $n=1)$, USP, São Paulo, 2005 
Figura 4- Distribuição da ingestão de cálcio por mulheres $(n=40)$ de 19 a 59 anos de idade, segundo as DRI's (2003), a partir de RH24's ( $n=5)$ e QSFA ( $n=1)$, USP, São Paulo, 2005

Figura 5 - Histograma da distribuição da ingestão de energia, ferro e cálcio por mulheres $(n=40)$ de 19 a 59 anos de idade, a partir de RH24's $(n=5)$, USP, São Paulo, 2005

Figura 6 - Histograma da distribuição da ingestão de energia, ferro e cálcio por mulheres $(n=40)$ de 19 a 59 anos de idade, a partir de QSFA ( $n=1)$, USP, São Paulo, 2005

Figura 7 - Histograma da distribuição da ingestão de energia, ferro e cálcio por mulheres $(n=100)$ de 19 a 59 anos de idade, a partir de RH24's ( $n=5)$, USP, São Paulo, 2005

Tabela 5 - Ingestão de ferro por mulheres ( $n=40)$, a partir de $\mathrm{RH} 24$ 's, corrigida pela variação inter e intrapessoal, USP, São Paulo, 2005

Tabela 6 - Ingestão de cálcio por mulheres ( $n=40)$, a partir de RH24's, corrigida pela variação inter e intrapessoal, USP, São Paulo, 2005

Tabela 7 - Correlação dos dados de ingestão de ferro por mulheres ( $\mathrm{n}=$ 40) obtidos por RH24's e QSFA, antes e após o ajuste pela energia, USP, São Paulo, 2005

Tabela 8 - Correlação dos dados de ingestão de cálcio por mulheres ( $\mathrm{n}=$ 40) obtidos por RH24's e QSFA, antes e após o ajuste pela energia, USP, São Paulo, 2005 
Tabela 9 - Teste Kappa - categorização por quartis dos dados de ingestão de energia, ferro e cálcio por mulheres $(n=40)$ obtidos por RH24's e QSFA, USP, São Paulo, 2005 


\section{1 - INTRODUÇÃO}

A Internet é considerada um meio promissor para intervenções de promoção à saúde, em geral e tem grande potencial para a disseminação de educação nutricional personalizada, em particular (STREET, GOLD e MANNING, 1997).

As vantagens da Internet incluem o acesso rápido à informação, especialmente a acervos raros ou não disponíveis em meio impresso, bem como a possibilidade de atualização constante (KIPP, RADEL e HOGUE, 1996). Como desvantagens pode-se citar o excesso de informações e a dificuldade em garantir sua veracidade (KIPP, RADEL e HOGUE, 1996).

Sabe-se que o equilíbrio alimentar é fundamental para evitar disfunções nutricionais e que o excesso de alguns nutrientes está fortemente correlacionado com doenças crônicas não transmissíveis. Por outro lado, quando o objetivo é combater as deficiências nutricionais, o levantamento adequado do consumo alimentar é fundamental para elaborar e monitorar programas de combate à desnutrição (CESAR, CARANDINA, ALVES, BARROS e GOLDBAUM, 2005; MAJEM, 1995; ALBANO, 2005; MORIMOTO, 2005; NEUMANN, 2005).

Como nos demais países em desenvolvimento, no Brasil ainda são escassas as pesquisas sobre métodos de avaliação do consumo alimentar (MONDINI e MONTEIRO, 1994).

Os altos índices de anemia e de doenças causadas pela deficiência de ácido fólico, na população brasileira, levaram o Ministério da Saúde e a ANVISA (Agência Nacional de Vigilância Sanitária) tornar obrigatória a fortificação das farinhas de trigo e de milho, o que representou um avanço na política de Saúde Pública do país. A Resolução RDC no. 344 de 13 de dezembro de 2002 regulamenta que, a partir de junho de 2004, cada 100 gramas de farinha de trigo e de milho devem conter 4,2 mg de ferro e $150 \mu \mathrm{g}$ de ácido fólico. Com isso, as farinhas e seus derivados, como pães, biscoitos, bolos, macarrão e salgadinhos devem apresentar maior quantidade de ferro e de ácido fólico em sua formulação final (MINISTÉRIO DA SAÚDE, 2006).

O acompanhamento das alterações do consumo de ferro é importante na avaliação de possíveis excessos. Assim, novos estudos são de fundamental importância para o conhecimento dos hábitos alimentares da população, com a finalidade de desenvolver programas de saúde para a prevenção e/ou tratamento 
das deficiências ou excessos nutricionais (ESPINO et al., 2001; FISBERG, SLATER VILLAR, MORIMOTO e BUENO, 2005).

Questionários eletrônicos validados podem ser um instrumento precioso na avaliação do consumo alimentar, utilizados como alternativa a outros métodos já consolidados (ELEY, 1999; WISE, 1999). 


\section{2 - REVISÃO DA LITERATURA}

\section{1 - INTERNET}

\section{Histórico}

Há poucas dúvidas quanto à revolução atual na área da informação e entre os avanços tecnológicos, a Internet possivelmente represente o maior impacto cultural da década (BALARINE, 2002). Alguns autores já apontam a recente mudança de século como o momento de passagem para uma era pós-informação, caracterizada pela personalização das informações e remoção de barreiras geográficas (GATES, 1995; NEGROPONTE, 1995).

Desde o surgimento dos computadores eletrônicos, na década de 40, o tamanho e o preço dessas máquinas vêm caindo muito. Ao mesmo tempo, seu poder de processamento tem crescido quase que exponencialmente. Este fato possibilitou que, na década de 80 , ocorresse uma explosão do número de computadores existentes nas indústrias, nos estabelecimentos comerciais e nos grandes centros de ensino e pesquisa (KIPP, RADEL e HOGUE, 1996; SETZER e KON, 1997; SOSA-IUDICISSA, et al., 1997; GINSBERG-JAECKLE, 2004).

Conseqüentemente, veio à tona o desejo de interconectar as diversas máquinas localizadas em um mesmo edifício a fim de compartilhar os recursos disponíveis como já se fazia através dos computadores de grande porte. Desta forma, as redes locais se difundiram e começaram a fazer parte da vida profissional de um número cada vez maior de pessoas. Através de redes de escala mundial, como a Internet, por exemplo, tornou-se possível a troca de informações entre usuários presentes em qualquer parte do planeta (SETZER e KON, 1997; SOSAIUDICISSA, et al., 1997).

A Internet começou nos Estados Unidos, na década de 60, como produto da guerra fria. descendendo da rede militar ARPANET criada pelo departamento de defesa. Posteriormente, foi divulgado publicamente o Protocolo Internet (IP) que define detalhadamente um protocolo de comunicação entre diferentes redes locais de computadores. Juntamente com o IP, pode ser utilizado um outro protocolo chamado TCP. A rede Internet é formada por todos os computadores que se encontram interligados e que utilizam os protocolos TCP/IP para se comunicar 
(SETZER e KON, 1997; SOSA-IUDICISSA, et al., 1997; GINSBERG-JAECKLE, 2004).

Também chamada de WWW ou $\mathrm{W}^{3}$, a "teia de alcance mundial" ou "rede mundial de computadores" é uma poderosa ferramenta para obtenção de informações na Internet. Oferece uma interface do tipo hipertexto multimídia ou hipermídia, permitindo que o usuário navegue através de milhares de telas interligadas contendo textos, sons, imagens animadas ou não (GATES, 1995; NEGROPONTE, 1995; SETZER e KON, 1997; SOSA-IUDICISSA, et al., 1997).

A rede Internet pode ser considerada como fruto de uma tecnologia (o software que a implementa) sobre outras duas tecnologias (a rede física e o computador). Como qualquer tecnologia, elas não são neutras: quando em uso normal, sempre apresentam efeitos colaterais indesejáveis. Para que estes possam ser diminuídos e para não afetarem demasiadamente os usuários, é preciso conhecê-los. Além disto, é preciso conhecer os problemas causados pelas máquinas para colocá-las em seu devido lugar, dominando-as no lugar de ser por elas dominado. Dentre os perigos do computador, estão os seguintes: indução de pensamento restrito, sensação de poder e frustração, velocidade, indisciplina mental, informações telegráficas, excesso de correspondência, dilúvio de informações, atração pelo meio, pornografia, aberrações, solução geral (SETZER e KON, 1997; SOSA-IUDICISSA, et al., 1997).

Atualmente, a Internet integra computadores de universidades, institutos de pesquisa, empresas comerciais, sistemas privados de interligação de pessoas físicas e diversos outros tipos de organizações, em dezenas de países dos cinco continentes (SETZER e KON, 1997; SOSA-IUDICISSA, et al., 1997).

O surgimento de computadores pessoais com dispositivos de ligação à rede telefônica (modems) permitiu, por sua vez, a presença de pessoas físicas a partir de seus lares, nas redes de longo alcance (SETZER e KON, 1997; SOSA-IUDICISSA, et al., 1997).

Em 1998, o Brasil tinha aproximadamente 3,8 milhões de usuários de Internet (IBGE, 1999), correspondendo a $2,35 \%$ da população, estando este número em constate crescimento. Em 2002, esta proporção aumentou para $8 \%$ da população brasileira (IBOPE, 2002).

Apesar de todo esse tamanho e complexidade, a Internet não possui órgãos 
dirigentes ou entidades responsáveis. A administração da rede, assim como o seu custo, é distribuída entre todas as entidades que a constituem (SETZER e KON, 1997).

\section{A Internet na área das Ciências da Saúde}

A utilização da Internet na área de saúde e nutrição é comum na sociedade atual (GOLDBERG, 2000), estando este tipo de informação em segundo lugar na relação de assuntos mais procurados. O público pode acessar, em frações de segundos, uma enorme variedade de informações sobre estes temas, em mais de 15 mil websites (sítios da rede mundial de comunicações) (NATIONAL TELECOMMUNICATIONS AND INFORMATION ADMINISTRATION, 2002).

Para serem eficientes, estratégias de promoção à saúde devem ser criativas, atraentes, de baixo custo e amplamente disseminadas. Oportunidades de alcançar grandes audiências são agora viáveis pelas tecnologias online (MILOI, 1996; DANIEL e BALOG, 1997; IZENBERG e LIEBERMAN, 1998). Tecnologias de informação oferecem grandes oportunidades de utilizar a Internet como um catalisador para estudos, discussões, soluções de problemas e ações sociais para promoção da saúde (LUTZ et al., 1999).

O crescente interesse na relação entre dieta e doenças crônicas criou a necessidade de se ter dados de consumo alimentar válidos, confiáveis, coletados de maneira padronizada e eficiente (SLATTERY et al., 1994).

O monitoramento do consumo alimentar pode ser feito por vários meios, inclusive pela Internet. A indústria alimentícia e de nutrição acatou esta nova tecnologia, com o desenvolvimento de programas específicos que permitem ao usuário analisar seu consumo dietético pela Internet. Estes programas podem ser de grande utilidade para profissionais da saúde e consumidores (PAINTER, 2000; NEIGHBORS-DEMBERECKYJ e PAINTER, 2002). Estudos apontam que indivíduos que monitoram seu consumo alimentar têm maior probabilidade de melhorarem sua qualidade de vida, do que aqueles que não o fazem (STREIT et al., 1991; BAKER e KIRSCHENBAUM, 1993; BOUTELLE e KIRSCHENBAUM, 1998).

Pelo grande investimento de tempo e de técnicas sofisticadas para a elaboração de programas de nutrição computadorizados, somente um número limitado destes foi desenvolvido até o momento (HARLOW, ROSENTHAL e 
ZIEGLER, 1985; VAILAS et al., 1987; FESKANICH et al., 1989; SLACK et al., 1989; SMUCKER et al., 1989; ENGLE et al., 1990).

Um levantamento feito no site de busca "Google", realizado em 2005, apresentou seis sites com programas que analisam dietas e promovem educação nutricional (NEIGHBORS-DEMBERECKYJ e PAINTER, 2002).

A Internet proporciona várias oportunidades de aprender, educar e trocar idéias. Pode ser uma ferramenta valiosa para profissionais da área da saúde, como extensão das fontes tradicionais de informação como, por exemplo, livrarias para sustentar pesquisas e a educação. Entretanto, deve-se ter em mente tanto seus potenciais como suas limitações. Ela não acaba com as fontes tradicionais de informações, como jornais, revistas e livros. Um pesquisador cuidadoso utiliza diversas fontes de pesquisa para obter as informações desejadas (KIPP, RADEL e HOGUE, 1996).

Profissionais da saúde têm se envolvido cada vez mais com as novas tecnologias online, devendo ser pró-ativos e se familiarizar com o novo ambiente. $O$ mercado para serviços de nutrição e saúde é complexo, oferecendo grandes oportunidades para profissionais desta área. A Internet promove empregos e novas oportunidades de melhor comunicação com o cliente, proporcionando um meio de desenvolvimento de recursos inovadores e programas criativos para influenciar consumidores (SUTHERLAND, 1999).

\section{Utilização do e-mail (correio eletrônico) na realização de pesquisas}

O serviço mais utilizado na Internet é o e-mail. Através dele é possível enviar mensagens para qualquer usuário que possuir uma conta em uma máquina da Internet (SETZER e KON, 1997; SOSA-IUDICISSA, et al., 1997).

Aconselhamento via e-mail traz flexibilidade para o profissional bem como para o paciente. Este meio de comunicação permite rápida troca de informações e não apresenta barreiras geográficas. Pessoas de locais distantes podem usufruir desta ferramenta, sem precisar locomover-se até um consultório, por exemplo (THACH, 1995; ELEY,1999; PALUMBO, 1999).

As desvantagens do e-mail são seu acesso limitado somente àqueles que possuem computador, o entendimento incorreto e/ou incompleto das informações transmitidas e a não preservação de identidade que pode comprometer a validade 
dos questionários eletrônicos (ELEY, 1999; PALUMBO, 1999).

É recomendado sempre ter cópias de segurança de todos os dados, pois apesar de eletrônicos, os mesmos valem como documento e podem ser requisitados em ocasiões futuras (ELEY, 1999; PALUMBO, 1999).

\section{Educação nutricional computadorizada}

A educação nutricional contribui para a promoção de hábitos alimentares e estilo de vida saudáveis (GOLDBERG, 2000).

As ciências da saúde podem se beneficiar com a substituição de questionários via correio tradicional pelos eletrônicos. Estudos comprovam que a taxa de retorno de questionários eletrônicos é maior do que a de questionários via correio convencional (MEHTA e SIVADAS, 1995). Idade, cultura, educação, posição socioeconômica, condições de saúde são somente alguns fatores que podem influenciar a adesão ou não de indivíduos à comunicação de massa (GOLDBERG, 2000).

O uso da tecnologia na educação nutricional proporciona custos mais baixos, melhor interatividade, redução do tempo entre a entrada de dados e a saída dos resultados, entre outros. Permite aos participantes a entrada direta dos dados, com um clique no mouse, por teclado, via sistema ativado por voz ou toque no monitor, por exemplo, aparecendo a resposta imediatamente na tela do monitor (OENEMA, BRUG e LECHNER, 2001).

A Internet foi avaliada em alguns estudos como ferramenta para coletar dados de indivíduos e auxiliar na educação nutricional, mostrando-se tão eficiente ou mais quando comparada às versões tradicionais. Questionários eletrônicos podem ser utilizados como uma inovação promissora para auxiliar nesta área. Através de programas específicos para computador, é possível conhecer os hábitos alimentares do usuário, compará-los com as recomendações e promover educação nutricional em tempo real. A coleta de dados é facilitada, agilizando dessa forma a troca de informações e mantendo a adesão dos participantes. Pessoas estão mais abertas online do que pessoalmente, possivelmente pela impessoalidade da comunicação eletrônica (DAVIS, 1999; PALUMBO, 1999; DiSOGRA e GLANZ, 2000; OENEMA et al., 2001; BOECKNER, 2002; BRUG et al. 2003; FISBERG, MARCHIONI e SLATER VILLAR, 2005).

A informatização de questionários dietéticos provou ser um método eficiente 
para coletar e processar dados de consumo alimentar em grande escala e para estudos de caso-controle multicêntricos. Porém é importante atentar para as vantagens e desvantagens do método computadorizado e manual. Os maiores custos para questionários informatizados são os iniciais, de programação (SLATTERY et al., 1994).

Um estudo aponta que aproximadamente foram necessários de 5 a 10 minutos para preencher um questionário computadorizado, enquanto que um similar em papel levou de 40 a 50 minutos para ser preenchido (SLATTERY et al., 1994). Outro estudo mostrou que para questionários que levam de 20 a 30 minutos para serem preenchidos, este tempo é reduzido em 3 minutos para a versão computadorizada (HARLOW, ROSENTHAL e ZIEGLER, 1985).

A entrevista por meio de computador pode ser percebida como menos pessoal do que a forma em papel. Porém, não foram encontradas objeções por parte dos participantes em responder a questionários eletrônicos (SLACK e VAN CURA, 1968).

\section{Efetividade da educação nutricional personalizada via Internet}

A técnica de elaborar informações personalizadas por meio de computador tornou-se popular na década passada, em pesquisas de mudanças de hábitos alimentares, sendo adotada atualmente por educadores nutricionais (DE VRIES e BRUG, 1999; SKINNER et al., 1999).

Educação nutricional personalizada pode ser considerada um moderno recurso para se segmentar grupos populacionais de interesse. Contribui com a individualização e personalização da educação em saúde, baseada em características sócio-demográficas, comportamentais, motivacionais, psicossociais, bem como físicas (DE VRIES e BRUG, 1999; KREUTER et al., 2000).

Informações personalizadas mostram-se tão eficientes ou mais do que aquelas genéricas, especialmente quando se trata da promoção de hábitos alimentares saudáveis (BRUG, CAMPBELL e VAN ASSEMA, 1999; LUTZ et al., 1999; SKINNER et al., 1999).

Quando se trata de educação nutricional, personalizar significa qualquer combinação de informações ou estratégias de mudança, com a intenção de atingir uma pessoa em especial, baseado em características próprias desta pessoa, 
relacionado com os resultados de interesse derivados da avaliação individual (KREUTER et al., 2000).

O processo de educação nutricional computadorizada e personalizada tenta imitar o processo de aconselhamento pessoal. Indivíduos são entrevistados e os dados são utilizados para estabelecer respostas e recomendações individualizadas (BRUG, OENEMA e CAMPBELL, 2003).

A intervenção personalizada de educação nutricional deve ser (BRUG, OENEMA e CAMPBELL, 2003):

- uma combinação de informações nutricionais ou estratégias de mudança de hábitos alimentares;

- direcionada a uma pessoa em especial;

- baseada nos hábitos alimentares desta pessoa e/ou no estágio de mudança, bem como nos determinantes destes hábitos;

- avaliada para uma pessoa em particular.

Material impresso tradicional para promoção de educação nutricional tem baixo custo, mas não fornece informações individualizadas para cada leitor (LUTZ et al., 1999). Material personalizado via computador é relativamente barato quando comparado com aconselhamento pessoal e pode ser utilizado para educar um grupo grande de pessoas, podendo ser eficiente na promoção de hábitos saudáveis (CAMPBELL et al., 1994; SKINNER, STRECHER e HOSPERS, 1994; STRECHER et al., 1994; RIMER e GLASSMAN, 1998).

Aconselhar pessoalmente demanda muito tempo, conseqüentemente tem um alto custo e não atinge todas as pessoas. Atualmente é possível utilizar-se da tecnologia, de modo que um grande número de pessoas seja atingido pela educação nutricional personalizada, com custo relativamente baixo (BRUG, OENEMA e CAMPBELL, 2003).

Auto-avaliação é especialmente importante na educação nutricional. Muitas pessoas não têm a consciência da inadequação de seus hábitos alimentares (BRUG, HOSPERS e KOK, 1997; LECHNER et al., 1998).

As pessoas tendem a avaliar seu próprio comportamento, comparando-o com o de outros (BUUNK e GIBBONS, 1980). A educação nutricional personalizada permite fornecer respostas individualizadas sobre consumo alimentar e adequação com as recomendações, tornando as pessoas conscientes de sua ingestão (BRUG, 
CAMPBELL e VAN ASSEMA, 1999; DE BOURDEAUDHUIJ e BRUG, 2000).

Um estudo mostrou que participantes que receberam resposta personalizada apreciam mais as informações e são mais conscientes de seu consumo alimentar do que aqueles que receberam informações genéricas, não personalizadas (OENEMA, BRUG e LECHNER, 2001).

Vários estudos comprovam que indivíduos que consomem uma dieta com teor de gordura acima do recomendado, acreditam que sua dieta é pobre em gordura (BRUG et al., 1994; GLANZ, BRUG e VAN ASSEMA, 1997; BRUG e VAN ASSEMA, 2001). Esta falta de consciência resulta em falta da necessidade de mudanças e, conseqüentemente, em falta de motivação (BRUG, OENEMA e CAMPBELL, 2003).

Estudos revelam que a maioria dos participantes em pesquisas eletrônicas têm um nível de escolaridade mais elevado e são casados. Argumenta-se que a educação nutricional personalizada e computadorizada é eficiente apenas para indivíduos com maior nível de escolaridade e motivação para mudar sua dieta, pois a maioria das pesquisas utiliza questionários e fornece resposta escrita (LUTZ et al., 1999; BRUG e VAN ASSEMA, 2000).

De fato, intervenções nutricionais computadorizadas, em geral, têm sido mais eficientes com pessoas de maior nível de escolaridade (PRESTON, BARANOWSKI e HIGGINBOTHAM, 1988). Indivíduos desmotivados não se dispõem a preencher a pesquisa ou não lêem a resposta personalizada, porque acham que não precisam mudar seus comportamentos alimentares, não havendo então motivo para participar (BRUG, OENEMA e CAMPBELL, 2003).

A maioria dos estudos sobre o impacto da educação nutricional personalizada via computador foram conduzidos com amostras intencionais, resultando em maior participação de mulheres, de pessoas motivadas, com maior nível de escolaridade (BRUG, OENEMA e CAMPBELL, 2003). Porém, um estudo conduzido em uma empresa com predominância de trabalhadores do sexo masculino resultou em $74 \%$ de adesão e na redução significativa do consumo de gordura do grupo que obteve educação personalizada, indicando que os homens podem estar interessados em uma resposta personalizada sobre sua dieta (BRUG et al., 1996).

Educação nutricional personalizada tende a ser mais efetiva do que a generalizada, para pessoas desmotivadas. Ademais, os desmotivados representam $34 \%$ do total de participantes, indicando que pessoas, mesmo desmotivadas, têm 
interesse em respostas personalizadas, quando isto lhes é oferecido. Além disto, os "Health Works for Women and FoodSmart Studies" (trabalhos de saúde para mulheres e estudos sobre alimentos) obtiveram sucesso com pessoas de menor poder aquisitivo e com populações minoritariamente femininas (CAMPBELL et al., 1999; CAMPBELL, TESSARO e DE VELLIS, 2002).

Para participantes com baixo nível de escolaridade, a questão da alfabetização pode influenciar na habilidade do uso e no entendimento do material impresso. Porém, para pessoas alfabetizadas, material personalizado pode ser de grande valia, pois contém somente as informações relevantes para o indivíduo (BRUG, OENEMA e CAMPBELL, 2003).

Aconselhamento personalizado pode não ser efetivo, pois os hábitos alimentares, muitas vezes, são involuntários ou não determinados pela própria pessoa, uma vez que alimentos podem ser comprados e preparados por terceiros. Entretanto, a educação nutricional familiar mostrou-se mais eficiente do que a individual (DE BOURDEAUDHUIJ e BRUG, 2000). Em contrapartida, um estudo falhou na tentativa de provar a superioridade da educação nutricional familiar em relação à individual (DE BOURDEAUDHUIJ et al., 2002).

Intervenções personalizadas e computadorizadas já foram testadas para incentivar a redução no consumo de gordura, parar de fumar, praticar mais atividade física, prevenir o câncer de mama, incentivar o registro de doadores de órgãos e proteger-se dos raios solares (BRUG e DE VRIES, 1999; SKINNER et al., 1999; REUBSAET et al., 2001; NOOIJER et al.).

Alguns estudos abordaram mais de um comportamento, como por exemplo consumo de frutas, vegetais e gorduras (BRUG et al., 1998; JAMES, CAMPBELL e HUDSON, 2002). A inclusão de mais fatores simultaneamente requer pesquisas mais extensas, o que configura em um problema. Abordar somente um comportamento, que os participantes consideram prioritário, representa um método promissor nas intervenções personalizadas (CAMPBELL, TESSARO e DE VELLIS, 2000).

Argumenta-se que a personalização das respostas, por exemplo colocandose o nome do receptor como na mala direta, determina o efeito da individualização. Porém isto é parcialmente verdadeiro, pois diversos estudos mostram que intervenções individualizadas têm maior efeito do que mensagens somente 
personalizadas. Isto prova que individualização é mais do que personalização (BRUG et al., 1996; BRUG et al. 1998; KREUTER et al., 2000). Somente informações relevantes para 0 indivíduo são incluídas em mensagens individualizadas, omitindo-se as irrelevantes (BRUG, OENEMA e CAMPBELL, 2003). 


\section{2 - INQUÉRITOS ALIMENTARES}

Os métodos de inquéritos alimentares foram descritos pela primeira vez em 1932 pela Organização de Saúde da Liga das Nações (Health Organization of the League of Nations). Em 1955, o Comitê Interdepartamental de Nutrição para Defesa Nacional (Interdepartamental Committee on Nutrition for National Defense) acompanhou populações de países em desenvolvimento na avaliação do seu estado nutricional, objetivando identificar os problemas de má nutrição e as maneiras de resolver os mesmos. Destes estudos, em 1963, surgiu o primeiro manual ou guia de orientação, com intenção de padronizar os métodos dos inquéritos alimentares bem como a interpretação dos resultados advindos destes métodos. Jelliffe, em 1966, consultou 25 especialistas no assunto de vários países e desenvolveu a segunda edição deste guia (GIBSON, 1990).

As técnicas para estimar a ingestão dietética podem ser classificadas em dois grandes grupos (GIBSON, 1990):

- prospectivas, utilizadas para avaliar o consumo atual, como registros dietéticos e recordatórios alimentares; e

- retrospectivas, utilizadas para avaliar a ingestão habitual de grupos específicos de alimentos para verificar a associação entre consumo alimentar e doença, como história dietética e questionário de freqüência alimentar.

No Recordatório de 24 horas ( $\mathrm{RH} 24$ ), o indivíduo relata seu consumo alimentar nas últimas 24 horas ou no dia anterior à entrevista. Este método é apropriado para se estimar o consumo usual de uma população, desde que a amostra seja representativa e os dias da semana adequadamente escolhidos. Usado para avaliar a relação entre dieta e doenças crônicas não transmissíveis, é um método barato, rápido, simples, pode ser usado para pessoas de baixa escolaridade ou analfabetas. O elemento surpresa garante não alterar os hábitos alimentares do indivíduo. Depende da memória, sendo inapropriado para idosos e crianças. Um único Recordatório pode omitir alimentos consumidos com menor freqüência (Gibson, 1990).

O Questionário de Freqüência Alimentar (QFA) utiliza uma lista de itens alimentares para registrar o consumo em um determinado período (dia, semana, mês, ano). Pode ser obtido através de entrevista ou ser auto-preenchido. Este 
método foi desenvolvido para obter dados qualitativos e descritivos do consumo usual de alimentos ou grupos de alimentos em um determinado período. Útil em estudos epidemiológicos, classificando indivíduos em categorias de consumo de alimentos e/ou nutrientes específicos, para comparar com as prevalências de determinada enfermidade. Também pode identificar o consumo inadequado de um determinado nutriente. É um método rápido, com alta taxa de receptividade, porém com menor acurácia (GIBSON, 1990).

Recordatórios alimentares são usados com freqüência por nutricionistas clínicos, para avaliar a adequação nutricional de indivíduos (STREIT et al., 1991; FISBERG, MARTINI e SLATER VILLAR, 2005).

Os inquéritos alimentares, realizados através de diferentes metodologias, apresentam como principal vantagem a possibilidade da medida direta do consumo de alimentos, propiciando assim condições para se inferir com maior precisão a quantidade de alimentos efetivamente consumida por famílias ou indivíduos. Dentre suas limitações está a dificuldade em se captar a grande variabilidade do consumo alimentar em um período curto de tempo (MONDINI e MONTEIRO, 1994). A validação dos questionários de freqüência alimentar é aceitável quando se faz a comparação da média de ingestão de nutrientes com outros métodos (WILLETT, 1998).

Ainda não há um método de avaliação do consumo alimentar totalmente eficaz, uma vez que todos apresentam algum tipo de limitação. Registros dietéticos colhidos em vários dias apresentam boa exatidão comparando-se com marcadores bioquímicos, considerados métodos padrão-ouro, porém de custo alto e difícil aplicação em grupos populacionais (WILLET, 1998; SLATER VILLAR, MARCHIONI e FISBERG, 2004).

Quando os inquéritos alimentares são auto administrados, os formulários podem ser entregues via correio normal ou via correio eletrônico (e-mail) (SHILS et al., 2001).

O primeiro Inquérito alimentar eletrônico foi desenvolvido por Stockley et al. em 1986, para avaliar o consumo alimentar de indivíduos por um período de três semanas (GIBSON, 1990). 


\section{3 - VALIDAÇÃO}

O termo validade é geralmente definido como o grau com que um instrumento mede o que se propõe a medir. Os estudos de validação são processos longos e difíceis nos quais as estimativas do consumo alimentar, pelo método escolhido, são comparadas com as obtidas por outro método de avaliação dietética considerado mais preciso e, portanto, de referência (GIBSON, 1990; SLATER VILLAR e LIMA, 2005; SLATER VILLAR, PHILIPPI, FISBERG e LATORRE, 2003; FISBERG, SLATER, MARCHIONI e MARTINI, 2005).

Devido à dificuldade de se medir a validade absoluta de inquéritos alimentares, pesquisadores adotaram a validade relativa, onde um método é comparado com outro de referência. A seleção do método de referência depende de vários fatores:

- acurácia e precisão: ambos devem ser altos no método de referência;

- tempo entre a coleta de dados: deve ser avaliado cuidadosamente, para um método não influenciar a resposta do outro;

- erros: devem ser independentes nos dois métodos;

- outros efeitos: como sazonalidade, dia da semana, uso de suplementos, atividade física, devem ser levados em consideração nos dois métodos (GIBSON, 1990).

Quando se decide validar um instrumento, os propósitos da avaliação dietética e o marco de referência devem estar claramente definidos, para posterior identificação dos fatores que poderão confundir o processo de validação. Não existe "padrão ouro" para estimar ingestão habitual. Compara-se um instrumento com outro julgado superior para aquele propósito. Portanto é importante escolher cuidadosamente o método de referência adequado para cada estudo (SLATER, PHILIPPI, MARCHIONI e FISBERG, 2003; FISBERG, SLATER, MARCHIONI e MARTINI, 2005).

Os métodos desenvolvidos para obter o consumo alimentar usual de indivíduos são os mais difíceis de serem validados, pois não se tem a certeza absoluta do consumo verdadeiro (GIBSON, 1990). 


\section{4 - FERRO}

O ferro é um dos micronutrientes mais estudados e melhor descritos na literatura, desempenhando importantes funções no metabolismo humano, como transporte e armazenamento de oxigênio, reações de liberação de energia na cadeia de transporte de elétrons, conversão de ribose a desoxirribose, co-fator de algumas reações enzimáticas e inúmeras outras reações metabólicas essenciais (COOK et al., 1992). A maior quantidade de ferro do organismo encontra-se na hemoglobina (YIP e DALLMAN, 1997; MARTINI, 2005).

A deficiência de ferro é responsável por $90 \%$ das anemias. A anemia ferropriva, diminuição anormal na concentração de hemoglobina no sangue, é considerada a principal conseqüência da deficiência de ferro e um dos grandes problemas nutricionais no mundo (COOK et al., 1992).

Estima-se que 2,15 bilhões de pessoas, ou seja, quase $30 \%$ da população do mundo, apresentam essa deficiência, sendo crianças até 5 anos de idade, gestantes e mulheres em idade fértil os grupos vulneráveis (VITERI et al., 1993; OMS, 1998).

No mundo desenvolvido, é a deficiência nutricional mais comum, com taxas de 7\% (RUSSEL et al., 1999), 11\% (LOOKER et al., 1997) e 13\% (GREGORY et al., 1990), resultados estes de amostras representativas nacionais de mulheres adultas em idade fértil da Nova Zelândia, Estados Unidos e Inglaterra, respectivamente.

Um estudo da Organização Mundial da Saúde (OMS) realizado em 1968, mostrou que a prevalência de anemia ferropriva em mulheres em idade fértil de países em desenvolvimento alcançava 50\% (FINCH e COOK, 1984).

No Brasil, como em outros países, as informações sobre a prevalência de anemia ferropriva ainda são escassas. Os dados disponíveis indicam que a prevalência de anemia situa-se entre 22\% e 45\% (PAHO/WHO, 1994).

Além de sua elevada magnitude, a anemia tem marcantes implicações no processo saúde / doença, interagindo com outras enfermidades, elevando assim as estatísticas de morbi-mortalidade (BOTHWELL, 1979; OLIVEIRA, 1990; COLLI e SZARFARC, 2004). Reduz ainda a capacidade de aprendizado e o rendimento do trabalho físico (FINCH e COOK, 1984; COLLI e SZARFARC, 2004).

O balanço de ferro é resultado da interação entre perdas, necessidades fisiológicas e ingestão. Qualquer estudo para investigar a etiologia da deficiência de 
ferro deve estimar o consumo de ferro de seus participantes. O Questionário de Freqüência Alimentar permite estimar as médias de ingestão de grupos populacionais (WILLETT, 1998; HEATH, SKEAFF e GIBSON, 2000; COLUCCI, PHILIPPI e SLATER VILLAR, 2004; MORAIS, SPINELLI, SOUZA, SOUZA e SESOKO, 2004). A avaliação do consumo dietético é a primeira etapa de um estudo de acompanhamento de uma população de risco e importante para o acompanhamento de programas de fortificação (PAIVA et al., 2000). 


\section{5 - AS DRI'S (Dietary Reference Intakes)}

Os dados de consumo de ferro e de cálcio obtidos pelos RH24's foram avaliados de acordo com as DRl's.

A DRI (Dietary Reference Intakes), ou Ingestão Dietética de Referência, é um conjunto de quatro valores de referência de ingestão de nutrientes, com maior abrangência do que as Recomendações Nutricionais, ou RDA's (Recommended Dietary Allowances), publicadas desde 1941 pela Academia Nacional de Ciências das Estados Unidos. As DRI's foram elaborada para substituir as RDA's e podem ser usadas para planejar dietas, definir rotulagem e planejar programas de orientação nutricional. São amplamente usadas na avaliação das dietas de grupos de indivíduos (IOM, 2006).

Assim como as antigas RDA's, cada DRI refere-se a uma ingestão de nutriente ao longo do tempo por indivíduos saudáveis. As DRI's diferem das RDA's pois, para a construção de seus limites foi considerado também o risco de redução de doenças crônicas não transmissíveis, tendo sido incluída a recomendação de ingestão diária máxima para prevenir riscos de efeitos adversos (IOM, 2006).

Vale ressaltar que as DRI's foram estabelecidas para as populações americanas e canadenses e, para sua aplicação para a população brasileira deve-se considerar os dados de ingestão dietética com seu erro associado (IOM, 2006).

\section{EAR (Estimated Average Requirement)}

A Necessidade Média Estimada é um valor de ingestão diária de um nutriente que se estima que supra as necessidades de $50 \%$ dos indivíduos saudáveis de um determinado grupo de mesmo gênero e estágio de vida. A EAR é utilizada na determinação da RDA.

\section{RDA (Recommended Dietary Allowance)}

A Ingestão Dietética Recomendada é o nível diário suficiente para atender as necessidades de um nutriente de $97-98 \%$ dos indivíduos saudáveis de um determinado grupo de mesmo gênero e estágio de vida. 


\section{Al (Adequate Intake)}

A Ingestão Adequada é utilizada quando não há dados suficientes para a determinação da RDA. É um valor prévio à RDA. Baseia-se em níveis de ingestão ajustados experimentalmente ou em aproximação da ingestão observada de um grupo de indivíduos saudável.

\section{UL (Tolerable Upper Intake Level)}

O Limite Superior Tolerável de Ingestão é o valor mais alto de ingestão diária continuada de um nutriente que aparentemente não oferece nenhum efeito colateral à saúde em quase todas as pessoas de um determinado grupo de mesmo gênero e estágio de vida. Não é um nível de ingestão recomendado. 


\section{3 - JUSTIFICATIVA}

Questionários eletrônicos fornecem economia de tempo e de recursos financeiros. O entrevistado pode respondê-los no horário que lhe for mais conveniente. O profissional que faz a avaliação também pode trabalhar a qualquer hora, quando mais lhe convier. Também oferecem melhor logística, pois os envios podem ser controlados pela confirmação da data e horário de transmissão e recepção das mensagens (THACH, 1995; ELEY,1999; PALUMBO, 1999).

A combinação da maior efetividade com a possibilidade de se atingir um grande número de pessoas, faz da educação nutricional personalizada e computadorizada uma técnica promissora, digna de maiores pesquisas (BRUG, OENEMA e CAMPBELL, 2003).

Este trabalho dá continuidade à validação de um QSFA online para obter o consumo de cálcio em mulheres (GALANTE, 2004), focalizando agora a ingestão de ferro, também de mulheres.

Atualmente, informações personalizadas via computador representam um dos mais promissores e inovadores acessos para a educação nutricional. Ainda pouco se sabe e novas pesquisas tornam-se necessárias para se descobrir quando, porque, aonde e para quem a educação nutricional personalizada e computadorizada é efetiva (BRUG, OENEMA e CAMPBELL, 2003).

Como não é possível concluir o quanto panfletos, folders ou vídeos sobre educação nutricional são efetivos, torna-se difícil afirmar conclusivamente que a educação nutricional personalizada e computadorizada é efetiva. Entretanto, diversos estudos demonstram que materiais personalizados geralmente são mais eficientes do que mensagens padronizadas (BRUG, CAMPBELL e VAN ASSEMA, 1999; SKINNER et al., 1999). Brug, Campbell e Van Assema (1999) concluíram que a educação nutricional personalizada é mais eficiente do que a genérica, especialmente para redução do consumo de gordura.

Até o momento, ainda não estão totalmente esclarecidos os motivos pelos quais a educação nutricional personalizada tem maior sucesso do que a não personalizada (BRUG, CAMPBELL e VAN ASSEMA, 1999; DE VRIES e BRUG, 1999; DIJKSTRA e DE VRIES, 1999; SKINNER et al., 1999; KREUTER et al., 2000).

A individualização das mensagens pode ser uma razão pela qual a educação 
nutricional personalizada é efetiva. Entretanto, também pode ser criticada pela sua abordagem individual e pela falta do componente social presente em aconselhamentos pessoais (BRUG, CAMPBELL e VAN ASSEMA, 1999).

O poder da educação nutricional personalizada está na habilidade de se transmitir informações individualizadas e relevantes. Entretanto, a personalização da educação nem sempre é necessária. Se os determinantes de um hábito alimentar específico diferem minimamente entre as pessoas de um grupo, a personalização torna-se desnecessária. Material genérico bem elaborado, que aborda os determinantes do hábito desta população, será relevante para a maioria destes indivíduos (BRUG, OENEMA e CAMPBELL, 2003). Kreuter et al. (2000) provaram que quando o material genérico é adequado aos determinantes dos hábitos da população e contém as informações necessárias, o impacto é tão bom quanto o da informação personalizada.

Mais pesquisas são necessárias para provar a maior eficiência de material personalizado para promoção de mudanças alimentares em adultos saudáveis (LUTZ et al., 1999).

Um Questionário de Freqüência alimentar pode ser um instrumento valioso dentro do PRINUTHA (Projeto Integrado de Nutrição Humana Aplicada), possibilitando a avaliação do consumo alimentar dos participantes deste projeto, bem como difundir o interesse na população em conhecer melhor seu estado nutricional e seus hábitos alimentares, oferecendo informação nutricional de forma simples e compreensível para pessoas leigas.

Para este estudo foi escolhido um QSFA para ser validado, por ser um método utilizado em vários estudos de avaliação do consumo alimentar de grupos de indivíduos, relacionando as deficiências e os excessos de consumo de determinados nutrientes com doenças crônicas não transmissíveis (GIBSON, 1990; WILLETT, 1998) 


\section{4 - OBJETIVOS}

GERAL:

- Validar um Questionário Semi-quantitativo de Freqüência Alimentar (QSFA) online, para estimar a ingestão de ferro e de cálcio, em relação aos Recordatórios de 24 Horas (RH24's).

ESPECÍFICO:

- Caracterizar a população de mulheres da comunidade USP, que expontaneamente se propõem a participar do PRINUTHA (Projeto Integrado de Nutrição Humana Aplicada).

- Avaliar a adequação do consumo de ferro e de cálcio obtido pelos RH24's e QSFA, de acordo com as DRI's (2003). 


\section{5 - CASUÍSTICA E MÉTODOS}

\section{1 - CASUÍSTICA}

O projeto de pesquisa foi enviado ao Comitê de Ética em pesquisa, em 01/02/2005, sob o número de protocolo CAAE - 0001.0.018.000-05 e aprovado em $30 / 03 / 2005$.

Realizou-se uma pesquisa de campo com 100 freqüentadoras do CEPE-USP (Centro de Práticas Esportivas da USP), no mês de abril de 2004, durante o evento "Semana de Cartão Vermelho ao Sedentarismo", dentro do PRINUTHA (Projeto Integrado de Nutrição Humana Aplicada) que está inserido no PRONUT (Programa Interunidades de Nutrição Humana Aplicada) da USP (Universidade de São Paulo). O PRINUTHA tem como finalidade investigar a saúde, a nutrição e a qualidade de vida das pessoas (SOBRAL et al., 2006).

Também foi feita uma divulgação (Apêndice 1) da pesquisa na Cidade Universitária, para recrutar mulheres adultas sadias. 


\section{2 - SELEÇÃO DA AMOSTRA}

Para selecionar a população do estudo elaborou-se um questionário de caracterização (Apêndice 3), para obtenção de dados sobre idade, peso, estatura, nível de atividade física, grau de instrução, gravidez atual e enfermidades.

Os critérios de inclusão foram:

- ser mulher;

- ter idade entre 19 e 59 anos;

- fornecer R.G. e telefone;

- ter acesso a computador com Internet.

Os critérios de exclusão foram:

- ser gestante;

- referir alguma enfermidade;

- desistir de alguma etapa do estudo

No período de uma semana, 100 mulheres foram selecionadas. A participação foi voluntária e gratuita. Um Termo de Consentimento Livre e Esclarecido (Apêndice 2) foi preenchido. 


\section{3 - CARACTERIZAÇÃO DA AMOSTRA}

\section{Avaliação antropométrica}

No evento do PRINUTHA, os profissionais da área de educação física pesaram e mediram a população. A partir desses dados de peso $(\mathrm{kg})$ e estatura $(\mathrm{m})$, calculou-se o IMC (Índice de Massa Corpórea), pela seguinte fórmula:

$$
\mathrm{IMC}=\frac{\text { peso }(\mathrm{kg})}{\text { [estatura }(\mathrm{m})]^{2}}
$$

A classificação da população pelo IMC foi feita de acordo com a Organização Mundial da Saúde (WHO, 1998), onde:

$$
\begin{aligned}
& \text { IMC }<18,5 \Rightarrow \text { desnutrição } \\
& 18,5 \geq \text { IMC }<20 \Rightarrow \text { eutrofia } \\
& 20 \geq \text { IMC }<25 \Rightarrow \text { pré-obesidade } \\
& 25 \geq \text { IMC }<30 \Rightarrow \text { obesidade grau I } \\
& 35 \geq \text { IMC }<40 \Rightarrow \text { obesidade grau II } \\
& \text { IMC } \geq 40 \Rightarrow \text { obesidade grau III ou obesidade mórbida }
\end{aligned}
$$

\section{Nível de atividade física}

Os dados sobre atividade física foram obtidos através de um questionário preenchido pelo entrevistador (Apêndice 3), adaptação do "Questionário Internacional de Atividade Física - versão curta” do IPAQ (International Physical Activity Questionnaire) - CELAFISCS (Centro de Estudos do Laboratório de Aptidão Física de São Caetano do Sul) (IPAQ, 2006).

\section{Avaliação sócio-econômica}

Os dados de caracterização da população foram obtidos através de um questionário preenchido pelo entrevistador (Apêndice 3). 


\section{4 - VALIDAÇÃO DO QSFA}

\section{Questionário Semi-quantitativo de Freqüência Alimentar (QSFA) on-line}

Neste estudo foi utilizado um QSFA on-line validado por Galante (2004) para avaliar a ingestão de cálcio. Este, por sua vez, foi uma adaptação computadorizada do QSFA desenvolvido por Villar (2001), para avaliar o consumo de macronutrientes de adolescentes.

No mês seguinte ao último RH24, um QSFA on-line foi preenchido através do software "Maxinutri" (atual "Nutriquanti"), adaptado por Galante (2004), contendo 79 itens alimentares (Apêndice 4). Ao final do preenchimento, cada participante recebeu um relatório com informações sobre sua média de ingestão de energia e nutrientes.

A freqüência de consumo diário, semanal e mensal de cada item alimentar foi transformada em freqüência de consumo diário. A quantidade de cálcio e ferro contida nas porções de cada item alimentar foi multiplicada pela freqüência de consumo diário (VILLAR, 2001), conforme abaixo:

$\begin{array}{lll}\text { nunca } & \rightarrow & 0,00 \\ \text { menos de } 1 \text { x por mês } & \rightarrow & 0,03 \\ 1 \text { a } 3 \text { x por mês } & \rightarrow & 0,06 \\ 2 \text { a } 4 \text { x por semana } & \rightarrow & 0,43 \\ 1 \text { x por dia } & \rightarrow & 1,00 \\ 2 \text { ou mais x por dia } & \rightarrow & 3,00\end{array}$

Foram fornecidas instruções para auxiliar no preenchimento do QSFA on-line (Apêndice 5). Dúvidas foram sanadas por meio de e-mail, telefone ou pessoalmente.

O QSFA on-line foi aplicado uma única vez para avaliar as informações pregressas do consumo alimentar da população, nos últimos seis meses. Os dados foram analisados através do software "Maxinutri" (2004) - atual "Nutriquanti". Este software foi desenvolvido para avaliação on-line da ingestão alimentar e está disponível, sem custo, para pesquisa.

O método de referência utilizado para esta validação foi o RH24.

\section{Recordatório de 24 Horas (RH24)}

Foram obtidos dados de ingestão de energia (Kcal), macronutrientes (carboidratos, proteínas e lipídeos), ferro e cálcio por meio de cinco $\mathrm{RH} 24$ ’s, durante 
cinco meses consecutivos.

O primeiro $\mathrm{RH} 24$ foi obtido pessoalmente, em de entrevista, durante o evento do PRINUTHA, na primeira semana de abril de 2004. Depois de passarem pelo questionário sócio-econômico e pela avaliação antropométrica, as mulheres foram convidadas a participar na etapa de avaliação nutricional. Foi perguntado a cada participante o que havia ingerido no dia anterior, pedindo para especificar o tipo de alimento e a quantidade do mesmo em medidas caseiras.

Os quatro $\mathrm{RH} 24$ 's restantes foram coletados via e-mail e/ou telefone.

As dietas dos RH24's foram analisadas com o software "Virtual Nutri" (PHILIPPI et al., 1996). 


\section{5 - ADEQUAÇÃO DA INGESTÃO DE FERRO E DE CÁLCIO}

A ingestão de ferro e de cálcio foi avaliada a partir das médias dos cinco $\mathrm{RH} 24$ 's e foram consideradas adequadas ingestões de ferro entre a EAR e a RDA e de cálcio acima da Al. 


\section{6 - ANÁLISE ESTATÍSTICA}

\section{Estatística descritiva}

Foi realizada a análise descritiva dos dados de ingestão de energia, carboidratos, proteínas, lipídeos, ferro e cálcio, obtidos pelos dois métodos (QSFA e $\mathrm{RH} 24$ 's).

\section{Estatística analítica}

As variabilidade inter e intrapessoal foram verificadas através do teste de ANOVA.

Construiu-se histogramas de distribuição do consumo dos nutrientes avaliados e posteriormente foi testada a normalidade das curvas de distribuição.

Utilizou-se o teste de Kappa, utilizado para avaliar a concordância entre dois métodos. É calculado em tabelas cruzadas $r \times c$, onde $r=c$, ou seja, o número de linhas é igual ao número de colunas. Quanto mais próximo o valor estiver de 1 (um), maior a concordância entre os dados.

Para estimar a validade do QSFA em relação à média dos RH24's, utilizou-se o coeficiente de correlação de Spearman.

Para controlar os fatores de confusão gerados pelo consumo de energia e excluir os erros de medição, calculou-se o coeficiente de correlação existente entre os valores de ingestão de ferro e de cálcio, obtidos pelos dois métodos, após o ajuste de energia (LATORRE, 2005; MARCHIONI, SLATER VILLAR e FISBERG, 2005). Segundo Willett (1998), o ajuste pela caloria total incrementa o coeficiente de correlação quando a variabilidade do consumo do nutriente está correlacionada com a ingestão de energia, mas decresce quando a variabilidade dos dados depende de erros sistemáticos.

O coeficiente de correlação corrigido pela variação inter e intrapessoal $\left(r_{c}\right)$ é obtido pela seguinte fórmula:

$$
\begin{array}{ll}
r_{c}=r_{d}+\sqrt{(1+\lambda) / n} \quad \text { onde } \quad & r_{d}=\text { correlação após ajuste } \\
\lambda & =\text { razão entre as variabilidades } \\
n & =200
\end{array}
$$




\section{7 - ORIENTAÇÃO NUTRICIONAL}

Foi realizada orientação nutricional personalizada para a população do estudo, que foi informada dos seus dados de ingestão de macro e micronutrientes, por meio de e-mail ou telefone. Para os casos que apresentaram provável ingestão inadequada de ferro e/ou de cálcio, foram fornecidas orientações para manter uma alimentação equilibrada e adequada nutricionalmente. 


\section{6 - RESULTADOS}

\section{1 - ESTATÍSTICA DESCRITIVA}

A amostra inicial foi de 100 mulheres e 40 permaneceram até o final de todas as etapas do estudo.

Tabela 1 - Cronograma de desistência das mulheres durante as etapas do estudo, USP, São Paulo, 2005

\begin{tabular}{|c|c|c|}
\hline ETAPAS & n FINAL & DESISTÊNCIAS \\
\hline $1^{\circ} . \mathrm{RH} 24$ & 100 & 00 \\
\hline $2^{\circ} . \mathrm{RH} 24$ & 97 & 03 \\
\hline $3^{\circ} . \mathrm{RH} 24$ & 94 & 03 \\
\hline $4^{\circ} . \mathrm{RH} 24$ & 90 & 04 \\
\hline $5^{\circ} . \mathrm{RH} 24$ & 79 & 11 \\
\hline QSFA & 40 & 39 \\
\hline \hline TOTAL & & 60 \\
\hline
\end{tabular}

A idade média da população é de 32,2 anos $( \pm 11,8 \mathrm{DP})$ para a amostra de 100 mulheres e cai para 29,5 anos ( $\pm 9,8$ DP) na amostra de 40 mulheres. $\mathrm{Na}$ amostra inicial $(n=100) 54 \%$ tem entre 19 e 30 anos de idade e $46 \%$ mais de 30 anos. Já na amostra final $(n=40) 60 \%$ tem entre 19 e 30 anos de idade e $40 \%$ mais de 30 anos, como ilustram as figuras seguintes (Figuras 1 e 2).

Do total de mulheres na amostra inicial, 6\% está desnutrida, 59\% eutrófica, $23 \%$ pré-obesa e $12 \%$ obesa. Na amostra final estas proporções são de $5 \%, 62,5 \%$, $22,5 \%$ e $10 \%$, respectivamente. 
Na população estudada inicialmente, $3 \%$ das mulheres estudou até o ensino fundamental, $25 \%$ até o ensino médio e $72 \%$ são graduadas ou pós-graduadas. $\mathrm{Na}$ população final estas porcentagens são, respectivamente, de 0\%, 22,5\% e 77,5\%.

Inicialmente encontrou-se $64 \%$ de estudantes e $36 \%$ de funcionárias (ativas, aposentadas ou autônomas) da Universidade de São Paulo (USP). No final do estudo estes dados mudam para $70 \%$ e $30 \%$, respectivamente.

Praticam atividade física (leve, moderada e/ou intensa) pelo menos um dia na semana, pelo menos 30 minutos por dia, $88 \%$ da população inicial estudada e $12 \%$ não pratica nenhum tipo de atividade física. Na população final estes valores variam para $97,5 \%$ de ativas e $2,5 \%$ de sedentárias. 


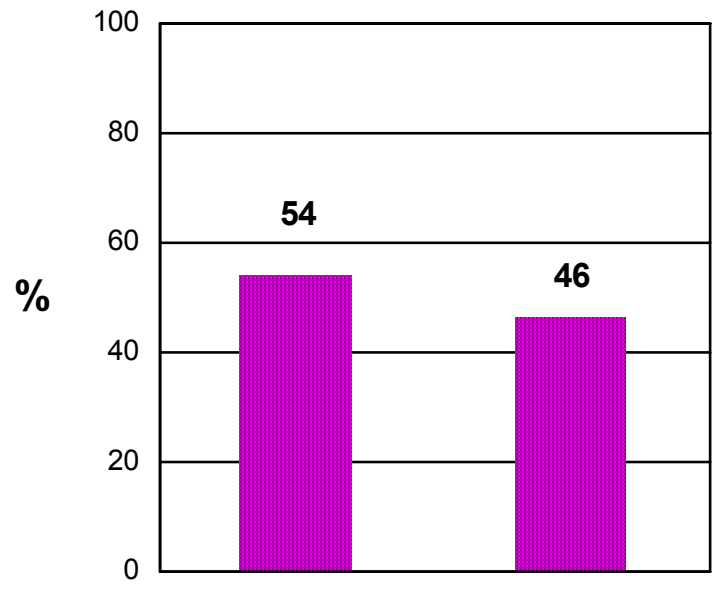

$19-30$

idade (anos)

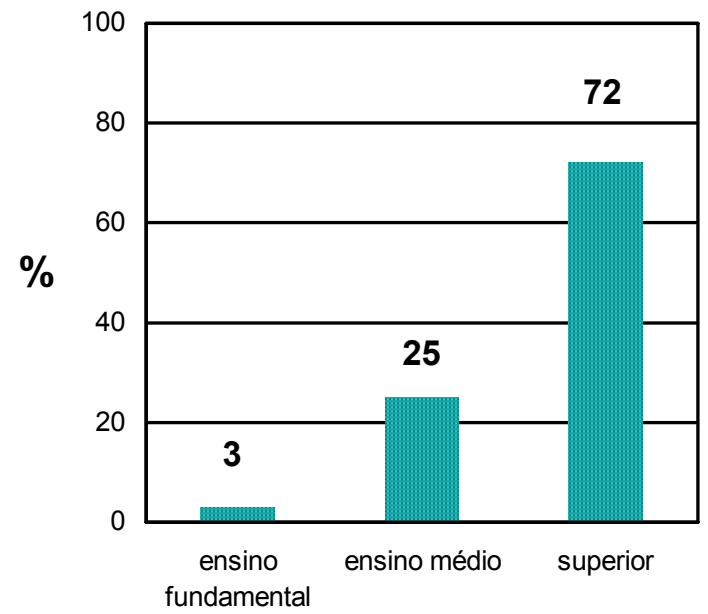

escolaridade

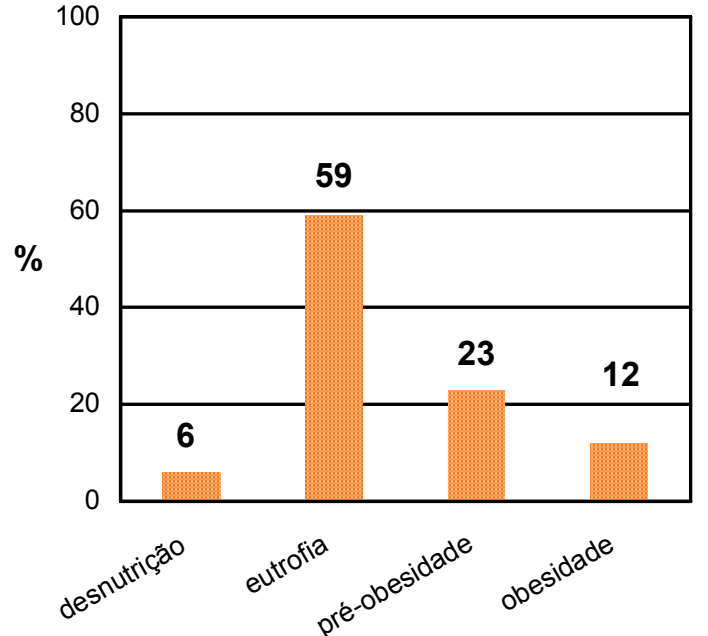

estado nutricional

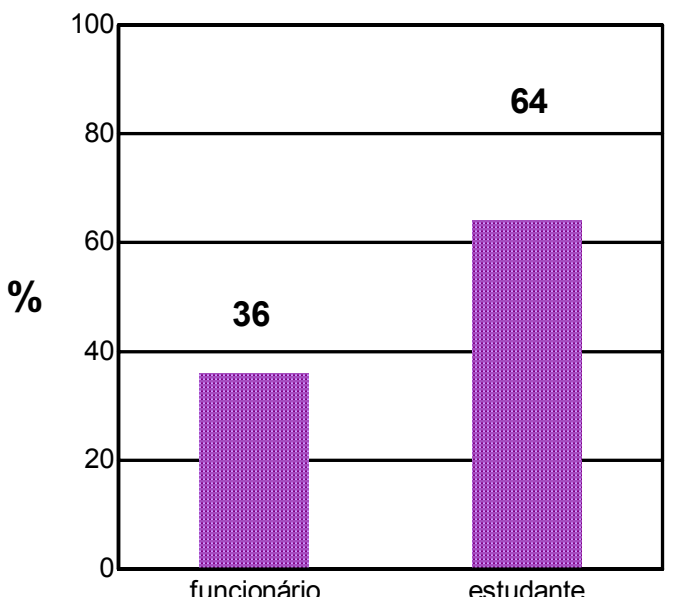

ocupação

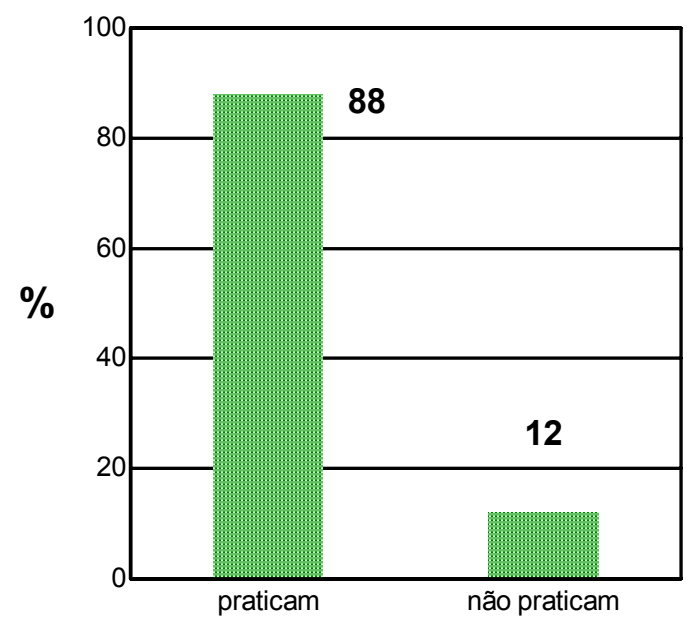

prática de atividade física

Figuras 1 - Classificação da amostra ( $n$ inicial $=100$ ) de acordo com a faixa etária, o estado nutricional, a instrução, a ocupação e a prática de atividade física, USP, São Paulo, 2005. Distribuição percentual. 


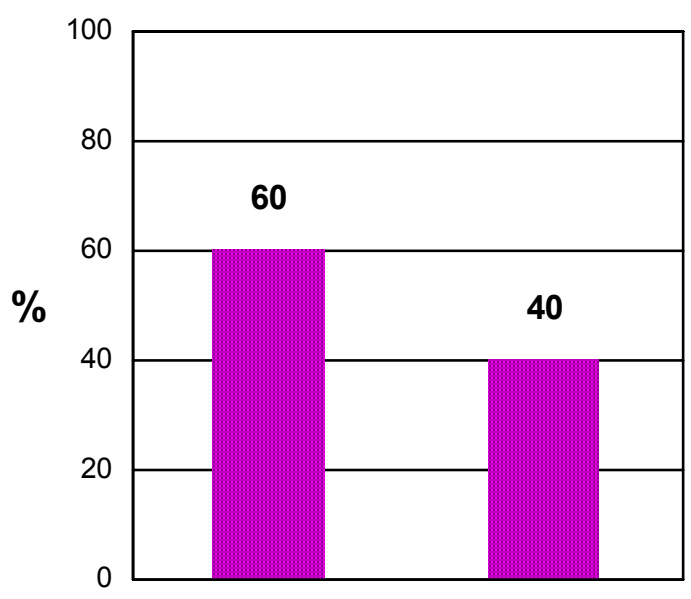

19-30

idade (anos)

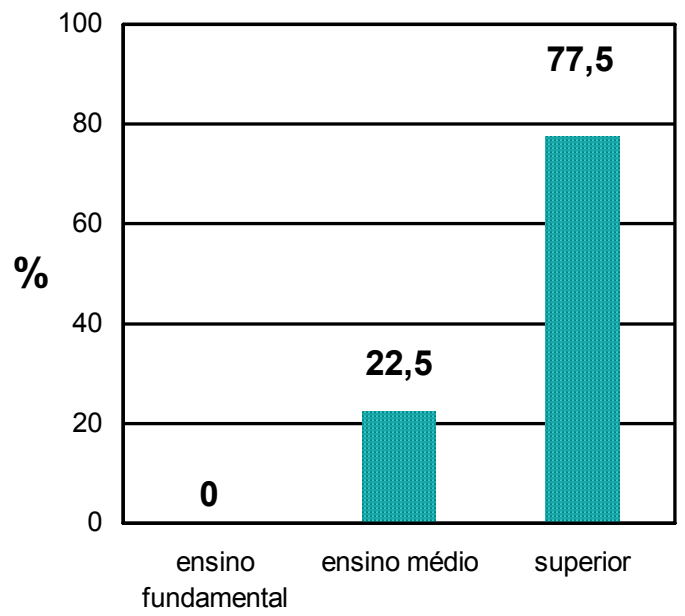

escolaridade

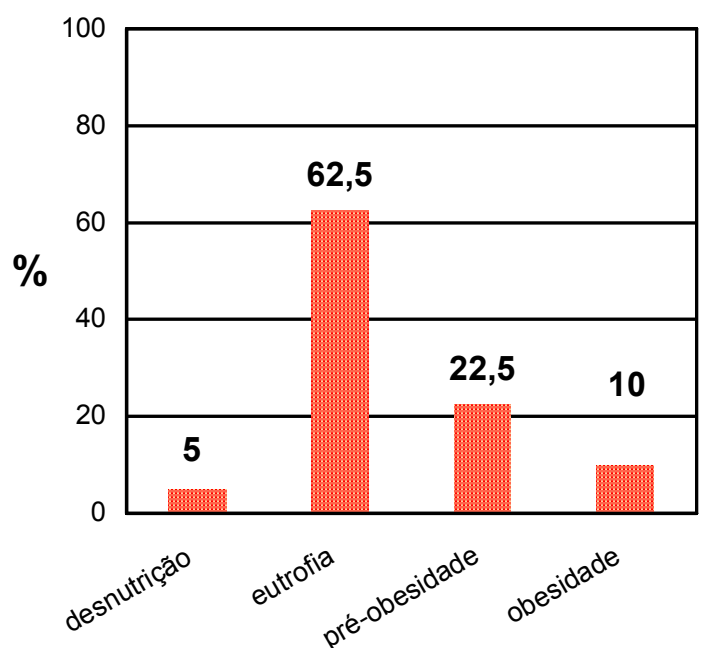

estado nutricional

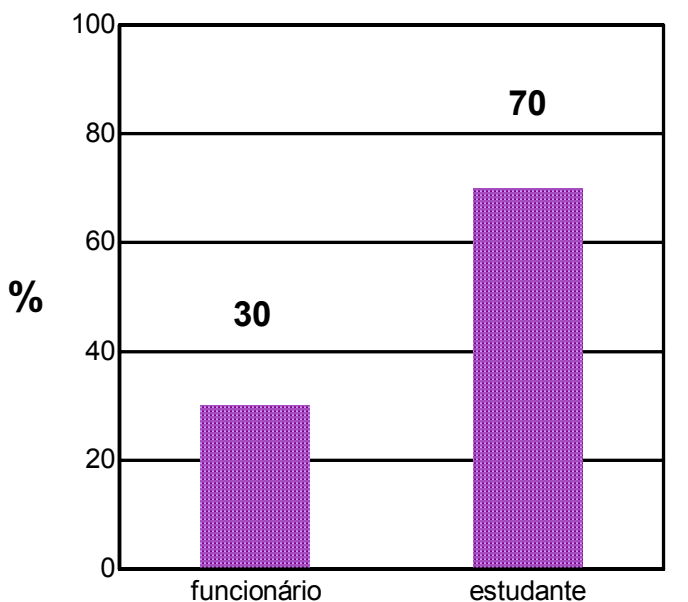

ocupação

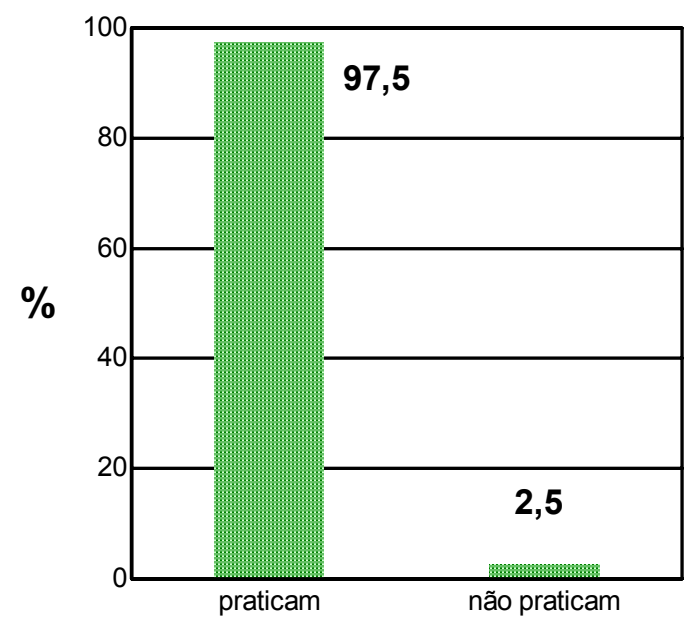

prática de atividade física

Figuras 2 - Classificação da amostra ( $n$ final $=40$ ) de acordo com a faixa etária, o estado nutricional, a instrução, a ocupação e a prática de atividade física, USP, São Paulo, 2005. Distribuição percentual. 
Tabela 2 - Ingestão de nutrientes por mulheres $(n=40)$ de 19 a 59 anos de idade a partir de Recordatórios de 24 horas (média $n=5$ ) e QSFA $(n=1)$. Valor calórico, macronutrientes, ferro e cálcio, USP, São Paulo, 2005

\begin{tabular}{|c|c|c|c|c|c|c|c|c|c|c|c|c|}
\hline & \multicolumn{6}{|c|}{ RH24's ( $n=5)$} & \multicolumn{6}{|c|}{ QSFA $(n=1)$} \\
\hline $\mathbf{N}$ & KCAL & $\mathrm{CHO}(\mathrm{g})$ & PTN (g) & $\operatorname{LIP}(\mathbf{g})$ & $\mathrm{FE}(\mathrm{mg})$ & $\mathrm{CA}(\mathrm{mg})$ & KCAL & $\mathrm{CHO}(\mathrm{g})$ & PTN (g) & $\operatorname{LIP}(g)$ & FE (mg) & CA (mg) \\
\hline 1 & 1.031 & 122 & 46 & 42 & 6,8 & 225,2 & 1.496 & 249 & 40 & 26 & 14,7 & 637,8 \\
\hline 2 & 1.531 & 157 & 60 & 68 & 6,0 & 699,0 & 1.482 & 167 & 67 & 61 & 8,0 & $1.166,2$ \\
\hline 3 & 1.625 & 188 & 70 & 61 & 9,0 & 652,4 & 1.891 & 293 & 63 & 40 & 13,5 & $1.117,4$ \\
\hline 4 & 1.265 & 135 & 46 & 46 & 5,3 & 328,0 & 2.103 & 348 & 63 & 40 & 13,7 & $1.128,3$ \\
\hline 5 & 1.556 & 171 & 48 & 57 & 5,9 & 305,0 & 2.541 & 369 & 87 & 68 & 17,2 & $1.456,6$ \\
\hline 6 & 2.039 & 264 & 85 & 84 & 14,2 & 624,1 & 1.437 & 178 & 72 & 47 & 11,0 & 720,1 \\
\hline 7 & 2.009 & 266 & 78 & 66 & 6,3 & 255,4 & 2.007 & 326 & 59 & 41 & 13,2 & $1.116,3$ \\
\hline 8 & 1.423 & 150 & 56 & 57 & 8,2 & 278,6 & 1.932 & 295 & 63 & 44 & 13,8 & $1.135,2$ \\
\hline 9 & 1.335 & 124 & 53 & 51 & 6,6 & 362,8 & 2.159 & 339 & 67 & 48 & 14,1 & $1.206,8$ \\
\hline 10 & 2.158 & 245 & 74 & 103 & 11,6 & 511,2 & 2.027 & 282 & 90 & 63 & 16,8 & $1.255,9$ \\
\hline 11 & 2.251 & 244 & 115 & 96 & 12,3 & 915,8 & 2.161 & 339 & 67 & 49 & 14,6 & $1.212,2$ \\
\hline 12 & 1.467 & 233 & 49 & 33 & 8,3 & 772,2 & 1.735 & 222 & 93 & 56 & 17,4 & $1.311,9$ \\
\hline 13 & 1.609 & 125 & 80 & 87 & 11,0 & 714,4 & 1.673 & 234 & 57 & 46 & 12,0 & $1.208,3$ \\
\hline 14 & 1.358 & 147 & 76 & 54 & 7,1 & 395,2 & 1.367 & 142 & 117 & 34 & 10,8 & 417,1 \\
\hline 15 & 1.384 & 153 & 54 & 45 & 7,2 & 319,4 & 2.052 & 309 & 62 & 53 & 14,2 & $1.281,8$ \\
\hline 16 & 1.671 & 161 & 60 & 67 & 8,7 & 348,5 & 2.567 & 341 & 113 & 81 & 12,2 & 937,4 \\
\hline 17 & 1.282 & 147 & 53 & 43 & 8,2 & 759,5 & 1.935 & 262 & 71 & 57 & 17,8 & $1.455,6$ \\
\hline 18 & 1.448 & 154 & 80 & 49 & 9,0 & 356,3 & 1.836 & 294 & 54 & 40 & 15,6 & $1.120,8$ \\
\hline 19 & 1.582 & 148 & 78 & 66 & 10,1 & 599,0 & 1.890 & 295 & 56 & 44 & 13,6 & $1.193,1$ \\
\hline 20 & 2.257 & 282 & 91 & 90 & 12,1 & $1.031,2$ & 1.991 & 301 & 63 & 49 & 13,7 & $1.350,5$ \\
\hline 21 & 2.112 & 204 & 135 & 91 & 16,7 & 592,8 & 2.048 & 215 & 118 & 75 & 16,8 & 827,0 \\
\hline 22 & 2.111 & 267 & 75 & 73 & 11,9 & 317,3 & 2.376 & 335 & 118 & 58 & 15,1 & $1.047,7$ \\
\hline 23 & 1.635 & 200 & 66 & 72 & 9,1 & 599,3 & 1.006 & 170 & 41 & 15 & 8,0 & 977,7 \\
\hline 24 & 2.223 & 140 & 143 & 125 & 15,8 & 626,2 & 1.828 & 219 & 113 & 54 & 11,7 & $1.096,5$ \\
\hline 25 & 1.969 & 209 & 80 & 87 & 13,0 & 680,3 & 1.962 & 296 & 62 & 49 & 13,0 & $1.290,3$ \\
\hline 26 & 1.284 & 154 & 48 & 45 & 5,6 & 743,8 & 1.761 & 252 & 83 & 47 & 10,2 & $2.087,3$ \\
\hline 27 & 2.810 & 287 & 117 & 127 & 15,0 & $1.245,0$ & 2.298 & 279 & 134 & 71 & 13,2 & $1.347,5$ \\
\hline 28 & 2.012 & 169 & 99 & 93 & 10,4 & 846,5 & 2.235 & 320 & 70 & 66 & 15,7 & $1.481,7$ \\
\hline 29 & 1.726 & 224 & 80 & 53 & 7,2 & 366,5 & 1.767 & 269 & 55 & 42 & 12,5 & $1.139,5$ \\
\hline 30 & 1.650 & 205 & 73 & 56 & 11,6 & 518,5 & 1.853 & 286 & 57 & 43 & 13,2 & $1.217,3$ \\
\hline 31 & 1.817 & 234 & 64 & 67 & 8,5 & 376,5 & 1.911 & 299 & 57 & 44 & 14,1 & $1.178,4$ \\
\hline 32 & 1.474 & 162 & 43 & 57 & 8,3 & 374,8 & 2.052 & 302 & 65 & 55 & 13,7 & $1.377,5$ \\
\hline 33 & 1.380 & 154 & 78 & 45 & 10,2 & 440,1 & 1.691 & 245 & 55 & 44 & 12,0 & $1.273,4$ \\
\hline 34 & 1.829 & 240 & 107 & 100 & 15,3 & $1.034,2$ & 1.237 & 177 & 62 & 29 & 13,6 & 901,4 \\
\hline 35 & 1.274 & 162 & 86 & 31 & 8,7 & 494,8 & 1.387 & 62 & 12 & 10 & 3,1 & 165,1 \\
\hline 36 & 1.534 & 170 & 69 & 52 & 8,2 & 547,1 & 2.101 & 304 & 111 & 38 & 11,3 & 918,2 \\
\hline 37 & 1.649 & 237 & 71 & 61 & 10,0 & 690,3 & 1.096 & 117 & 85 & 28 & 10,8 & 421,7 \\
\hline 38 & 1.751 & 237 & 53 & 58 & 8,3 & 765,1 & 2.208 & 268 & 79 & 95 & 12,6 & $1.450,2$ \\
\hline 39 & 1.819 & 262 & 65 & 62 & 12,8 & 618,4 & 1.154 & 179 & 56 & 33 & 8,2 & 376,0 \\
\hline 40 & 1.453 & 190 & 39 & 49 & 9,0 & 455,0 & 1.773 & 308 & 56 & 32 & 12,9 & 784,6 \\
\hline $\mathbf{X}$ & 1.695 & 193 & 74 & 67 & 9,7 & 569,6 & 1.851 & 262 & 73 & 48 & 13,0 & $1.094,7$ \\
\hline DP & 363 & 49 & 24 & 23 & 3,0 & 237,1 & 372 & 69 & 25 & 17 & 2,9 & 354,9 \\
\hline
\end{tabular}


Nas tabelas 3 e 4 é apresentada a distribuição de mulheres segundo a adequação da ingestão de ferro em relação à EAR (estimated average requirement ou necessidade média estimada) e RDA (recommended dietary allowance ou ingestão dietética recomendada) e de cálcio em relação à Al (adequate intake ou ingestão adequada) (IOM, 2006).

Tabela 3 - Distribuição de mulheres $(n=40)$ segundo a adequação da ingestão de ferro, segundo as DRI's (2003), a partir de RH24's ( $n=5)$, USP, São Paulo, 2005

\begin{tabular}{c|c|c|c}
\hline MÉTODO & < EAR (n) & EAR - RDA (n) & $>$ RDA (n) \\
\hline RH24's & 10 & 30 & 00 \\
\hline
\end{tabular}

Fonte: IOM, 2006

$\mathrm{n}=$ número de mulheres

$\mathrm{EAR}=$ Estimated Average Requirement $(\mathrm{Fe}=8 \mathrm{mg} / \mathrm{dia})$

$\mathrm{RDA}=$ Recommended Dietary Allowance $(\mathrm{Fe}=18 \mathrm{mg} / \mathrm{dia})$

Tabela 4 - Distribuição de mulheres $(n=40)$ segundo a adequação da ingestão de cálcio, segundo as DRI's (2003), a partir de RH24's ( $n=5)$, USP, São Paulo, 2005

\begin{tabular}{c|c|c}
\hline MÉTODO & $<\mathrm{Al}(\mathbf{n})$ & $\geq \mathbf{A l}(\mathbf{n})$ \\
\hline RH24's & 37 & 03 \\
\hline
\end{tabular}

Fonte: IOM, 2006

$\mathrm{n}=$ número de mulheres

$\mathrm{Al}=$ Adequate Intake $(\mathrm{Ca}=1.000 \mathrm{mg} / \mathrm{dia})$ 
Nas figuras 3 e 4 é apresentada a distribuição da ingestão de ferro da população em relação à EAR e RDA e da ingestão de cálcio em relação à Al.

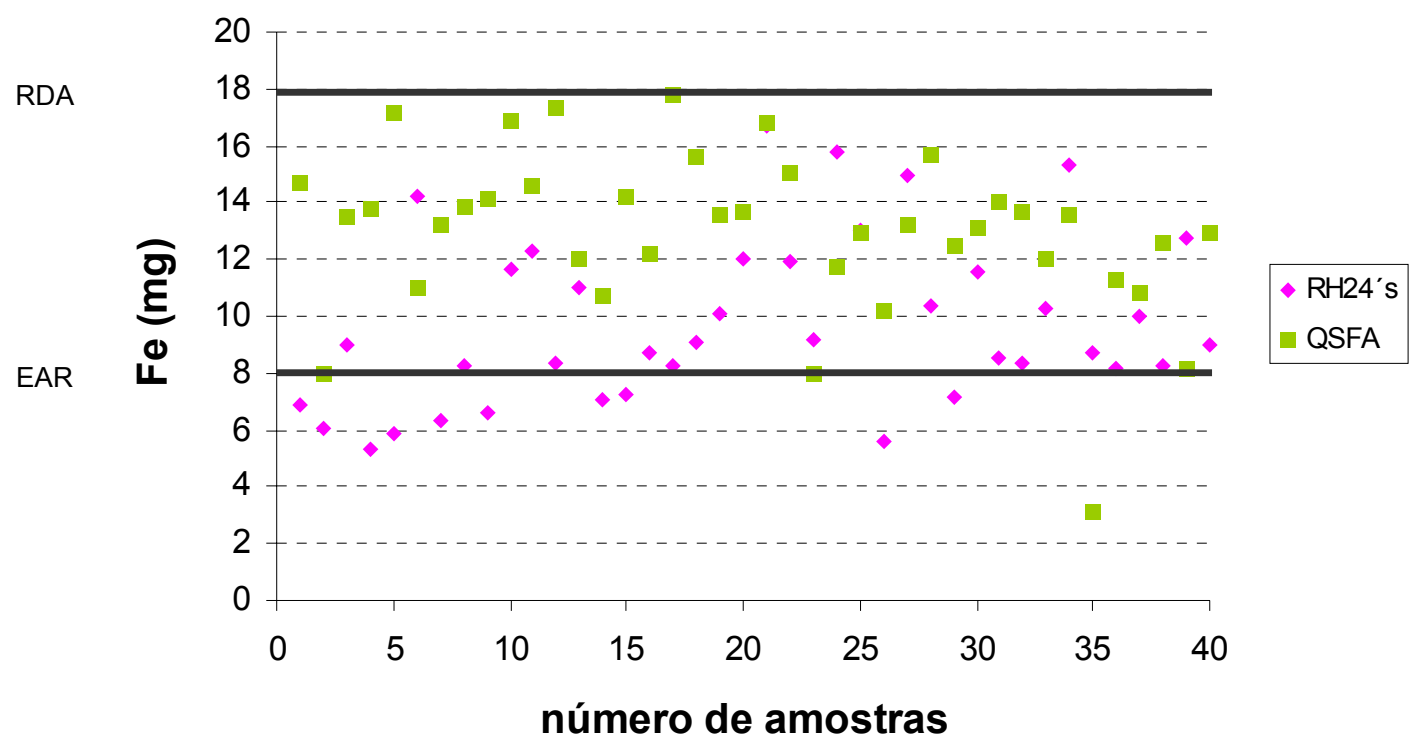

Figura 3 - Distribuição da ingestão de ferro por mulheres $(n=40)$ de 19 a 59 anos de idade, segundo as DRI's (2003), a partir de RH24's $(n=5)$ e QSFA ( $n=1)$, USP, São Paulo, 2005

Al

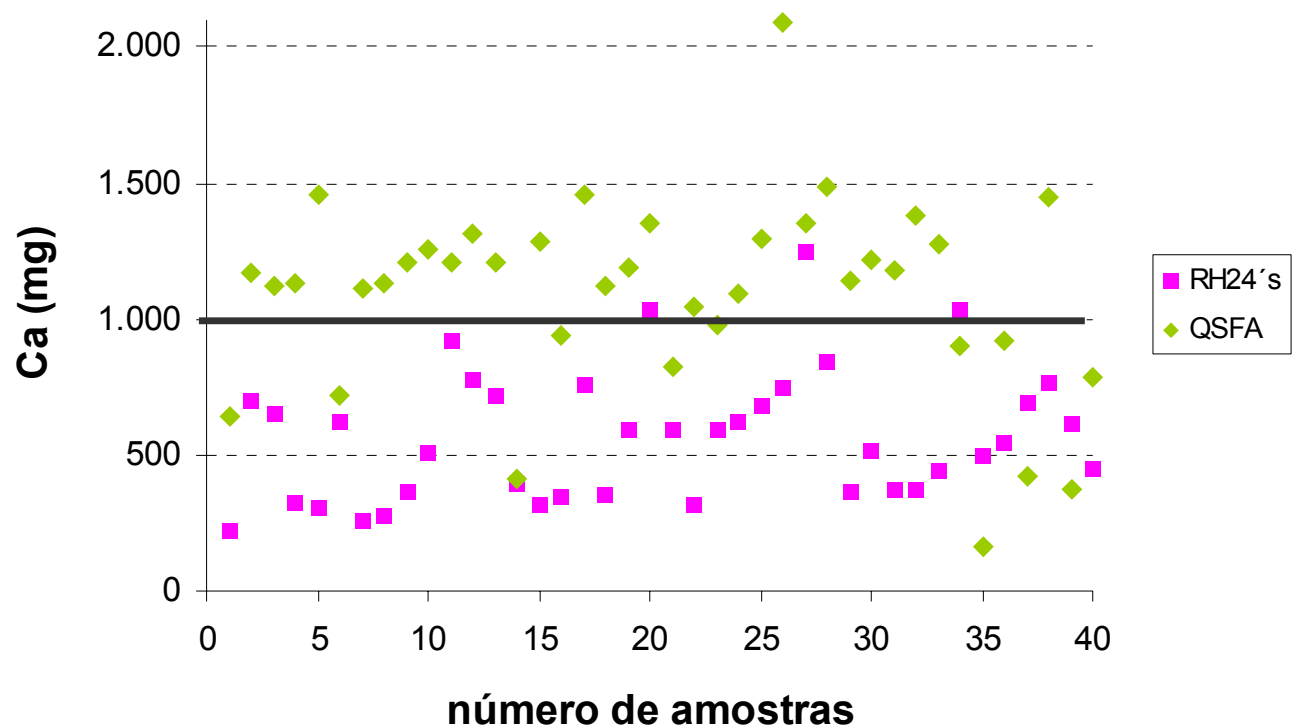

Figura 4- Distribuição da ingestão de cálcio por mulheres $(n=40)$ de 19 a 59 anos de idade, segundo as DRI's (2003), a partir de RH24's $(n=5)$ e QSFA ( $n=1)$, USP, São Paulo, 2005 


\section{2 - ESTATÍSTICA ANALÍTICA}

Os dados de ingestão de cálcio apresentam distribuição normal pelos dois métodos, enquanto que os de ingestão de ferro apresentam distribuição log-normal (Figura 5).

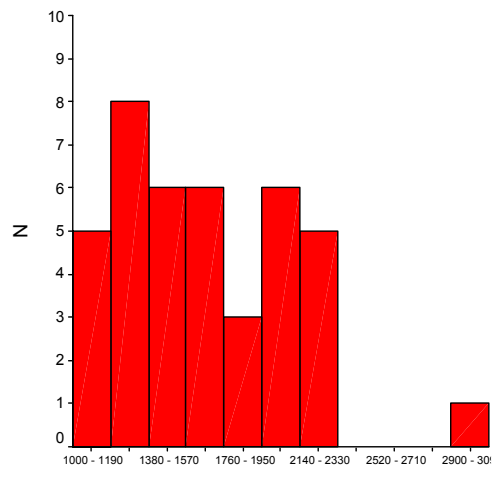

Recordatório Kcal

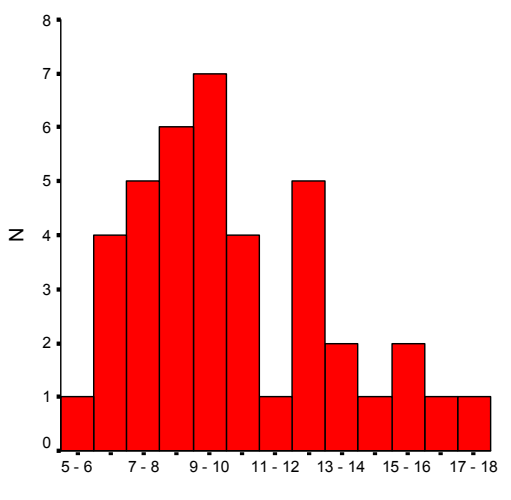

Recordatório $\mathrm{Fe}$

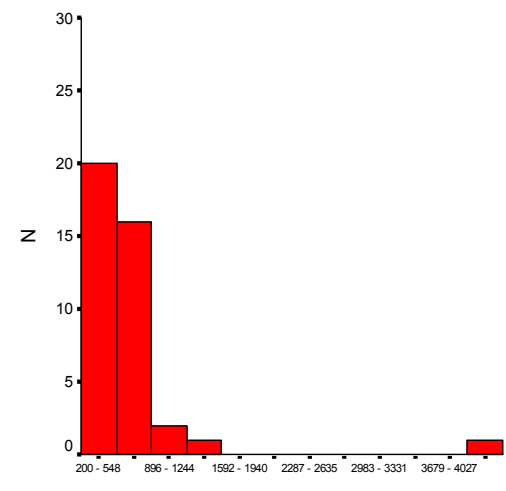

Recordatório $\mathrm{Ca}$

Figura 5 - Histograma da distribuição da ingestão de energia, ferro e cálcio por mulheres $(n=40)$ de 19 a 59 anos de idade, a partir de RH24's $(n=5)$, USP, São Paulo, 2005

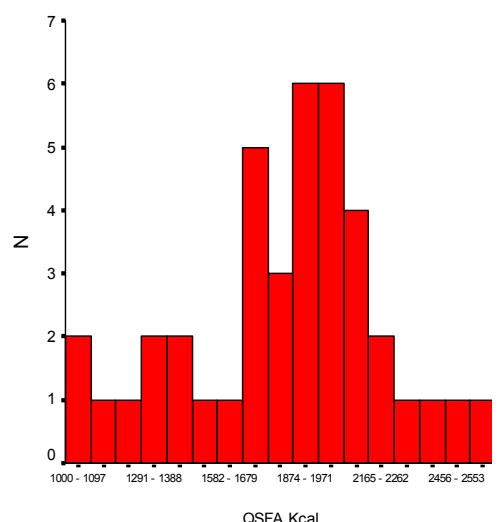

QSFA Kcal

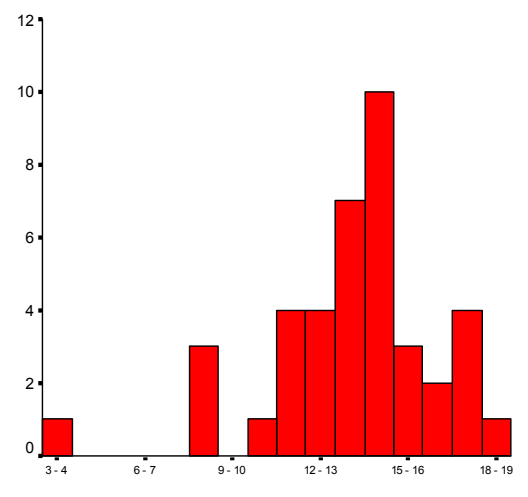

QSFA Fe

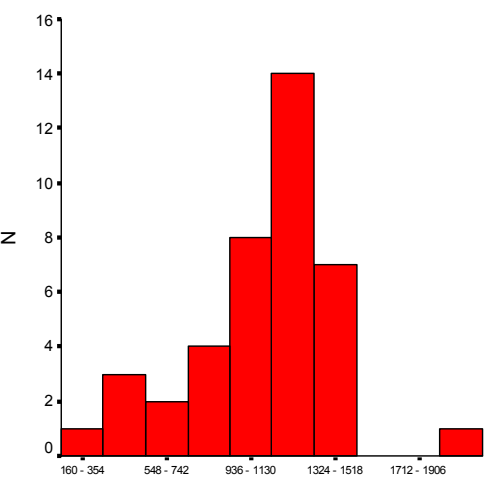

QSFACa

Figura 6 - Histograma da distribuição da ingestão de energia, ferro e cálcio por mulheres $(n=40)$ de 19 a 59 anos de idade, a partir de QSFA $(n=1)$, USP, São Paulo, 2005 


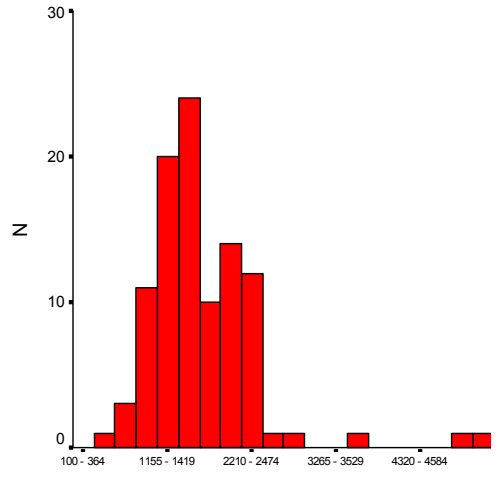

KCAL

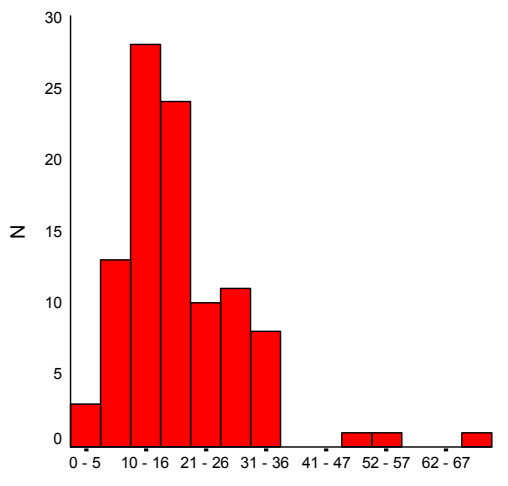

FE

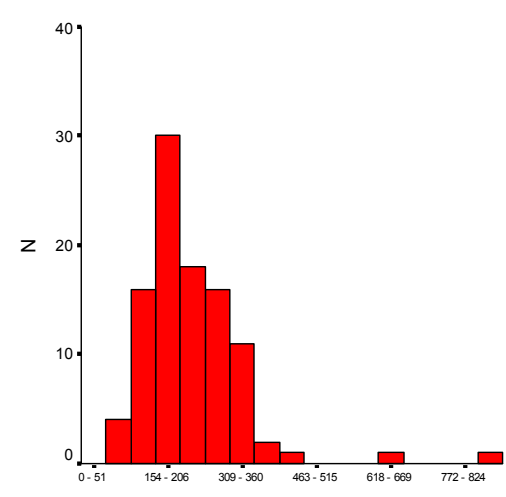

$\mathrm{CA}$

Figura 7 - Histograma da distribuição da ingestão de energia, ferro e cálcio por mulheres $(n=100)$ de 19 a 59 anos de idade, a partir de RH24's ( $n=5)$, USP, São Paulo, 2005

A variabilidade interpessoal da ingestão de ferro foi estimada em 4,1, representando $14,8 \%$ da variabilidade total. A intrapessoal estimada em 23,6 representa $85,2 \%$ da variabilidade total. A razão entre as duas variabilidades $(\lambda)$ é de 5,75 , implicando na necessidade de ajuste pela energia (Tabela 5).

Para a ingestão de cálcio, a variabilidade interpessoal é de 28.826,0 o que representa $19,3 \%$ da variabilidade total. A intrapessoal estimada em 120.263,0 representa $80,7 \%$ da variabilidade total. A razão entre as duas variabilidades $(\lambda)$ resulta em 4,17, implicando também na necessidade de ajuste pela energia (Tabela $6)$. 
Tabela 5 - Ingestão de ferro por mulheres $(n=40)$, a partir de $\mathrm{RH} 24$ 's, corrigida pela variação inter e intrapessoal, USP, São Paulo, 2005

\begin{tabular}{c|c|c|c|c|c}
\hline $\begin{array}{c}\text { CAUSA DA } \\
\text { VARIAÇÃO }\end{array}$ & $\begin{array}{c}\text { GRAU DE } \\
\text { LIBERDADE }\end{array}$ & $\begin{array}{c}\text { SOMA } \\
\text { QUADRADOS }\end{array}$ & $\begin{array}{c}\text { QUADRADO } \\
\text { MÉDIO }\end{array}$ & F & P \\
\hline INTERPESSOAL & 39 & $1.718,235$ & 44,057 & 1,83 & 0,0038 \\
\hline INTRAPESSOAS & 160 & $3.769,585$ & 23,560 & & \\
\hline TOTAL & 199 & $5.487,820$ & & & \\
\hline
\end{tabular}

Tabela 6 - Ingestão de cálcio por mulheres ( $n=40)$, a partir de RH24's, corrigida pela variação inter e intrapessoal, USP, São Paulo, 2005

\begin{tabular}{c|c|c|c|c|c}
\hline $\begin{array}{c}\text { CAUSA DA } \\
\text { VARIAÇÃO }\end{array}$ & $\begin{array}{c}\text { GRAU DE } \\
\text { LIBERDADE }\end{array}$ & $\begin{array}{c}\text { SOMA } \\
\text { QUADRADOS }\end{array}$ & $\begin{array}{c}\text { QUADRADO } \\
\text { MÉDIO }\end{array}$ & F & P \\
\hline INTERPESSOAL & 39 & $10.311 .458,360$ & $264.396,370$ & 2,20 & 0,0003 \\
\hline INTRAPESSOAS & 160 & $19.242 .079,490$ & $120.263,000$ & & \\
\hline TOTAL & 199 & $29.553 .537,850$ & & & \\
\hline
\end{tabular}

Para a variável ferro, o coeficiente de correlação corrigido pela variação inter e intrapessoal $\left(r_{c}\right)$ é de 0,402 (Tabela 7).

A variável cálcio, por sua vez, apresentou coeficiente de correlação corrigido pela variação inter e intrapessoal $\left(r_{c}\right)$ de 0,605 (Tabela 8). 
Tabela 7 - Correlação dos dados de ingestão de ferro por mulheres $(n=40)$ obtidos por RH24's e QSFA, antes e após o ajuste pela energia, USP, São Paulo, 2005

\begin{tabular}{c|c|c}
\hline AJUSTE PELA ENERGIA & $\mathbf{r}$ & $\mathbf{p}$ \\
\hline antes & 0,062 & 0,706 \\
\hline após & 0,218 & 0,177 \\
\hline corrigido pela variação $\left(r_{c}\right)$ & 0,402 & \\
\hline
\end{tabular}

Tabela 8 - Correlação dos dados de ingestão de cálcio por mulheres $(n=40)$ obtidos por RH24's e QSFA, antes e após o ajuste pela energia, USP, São Paulo, 2005

\begin{tabular}{c|c|c}
\hline AJUSTE PELA ENERGIA & $\mathbf{r}$ & $\mathbf{p}$ \\
\hline antes & 0,213 & 0,187 \\
\hline após & 0,444 & $<0,001$ \\
\hline corrigido pela variação $\left(r_{c}\right)$ & 0,605 & \\
\hline
\end{tabular}

A categorização por quartis dos dados de ingestão de energia, ferro e cálcio obtidos pelos dois métodos (RH24's e QSFA) não foi a mesma, ou seja, o valor kappa está distante de 1 (Tabela 9).

Tabela 9 - Teste Kappa - categorização por quartis dos dados de ingestão de energia, ferro e cálcio por mulheres $(n=40)$ obtidos por RH24's e QSFA, USP, São Paulo, 2005

\begin{tabular}{c|c|c|c}
\hline & ENERGIA & FERRO & CÁLCIO \\
\hline KAPPA & 0,067 & 0,033 & 0,033 \\
\hline
\end{tabular}




\section{7 - DISCUSSÃO}

Questionários eletrônicos validados podem ser um instrumento precioso na avaliação do consumo alimentar, utilizados como alternativa a outros métodos já consolidados (ELEY, 1999; WISE, 1999).

Para sua validação é necessário uma elaboração cuidadosa e detalhada, principalmente quanto ao número de questões a serem formuladas. Segundo a literatura, um QSFA deve conter no máximo 100 itens alimentares, pois acima deste número pode ocorrer cansaço do entrevistado. Também não deve conter menos de 30 alimentos, pois há o risco de não refletir o consumo dos nutrientes avaliados (WILLETT, 1998).

Um QSFA online proposto por Heath, Skeaff e Gibson (2000) contem 206 itens alimentares divididos em 17 grupos. Apesar do grande número de itens, apresentou boa exatidão e reprodutibilidade quando comparado ao método de pesagem de alimentos, pelo fato de motivar o entrevistado a preenchê-lo até o final e dar uma resposta em tempo real. Sichieri Everhart (1998) validaram um QSFA em mulheres adultas no Brasil, com 64 itens alimentares, obtendo boa reprodutibilidade em relação ao $\mathrm{RH} 24$.

O e-mail e o telefone foram utilizados para a obtenção dos dados e a participação das mulheres foi diminuindo ao longo do tempo, mostrando talvez uma certa "estafa" das mesmas.

Inicialmente 100 mulheres responderam ao questionário de caracterização e ao primeiro RH24. Do segundo ao quinto $\mathrm{RH} 24$ houve desistência de 21 pessoas, representando $21 \%$ da população inicial., mostrando talvez uma certa "estafa" das mulheres em questão.

Na última etapa, a o QSFA online, $40 \%$ do total permaneceram na pesquisa. Estudos de validação de QSFA recomendam, em geral, uma amostra superior a 50 pessoas, porém, assinalam a possibilidade de realização com um número inferior (WILLETT, 1998).

Possivelmente a desistência deve-se ao fato de o questionário eletrônico ser muito extenso (79 itens alimentares e várias páginas). Em alguns horários do dia a Internet fica mais congestionada, dificultando o acesso e prolongando o tempo de processamento. Outro fato é que nem todos possuem um sistema de banda larga, 
que possibilita acesso rápido à Internet.

O número de itens alimentares poderá ser reduzido, sendo uma questão a ser analisada no aprimoramento deste software.

Slattery et al. (1994) mostraram que questionários computadorizados são mais rápidos de serem preenchidos, 5 a 10 minutos, enquanto que similares em papel levaram de 40 a 50 minutos. Outro estudo apontou que questionários convencionais levam de 20 a 30 minutos para serem preenchidos e, esse tempo é reduzido a 3 minutos com o uso da versão computadorizada (HARLOW, ROSENTHAL e ZIEGLER, 1985).

$\mathrm{Na}$ entrevista por telefone, muitas participantes alegavam falta de tempo ou muitas vezes nem era possível um contato telefônico com elas. Por e-mail o retorno era maior, uma vez que elas respondiam aos recordatórios quando melhor lhes convinha.

Notou-se que a pesquisa, por ser pela Internet, despertou um grande interesse e curiosidade.

A população brasileira estimada é de quase 170 milhões de habitantes, sendo 86 milhões de mulheres. Residem na região sudeste 72 milhões de pessoas, sendo 37 milhões de mulheres.

$\mathrm{Na}$ amostra inicial do estudo a proporção de mulheres entre 19 e 30 anos de idade e com mais de 30 anos era de $54 \%$ e $46 \%$, respectivamente, ou seja, bem equilibrada. Na amostra final esta proporção mudou para $60 \%$ e 40\%, respectivamente, mostrando que as mais velhas desistiram mais e uma proporção inversa da realidade brasileira.

O presente estudo difere da realidade brasileira, onde do total de mulheres entre 19 e 59 anos de idade $36,4 \%$ têm entre 19 e 30 anos e $63,6 \%$ mais de 30 anos (IBGE, 2006).

Encontrou-se na amostra um número significativo de mulheres pré-obesas e obesas, evidenciando ser um espelho da população brasileira, onde o sobrepeso e a obesidade são objetos de discussão e de muitos estudos, como mostra pesquisa do IBGE (2006) que aponta para $41 \%$ de sobrepeso e obesidade na região sudeste.

A população avaliada é diferenciada da média da população brasileira quanto ao nível de instrução, uma vez que a grande maioria possui nível superior. No Brasil, somente $2,8 \%$ da população possuem nível superior de ensino e na região sudeste 
esta proporção é de 3,3\%.

Constata-se que mais estudantes do que funcionárias participaram do estudo,

Embora não existam estudos de relevância nacional que relatem a prática de atividade física da população, a amostra estudada é diferenciada também neste aspecto. Um estudo conduzido por Gomes, Siqueira e Sichieri (2001), aponta para $78 \%$ de mulheres que não realizavam nenhum tipo de atividade física. Neste estudo a grande maioria pratica algum tipo de atividade física pelo menos um dia na semana, por pelo menos 30 minutos e a grande minoria é sedentária.

Assim, pode-se dizer que a amostra deste estudo é diferenciada da população brasileira no que diz respeito à faixa etária, instrução e prática de atividade física. Se assemelha somente no que se refere ao estado nutricional.

Galante, em 2004, elaborou e validou um QSFA online para ferro, utilizando também dados de consumo de cálcio, comparando com registros alimentares de quatro dias (3 dias da semana e 1 final de semana), obtendo médias de 13,3 mg ( \pm $5,0)$ para ferro e $940,0 \mathrm{mg}( \pm 471,0)$ para cálcio, valores semelhantes a este estudo.

Um estudo transversal de validação de QSFA computadorizado na Nova Zelândia (HEATH, SKEAFF e GIBSON, 2000), em população adulta, utilizando como método de referência a pesagem de alimentos, registrou valores para ferro de 11,5 mg $( \pm 4,5)$ e para cálcio de $820,0 \mathrm{mg}( \pm 470,0)$, valores estes semelhantes com este estudo.

Outro estudo de Sichieri e Everhart (1998), em população adulta no Brasil, aponta para médias de ingestão $15,1 \mathrm{mg}( \pm 7,0)$ de ferro e $619,0 \mathrm{mg}( \pm 384,0)$ de cálcio, obtidas por QSFA.

Block et al. (1990) obtiveram dados de ingestão de ferro e de cálcio pelo QSFA em população de mulheres adultas americanas, encontrando valores de 10,6 $\mathrm{mg}( \pm 3,5)$ para ferro e $819,0 \mathrm{mg}( \pm 383,0)$ para cálcio. O método de referência utilizado foi o registro alimentar de quatro dias.

Quanto à adequação da ingestão de ferro e de cálcio (IOM, 2006; SBAN, 2006), o presente estudo mostrou que a maioria da amostra, $75 \%$, tem consumo de ferro dentro da EAR e RDA e 25\% abaixo da EAR. Quanto ao cálcio, 92,5\% têm um consumo provavelmente inadequado, ou seja, abaixo da Al.

Galante (2004) obteve dados semelhantes em seu estudo, onde $70 \%$ possuíam consumo de ferro entre a EAR e RDA e $80 \%$ tinham consumo de cálcio 
abaixo da Al.

A validade relativa de um QSFA pode ser entendida como a capacidade deste instrumento obter médias de ingestão de indivíduos conforme seu consumo pregresso, comparando com um método considerado de referência (GIBSON, 1990; SLATER VILLAR e LIMA, 2005; SLATER VILLAR, PHILIPPI, FISBERG e LATORRE, 2003; FISBERG, SLATER, MARCHIONI e MARTINI, 2005).

Ao realizar o teste de correlação, observou-se que o QSFA online apresentou coeficientes de $r=0,062$ para ferro e $r=0,213$ para cálcio.

Para melhorar a correlação entre os dois métodos, a literatura sugere que seja realizado o ajuste dos valores de ingestão pela energia, cujo consumo varia muito de pessoa para pessoa, devido a diferenças relativas como idade, peso, estatura e atividade física. Assim, para eliminar a dispersão de dados devido a essa grande variabilidade, o consumo do nutriente é alinhado ao consumo médio de energia do indivíduo e à ingestão média de energia do grupo. Se, após este ajuste, os valores dos dois métodos se correlacionarem, pode-se afirmar que os métodos se equivalem (WILLETT, 1998).

Como os valores de consumo de ferro e de cálcio se correlacionam com a energia, foi realizado o ajuste pela energia, que eliminou o efeito da energia sobre o nutriente.

Após o ajuste pela energia, a correlação entre os dois métodos melhorou, apresentando coeficientes de $r=0,218$ para ferro e $r=0,444$ para cálcio.

Estudos de Block et al. (1992) e de Rockett et al. (1997) também mostraram aumento do coeficiente de correlação após o ajuste pela energia. Já nos estudos conduzidos por Heath, Skeaff e Gibson (2000) e por Villar (2001), o coeficiente de correlação tendeu a diminuir após o ajuste pela energia.

O ajuste pela energia causa decréscimo no coeficiente de correlação quando a variação do nutriente está associada a erros sistemáticos (WILLETT, 1998).

A correlação entre os dois métodos após o ajuste pela variabilidade inter $\mathrm{e}$ intrapessoal resultou em um coeficiente de $r_{c}=0,402$ para ferro e de $r_{c}=0,605$ para cálcio, melhorado para ambos os nutrientes.

Galante (2004) obteve dados, após os ajustes, para ferro de $r_{c}=-0,130$ e para cálcio de $r_{c}=0,570$, evidenciando a não validação para o nutriente ferro.

O teste de distribuição pelos quartis, teste Kappa, mostra diferenças na 
categorização dos indivíduos pelos dois métodos. Esse resultado aponta para a necessidade de se aumentar a amostra, o que a nosso ver será possível reduzindo o número de itens alimentares.

O desenvolvimento de uma metodologia é um processo que está sempre em construção. A próxima etapa após a validação deste questionário é utilizar os registros para avaliar a ingestão de ferro dessa população após a fortificação da farinha de trigo e de milho com ferro e acompanhar essa evolução. 


\section{8 - CONCLUSÃO}

O QSFA online apresentou validade para obter dados de ingestão de ferro e de cálcio para esta população, ou seja, apresentou desempenho similar aos RH24's quando avaliado pelo teste de correlação. Os coeficientes de correlação obtidos neste estudo, tanto para ferro como para cálcio, foram considerados bons, de acordo com estudos de validação anteriores.

Com isto é possível acompanhar a mesma população durante um período determinado, para avaliar mudanças de hábito alimentar.

A população é diferenciada da média brasileira, devido ao alto nível de escolaridade.

Como sugestão para trabalhos futuros, deve-se limitar o número de itens alimentares no QSFA para melhor adesão e menor desistência por parte dos participantes, aumentando a amostra para no mínimo 50 pessoas.

Os dados dos RH24's mostram que $25 \%$ da população estão com ingestão inadequada de ferro (<EAR), anteriormente à fortificação das farinhas de trigo e de milho. A ingestão de cálcio está abaixo da $\mathrm{Al}$ em 92,5\% da amostra, portanto não se pode concluir que a mesma esteja adequada. 


\section{9 - REFERÊNCIAS BIBLIOGRÁFICAS}

ALBANO, R.D. Estado nutricional e consumo alimentar entre estudantes dos cursos de nutrição e letras: um estudo longitudinal. São Paulo: 2005.90 p. Tese (Doutorado) - Faculdade de Saúde Pública da USP. Departamento de Nutrição.

ANDERSON, S.E.; GANSNEDER, B.M. Using electronic mail surveys and computer monitored data for studying computer mediated communication systems. Soc Sci Comput Rev 1995, 13(1): 33-46.

BAKER, L.E.; KIRSCHENBAUM, D.S. Self-monitoring may be necessary for successful weight control. Behavior Therapy 1993, 24: 377-94.

BALARINE, O.F.O. Tecnologia da informação como vantagem competitiva. RAEeletrônica jan.-jun. 2002; 1(1): 1-11.

BLOCK, G.; THOMPSON, F.E.; HARTMAN, A.; LARKIN, A.; GUIRE, K.E. Comparison of two dietary questionnaires validated against multiple dietary records collected during a 1-year period. J Am Diet Assoc 1992; 92(9): 686-93.

BLOCK, G.; WOODS, M.; POTOSKY, A.; CLIFFORD, C. Validation of a selfadministrated diet history questionnaire using multiple diet records. J Clin Epidemiol 1990; 43(12): 1326-35.

BOECKNER, L.S.; PULLEN, C.H.; WALKER, S.N.; ABBOTT, G.W.; BLOCK, T. Use and reliability of the world wide web version of the Block health habits and history questionnaire with older rural women. J Nutr Educ Behav 2002; 34: S20-S24.

BOTHWELL, T; CHARLTON, R.W. Iron deficiency in women. Oxford: Blackwell Scientific Publication; 1981. 
BOUTELLE, K.N.; KIRSCHENBAUM, D.S. Further support for consistent selfmonitoring as a vital component of successful weight comparison. Obes Res 1998, 6: $219-24$.

BRUG, J.; CAMPBELL, M.; VAN ASSEMA, P. The application and impact of computer-generated personalized nutrition education: a review of the literature. Patient Educ Couns 1999; 36: 145-56.

BRUG, J.; DE VRIES, H. Computer-tailored education. Patient Educ Couns 1999; 36: 99-105.

BRUG, J.; GLANZ, K.; VAN ASSEMA, P.; KOK, G.; VAN BREUKELEN, G.J. The impact of computer-tailored feedback and interative feedback on fat, fruit and vegetable intake. Health Educ Behav 1998; 25: 517-31.

BRUG, J.; HOSPERS, H.; KOK, G. Differences in psychosocial factors and fat consumption between stages of change for fat reduction. Psychol Health 1997; 12: 719-27.

BRUG, J.; OENEMA, A.; CAMPBELL, M. Past, present and future of computertailored nutrition education. Am J Clin Nutr 2003; 77(4S): 1028S-34S.

BRUG, J.; STEENHUIS, I.H.M.; VAN ASSEMA, P.; DE VRIES, H. The impact of a computer-tailored nutrition intervention. Prev Med 1996; 25: 236-42.

BRUG, J.; VAN ASSEMA, P. Differences in use and impact of computer-tailored fatfeedback according to stage of chance and education. Appetite 2000; 34: 285-93.

BRUG, J.; VAN ASSEMA, P. Beliefs about fat. Why do we hold beliefs about fat and why and how do we study these beliefs? In: FREWER, L; RISVIK, E.; SCHIFFERSTEIN, H. Food, people and society: a European perspective of consumer's food choice. Berlin: Springer-Verlag, 2001; 39-52. 
BRUG, J.; VAN ASSEMA, P.; LENDERINK, T.; GLANZ, K.; KOK, G.J. Self-rated dietary fat intake: association with objective assessment of fat, psychosocial factors and intention to change. J Nutr Educ 1994; 26: 218-23.

BUUNK, B.P.; GIBBONS, F.X. Health, coping and well-being: perspectives from social comparison theory. Mahwah, NJ: Lawrence Erlbaum, 1997.

BUZZARD, M. 24-hour dietary recall and food record methods. In: Willet W. Nutritional epidemiology. 2. ed. Oxford: University Press; 1998. p. 50-73.

CAMPBEL, M.K.; DE VELLIS, B.M.; SRECHER. V.J.; AMMERMAN, A.S.; DE VILLES, R.F.; SANDLER, R.S. Improving dietary behavior: the effectiveness of tailored messages in primary care settings. Am Public Health 1994; 84: 783-7.

CAMPBELL, M.K.; HONESS, L.; FARRELL, D.; CARBONE, E.; BRASURE, M. Effects of a tailored multimedia nutrition education program for low income women receiving food assistance. Health Educ Res 1999; 14: 246-56.

CAMPBELL, M.K.; TESSARO, I.; DE VELLIS, B. Tailoring and targeting a health promotion program to address multiple health behaviors among blue-collar women. Am J Health Promot 2000; 14: 306-13.

CAMPBELL, M.K.; TESSARO, I.; DE VELLIS, B. Effects of a tailored health promotion program for female blue-collar workers. Health Works for Women Prev Med 2002; 34: 313-23.

CESAR, C.L.G.; CARANDINA, L.; ALVES, M.C.G.P.; BARROS, M.B.A.; GOLDBAUM, M. Saúde e condição de vida em São Paulo: inquérito multicêntrico de saúde no Estado de São Paulo. São Paulo, FSP da USP, 2005. 212 p.

COLLI, C.; SZARFARC, S.C. Reflexões sobre a deficiência de ferro no Brasil. Cad Debate 2004; 10: 87-101. 
COLUCCI, A.C.A.; PHILIPPI, S.T.; SLATER VILLAR, B. Desenvolvimento de um questionário de freqüência alimentar para avaliação do consumo alimentar de crianças de 2 a 5 anos de idade. Rev Bras Epidemiol 2004; 7(4): 393-401.

COOK, J.D.; BAYNES, R.D.; SKIKNE, B.S. Iron deficiency and the measurement of iron status. Nutr Res Rev 1992; 5: 189-202.

CUPPARI, L.; ANÇÃO, M.S. Uso de programas computadorizados na avaliação dietética. In: Fisberg, R.M.; Slater, B.; Marchioni, D.M.L.; Martini, L.A. Inquéritos alimentares: métodos e bases científicos. Barueri, Manole, 2005. p. 71-82.

DANIEL, E.L.; BALOG, J.E. Utilization of the worl wide web in health education. J. Health Educ 1997, 28: 260-7.

DE BOURDEAUDHUIJ, I.D.; BRUG, J. Tailoring dietary feedback to reduce fat intake: an intervention at the family level. Health Educ Res 2000; 15: 449-62.

DE BOURDEAUDHUIJ, I.D.; BRUG, J.; VANDELANOTTE, C.; VAN OOST, P. Differences in impact between a family versus an individual based tailored intervention to reduce fat intake. Health Educ Res 2002; 17: 435-49.

DE NOOIJER, J.; LECHNER, L.; CANDEL, M.; DE VRIES, H. A randomized controlled study of short-term and long-term effects of tailored information versus general information on intention and behavior related to early detection of cancer. Cancer Epidemiol Biomarkers Prev 2002, 11: 1489-91.

DE VRIES, H.; BRUG, J. Computer-tailored interventions to promote health promoting behaviors: na introduction to a new approach. Patient Educ Couns 1999, 36: 99-105.

DIJKSTRA, A.; DE VRIES, H. The development of computer-generated tailored interventions. Patient Educ Couns 1999; 36: 193-203. 
DISOGRA, L.; GLANZ, K. The 5 a Day virtual classroom: an online strategy to promote healthful eating. J Am Diet Assoc Mar. 2000, 100(3): 349-52.

ELEY, S. Nutrition research using electronic mail. In: Nutrition discution forum. British Journal of Nutrition 1999, 81: 413-4.

ENGLE, A.; LYNN, L.L.; KOURY, K.; BOYAR, A.P. Reproductibility and comparability of computerized self-administered food frequency questionnaire. Nutr Cancer 1990; 13: $281-92$.

ESPINO, J.M.; MARTINEZ, H.; GREINER, T. Iron deficiency anemia in Tarahumara women of reproductive-age in Northern México. Salud Pública del México 2001; 43(5): 392-401.

FESKANICH, D.; SIELAFF, B.H.; CHONG, K.; BUZZARD, I.M. Computerized collection and analysis of dietary intake information. Comput Methods Programs Biomed 1989; 30: 47-57.

FINCH, C.A.; COOK, J.D. Iron deficiency. Am J Clin Nutr 1984; 39: 471-7.

FISBERG, R.M.; MARCHIONI, D.M.L.; SLATER, B. Recomendações nutricionais. In: Fisberg, R.M.; Slater, B.; Marchioni, D.M.L.; Martini, L.A. Inquéritos alimentares: métodos e bases científicos. Barueri, Manole, 2005. p. 190-236.

FISBERG, R.M.; MARTINI, L.A.; SLATER, B. Métodos de inquéritos alimentares. In: Fisberg, R.M.; Slater, B.; Marchioni, D.M.L.; Martini, L.A. Inquéritos alimentares: métodos e bases científicos. Barueri, Manole, 2005. p. 1-31.

FISBERG, R.M.; SLATER VILLAR, B.; MORIMOTO, J.M.; BUENO, M.B. Hábito alimentar: qualidade da dieta. In: César, C.L.G.; Carandina, L.; Alves, M.C.G.P.; Barros, M.B.A.; Goldbaum, M. Saúde e condição de vida em São Paulo: inquérito multicêntrico de saúde no Estado de São Paulo. São Paulo, FSP da USP, 2005. p. 81-9. 
GALANTE, A.P. Validade relativa de um questionário semiquantitativo de freqüência alimentar online para estimar ingestão de cálcio e ferro. São Paulo: 2004. 114 p. Dissertação (Mestrado) - Faculdade de Ciências Farmacêuticas da USP. Faculdade de Economia, Administração e Contabilidade da USP. Faculdade de Saúde Pública da USP. Programa de Pós-Graduação Interunidades em Nutrição Humana Aplicada.

GATES, B. A estrada do futuro. São Paulo, Companhia das Letras, 1995.

GIBSON, R.S. Principles of nutritional assessment. New York: Oxford University Press; 1990. 691 p.

GINSBERG-JAECKLE, M. Who started the Internet? http://bvsd.k12.co.us/schools/cent/Newspaper/sum95/Matt-JGStory.html. Acesso em: 04/12/2006.

GLANZ, K.; BRUG, J.; VAN ASSEMA, P. Are awareness of fat intake and actual fat consumption associated? A dutch-american comparison. Eur J Clin Nutr 1997; 51: 54-47.

GOLDBERG, J.P. Nutrition communication in the 21st century: what are the challenges and how can we meet them? Nutrition 2000, 16(7/8): 644-6.

GREGORY, J.; FOSTER, K.; TYLER, H.; WISEMAN, M. The dietary and nutritional survey of british adults. London: HMSO, 1990.

HARLOW, B.L.; ROSENTHAL, J.F.; ZIEGLER, R.G. A comparison of computerassisted and paper copy telephone interviewing. Am J Epidemiol 1985; 122: 33540.

HEATH, A.L.M.; SKEAFF, C.M.; GIBSON, R.S. The relative validity of a computerized food frequency questionnaire for estimating intake of dietary iron and its absorption modifiers. Eur J Clin Nutr 2000; 54: 592-9. 
IBGE - INSTITUTO BRASILEIRO DE GEOGRÁFIA E ESTATÍSTICA. Censo demográfico. Disponível em: http://www.ibge.org.br. Acesso em: 04/12/2006.

IBGE - INSTITUTO BRASILEIRO DE GEOGRÁFIA E ESTATÍSTICA. Censo demográfico.

Disponível

em:

http://www.ibge.gov.br/home/estatistica/populacao/censo2000/tabelabrasil111.shtm\# . Acesso em: 04/12/2006.

IBGE - INSTITUTO BRASILEIRO DE GEOGRÁFIA E ESTATÍSTICA. Censo demográfico. Disponível em: http://www.ibge.gov.br/home/estatistica/populacao/censo2000/tabelagrandes_regioe s211.shtm. Acesso em: 04/12/2006.

IBGE - INSTITUTO BRASILEIRO DE GEOGRÁFIA E ESTATÍSTICA. Censo demográfico. Disponível em: http://www.ibge.org.br/\#. Acesso em: 04/12/2006.

IBOPE - INSTITUTO BRASILEIRO DE OPINIÃO PÚBLICA. Relatórios estatísticos. Disponível em: http//www.ibope.com.br. Acesso em: 04/12/2006.

IOM - INSTITUTE OF MEDICINE. Dietary reference intakes: applications in dietary assessment. Washington: National Academy Press, 2001. 289 p. Disponível em: http//www.nap.edu/openbook/0309071836/html. Acesso em: 04/12/2006.

IPAQ - INTERNATIONAL PHYSICAL ACTIVITY QUESTIONNAIRE. Questionário Internacional de Atividade Física - versão curta. Disponível em: http://www.celafiscs.org.br/downloads/lpaq-Longo-Ultima-Semana2004.doc. Acesso em: 04/12/2006.

IZENBERG, N.; LIEBERMAN, D.A. The web, communication trends and children's health: how children use the web. Clin Pediatr 1998, 37: 335-40. 
JAMES, A.; CAMPBELL, M.K.; HUDSON, M.A. Perceived benefits and barriers to colectal cancer screening among african americans in North Carolina: how does perception relate to screening behavior? Cancer Epidemiol Biomarkers Prev 2002; 11: $529-34$.

KIPP, D.E.; RADEL J.D.; HOGUE, J.A. The internet and the nutritional scientist. Am J Clin Nutr oct. 1996; 64: 659-62.

KLESGES, R.C. Accuracy of self-reports of food intake in obese and normal weight individuals: effects of parental obesity on reports of children's dietary intake. Am J Clin Nutr 1988; 48: 1252-6.

KREUTER, M.W.; FARRELL, D.; OLEVITCH, L.; BRENNAN, L. Tailoring health messages: customizing communication with computeer technology. Mahwah, NJ: Lawrence Erlbaum, 2000.

KREUTER, M.W.; OSWALD, D.L.; BULL, F.C.; CLARK, E.M. Are tailored health education materials always more effective than non-tailored materials? Health Educ Res 2000; 15: 101-11.

LATORRE, M.R.D.O; JAIME, P.C. Métodos estatísticos aplicados aos estudos de consumo alimentar. In: Fisberg, R.M.; Slater, B.; Marchioni, D.M.L.; Martini, L.A. Inquéritos alimentares: métodos e bases científicos. Barueri, Manole, 2005. p. 16789.

LECHNER, L.; BRUG, J.; DE VRIES, H.; VAN ASSEMA, P.; MUDDE, A. Stages of chance for fruit, vegetable and fat intake: consequences of misconception. Health Educ Res 1998; 13: 1-11.

LOOKER, A.C.; DALLMAN, P.R.; CARROLL, M.D.; GUNTER, E.W.; JOHNSON, C.L. Prevalence of iron deficiency in the United States. JAMA 1997; 277: 973-6. 
LUTZ, S.F.; AMMERMAN, A.S.; ATWOOD, J.R.; CAMPBELL, M.K.; DeVellis, R.F.; ROSAMOND, W.D. Innovative newsletter interventions improve fruit and vegetable consumption in health adults. J Am Diet Assoc 1999, 99: 705-9.

MAJEM, L.S.; BARTRINA, J.A.; VERDÚ, J.M. Nutrición y salud pública: métodos, bases cientifícas y aplicaciones. Barcelona: Masson; 1995. p. xi.

MARCHIONI, D.M.L.; SLATER, B.; FISBERG, R.M. Minimizando erros na medida da ingestão dietética. In: Fisberg, R.M.; Slater, B.; Marchioni, D.M.L.; Martini, L.A. Inquéritos alimentares: métodos e bases científicos. Barueri, Manole, 2005. p. 15966.

MARTINI, L.A. Marcadores bioquímicos da ingestão alimentar. In: Fisberg, R.M.; Slater Villar, B.; Marchioni, D.M.L.; Martini, L.A. Inquéritos alimentares: métodos e bases científicos. Barueri, Manole, 2005. p. 132-58.

MEHTA, R.; SIVADAS, E. Comparing response rates ans response content in mail versus electronic mail surveys. Journal of the Market Research Society 1995, 37: 429-39.

MILIO, N. Electronic network, community intermediaries and the public's health. Bull Med Libr Assoc 1996, 84: 223-8.

MINISTÉRIO DA SAÚDE. Alimentos. Resolução RDC no. 344 de 13 de dezembro de 2002. Disponível em: http://www.anvisa.gov.br/alimentos/farinha.htm. Acesso em: 04/12/2006.

MONDINI, I.; MONTERIO, C.A. Mudanças no padrão de alimentação da população urbana brasileira (1962-1988). Rev Saúde Pública 1994; 28(6): 433-9.

MORAIS, M.B. de; SPINELLI, M.G.N.; SOUZA, J.M.P. de; SOUZA, S.B. de; SESOKO, E.H. Sinais clínicos no diagnóstico de anemia: uma ação tardia e ineficiente no combate à deficiência de ferro. Rev Saúde Pública 2004; 38(2). 
MORIMOTO, J.M. Fatores associados à qualidade da dieta de adultos residentes na região metropolitana de São Paulo. São Paulo, s.n., 2005. 73 p.

NATIONAL TELECOMMUNICATIONS AND INFORMATION ADMINISTRATION (NTIA). A nation online: How americans are expanding their use of the internet. Washington, $2002 . \quad$ Disponível em: http://www.ntia.doc.gov/opadhome/digitalnation/index_2002.html. Acesso em: 04/12/2006.

NEGROPONTE, N. A vida digital. São Paulo, Companhia das Letras, 1995.

NEIGHBORS-DEMBERECKYJ, L.; PAINTER, J.E. Online diet analysis tools: a functional comparison. J Am Diet Assoc Dec. 2002, 102(12): 1738-42.

NEUMANN, A.I.C.P. Padrões de consumo alimentar associados a outros fatores de risco predisponentes a doenças cardiovasculares em residentes da área urbana do município de São Paulo. São Paulo: 2005. 113 p. Tese (Doutorado) Faculdade de Saúde Pública da USP. Departamento de Nutrição.

OCHSENHOFER, K. Manual de orientação para alimentação saudável de crianças e adultos. São Paulo: Karina Ochsenhofer; 2006. 104 p. No prelo.

OENEMA, A.; BRUG, J.; LECHNER, L. Web-based computer-tailored nutrition education: results of a randomised controlled trial. Health Educ Res 2001; 16: 64760.

OLIVEIRA, I. Anemia por deficiência de ferro. In: Figueira F; Ferreira OS; Alves JOB. Pediatria. Rio de Janeiro: MEDSI; 1990. p. 543-8.

ORGANIZACIÓN MUNDIAL DE LA SALUD. Anemias nutricionales. Ginebra: 1972. (Serie de Informes Tecnicos, 503). Informe de un Grupo de Expertos de la OMS. 
ORTEGA, R.M. Relationship between diet composition and mass index in a group of Spanish adolescents. Brit J Nutr 1995; 74: 765-73.

PAHO/WHO (Pan American Health Organization / World Health Organization). Nutritional situation in the anemias. Epidemiological Bulletin 1994; 15: 1-6.

PAINTER, J. Virtual estimation: internet program helps users determine nutrient intake and needs. J Am Diet Assoc sep. 2000; 100(9): 1002.

PAIVA, A.A.; RONDÓ, P.H.C; GUERRA-SHINOHARA, E.M. Parâmetros para avaliação do estado nutricional de ferro. Rev Saúde Pública 2000; 34(4): 421-6.

PALUMBO, C. Using new technology for nutrition counseling. J Am Diet Assoc nov. 1999; 99(11): 1363-4.

PEREIRA, R.A.; KOIFMAN, S. Uso do questionário de freqüência Ana avaliação do consumo alimentar pregresso. Rev Saúde Pública 1999; 33(6): 610-21.

PHILIPPI, S.T.; SZARFARC, S.C.; LATTERZA, A.R. Virtual Nutri: software. Versão 1.0. São Paulo: Departamento de Nutrição/FSP/USP, 1996. Três disquetes.

PRESTON, M.A.; BARANOWSKI, T.; HIGGINBOTHAM, J.C. Orchestrating the points of community intervention: enhancing the diffusion process. Int Q Community Health Educ 1988; 9: 11-34.

REINSTEIN, C.S.B. DietWin Software de Avaliação Nutricional - Profissional 2.0. Porto Alegre; Brubins, 2002.

REUBSAET, A.; BRUG, J.; VAN DEN BORNE, B.; DE VET, E. Different interventions to promote registration as organ donor among dutch adolescents. St Andrews, UK: European Health Psychology Society 2001: 60. 
RIMER, B.K.; GLASSMAN, B. Tailoring communications for primary care settings. Methods Inform Med 1998; 37(2): 171-7.

RIVA, A.; SMIGELSKI, C.; FRIEDMAN, R. WebDietAID: an interactive web-based nutritional counselor. Proc AMIA Symp. 2000; 709-13.

ROCKETT, H.R.H.; BREITENBACH, M.; FRAZIER, A.L.;WITSCHI, J.; WOLF, A.M.; FIELD, A.E.; COLDITZ, G.A. Validation of a youth/adolescent food frequency questionnaire. Prev Med 1997; 26(6): 808-16.

RUSSEL, D.; PARNELL, W.; WILSON, N. Key results of the 1997 national nutrition survey. Wellington: Ministry of Health, 1999.

SALVO, V.L.M.A; GIMENO, S.G.A. Reprodutividade e validade do questionário de freqüência de consumo de alimentos. Rev Saúde Pública 2002; 36(4): 505-12.

SBAN - SOCIEDADE BRASILEIRA DE ALIMENTAÇÃO E NUTRIÇÃO. Usos e aplicações das “Dietary Reference Intakes" DRIs. Disponível em: http://www.sban.com.br/educacao/pesquisa/dris.htm. Acesso em: 20 nov 2006.

SETZER, V.W.; KON, F. Introdução à rede internet e seu uso. São Paulo; Edgard Blücher, 1997. 115 p.

SHILS, M.E.; OLSON, J.A.; MOSHE, S.; ROSS, A.C. Tratado de nutrição moderna na saúde e na doença. 9. ed. v. 1. São Paulo: Manole; 2001. p.1001-24.

SICHIERI, R.; EVERHART, J.E. Validity of brazilian food frequency questionnaire against dietary recalls and estimated energy intake. Nutrition Research 1998; 18(10): 1649-59.

SKINNER, C.S.; CAMPBELL, M.K.; RIMER, B.K.; CURRY, S.; PROCHASKA, J.O. How effective is tailored print communication? Ann Behav Med 1999; 21: 290-8. 
SKINNER, C.S.; STRECHER, V.J.; HOSPERS, H. Physicans' recommendations for mammography: do tailored messages make a difference? Am J Public Health 1994; 84: 43-9.

SLACK, W.V.; PORTER, D.; WITSCHI, J.; SULLIVAN, M.; BUXBAUM, R.; STARE, F.J. Dietary interviewing by computer. J Am Diet Assoc 1976; 69: 514-7.

SLACK, W.V.; VAN CURA, L.J. Patient reaction to computer-based medical interviewing. Comput Biomed Res 1968; 1: 527-31.

SLATER, B.; MARCHIONI, D.L.; FISBERG, R.M. Estimando a prevalência da ingestão inadequada de nutrientes. Rev Saúde Pública 2004; 38(4).

SLATER, B.; LIMA, F.E.L. de. Validade e reprodutibilidade dos métodos de inquérito alimentar. In: Fisberg, R.M.; Slater, B.; Marchioni, D.M.L.; Martini, L.A. Inquéritos alimentares: métodos e bases científicos. Barueri, Manole, 2005. p. 10831.

SLATER, B.; PHILIPPI, S.T.; FISBERG, R.M.; LATORRE, M.R.D.O. Validation of a semi-quantitative adolescent food frequency questionnaire applied at a public school in São Paulo, Brazil. Eur J Clin Nutr 2003; 57(5): 629-35.

SLATER, B.; PHILIPPI, S.T.; MARCHIONI, D.M.L.; FISBERG, R.M. Validação de questionário de freqüência alimentar - QFA: considerações metodológicas. Rev Bras Epidemiol 2003; 6(3): 200-8.

SLATTERY, M.; CAAN, B.J.; DUNCAN, D.; BERRY, T.D.; COATES, A.; KERBER, R. A computerized diet history questionnaire for epidemiologic studies. J Am Diet Assoc 1994; 94(7): 761-6.

SMUCKER, R.; BLOCK, G.; COYLE, L.; HARVIN, A.; KESSLER. L. A dietary and risk factor questionnaire and analysis system for personal computers. Am $\mathbf{J}$ Epidemiol 1989; 129: 445-9. 
SOBRAL, C.R.M.; ARELLANO, E.B.; CONSTANTINO, M.A.; CYRILLO, D.C. Consumo de medicamentos na população fisicamente ativa com mais de $\mathbf{6 0}$ anos: um estudo exploratório. Disponível em: http://www.pdf4free.com. Acesso em: 04/12/2006.

SOSA-IUDICISSA, M.; OLIVERI, N.; GAMBOA. C.A.; ROBERTS, J. Internet, telematics and health. Amsterdam: IOS Press, 1997. 530 p.

STRECHER, V.J.; KREUTER, M.; DEN BOER, D.J.; KOBRIN, S.; HOSPERS, H.J.; SINNER, C.S. The effects of computer-tailored smoking cessation messages in family practice settings. J Fam Pract 1994; 39: 262-8.

STREET, R.L.; GOLD, W.R.; MANNING, T. Health promotion and interactive technology: theoretical applications and future directions. Mahwah, NJ: Lawrence Erlbaum, 1997.

STREIT, K.J.; STEVENS, N.H.; STEVENS, V.; ROSSNER, J. Food records: a predictor and modifier of weight change in a long-term weight loss program. $\mathbf{J}$ Am Diet Assoc 1991, 91(2): 213-6.

SUTHERLAND, L.A. Nutrition professionals in cyberspace: getting wired for the new millennium. J Am Diet Assoc Nov. 1999, 99(11): 1365-6.

TAMANINI, J.T.; DAMBROS, M.; D’ANCONA, C.A.L.; PALMA, P.C.R.; NETTO, N.R. Validação para o português do "International Consultation on Incontinence Questionnaire - Short Form" (ICIQ-SF). Rev Saúde Pública 2004; 38(3): 1-9.

THACH, E. Using electronic mail to conduct survey research. Educational Technology Mar.-Apr. 1995, 27-31.

TOMITA, L.Y.; CARDOSO, M.A. Avaliação da lista de alimentos e porções alimentares de questionário quantitativo de freqüência alimentar em população adulta. Cad Saúde Pública 2002, 18(6): 1747-56. 
VAILAS, L.I.; BLANKENHORN, D.H.; SELZER, R.H.; JOHNSON, R.L. A computerized quantitative food frequency analysis for the clinical setting: use in documentation and counseling. J Am Diet Assoc 1987; 87: 1539-43.

VILLAR, B.S. Desenvolvimento e validação de um questionário semiquantitativo de freqüência alimentar para adolescentes. São Paulo: 2001. 133 p. Tese (Doutorado) - Faculdade de Saúde Pública da USP.

VITERI, F.E. et al. Absortion of iron supplements administred daily or weekly: a colaborative study. In: Nestlé Fundation for the Study of the Problems of Nutrition in the World. Annual Report. Geneve: Nestlé; 1993. p. 82-96.

WESTERTERP-PLANTENGA, M.S. Use of a general information ans communication technology aspect for a specific aim. In: Nutrition discution forum. British Journal of Nutrition 1999, 81(5): 416.

WALSH, J.P.; KIESLER, S.; SPROUL, L.S.; HESSES, B.W. Self-selected and randomly selected respondents in a computer network survey. Public Opin Q 1992, 56: $241-4$.

WHO - WORLD HEALTH ORGANIZATION. Physical status: the use and interpretation of anthropometry: report of a WHO expert committee. Geneva: 1998. p. 350-69.

WILLETT, W. Food frequency methods. In: Willet W. Nutritional epidemiology. 2. ed. Oxford: University Press; 1998. p. 74-100.

WILLETT, W. Correction for the effects of measurement errors. In: Willet W. Nutritional epidemiology. 2. ed. Oxford: University Press; 1998. p. 302-20.

WILLETT, W.; LENART, E. Reproductibility and validity of food-frequency questionnaires. In: Willet W. Nutritional epidemiology. 2. ed. Oxford: University Press; 1998. p. 101-47. 
WISE, A. Using the internet in nutrition research. In: Nutrition discution forum. British Journal of Nutrition 1999, 81: 414-5.

YIP, R; DALLMAN, P.R.. Hierro. In: Instituto Int. De Ciencias de la Vida. Conocimentos actuales sobre Nutrición, $7^{\text {a }}$. ed. Washington (DC): OPS; 1997. (Publicación Científica, 565). 
APÊNDICE 1 - Divulgação

\title{
CONHEÇA SEU "ESTADO NUTRICIONAL"
}

\author{
AVALIE SUA ALIMENTAÇÃO
}

PARTICIPE DE NOSSO ESTUDO !!!

\author{
DEPARTAMENTO DE \\ ALIMENTOS E NUTRIÇÃO EXPERIMENTAL \\ FACULDADE DE CIÊNCIAS FARMACÊUTICAS \\ UNIVERSIDADE DE SÃO PAULO
}

CONTATO: KARINA OCHSENHOFER

TEL.: 8331-4984 
APÊNDICE 2 - Termo de Consentimento Livre e Esclarecido

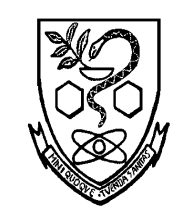

Universidade de São Paulo

Faculdade de Ciências Farmacêuticas

TERMO DE CONSENTIMENTO LIVRE E ESCLARECIDO

I - DADOS DE IDENTIFICAÇÃO DO SUJEITO DA PESQUISA OU LEGAL RESPONSÁVEL

1. Nome do Paciente:

Documento de Identidade $\mathrm{N}^{\circ}$ :

Sexo: ( ) M

( ) F

Data de Nascimento: / .......... / .........

Endereço:

$\mathrm{N}^{0}$ :

Apto:

Bairro:

Cidade:

CEP:

Telefone: $(\ldots .$.

II - DADOS SOBRE A PESQUISA

1. Título do Protocolo de Pesquisa: VALIDAÇÃO DE QUESTIONÁRIO SEMIQUANTITATIVO DE FREQÜÊNCIA ALIMENTAR ONLINE PARA FERRO

2. Pesquisadora: KARINA OCHSENHOFER

Cargo / Função: Nutricionista

Inscrição Conselho Regional No: CRN-3 14049

Departamento da FCF / USP: Departamento de Alimentos e Nutrição Experimental

3. AVALIAÇÃO DO RISCO DA PESQUISA

$\begin{array}{llll}\text { Sem Risco (X) } & \text { Risco Mínimo ( ) Risco Médio ( ) } \\ \text { Risco Baixo ( ) } & \text { Risco Maior } & (\text { ) }\end{array}$

(Probabilidade de que o indivíduo sofra algum dano como conseqüência imediata ou tardia do estudo. Nos projetos com coleta de sangue, incluir detalhadamente, como observação as possíveis reações decorrentes desse procedimento.)

4. Duração da Pesquisa: 8 (oito) meses 


\section{III - REGISTRO DAS EXPLICAÇÕES DO PESQUISADOR AO PACIENTE OU SEU REPRESENTANTE LEGAL SOBRE A PESQUISA, CONSIGNANDO}

1. Justificativa e os objetivos da pesquisa: Avaliar a validade relativa e a reprodutibilidade de um Questionário Semiquantitativo de Freqüência Alimentar (QSFA) "online", para estimar ingestão de ferro

2. Procedimentos que serão utilizados e propósitos: Preenchimento de 6 (seis) Recordatórios de 24 horas e 2 (dois) Questionários de Freqüência Alimentar durante um período de 8 (oito) meses

3. Desconfortos e riscos esperados: Nenhum

4. Benefícios que poderão ser obtidos: Conhecer a qualidade da dieta ingerida e sua adequação de acordo com as recomendações

5. Procedimentos alternativos que possam ser vantajosos para o indivíduo: Não há

\section{IV - ESCLARECIMENTOS DADOS PELO PESQUISADOR SOBRE GARANTIAS DO SUJEITO DA PESQUISA}

O sujeito da pesquisa está ciente que tem acesso, a qualquer tempo, às informações sobre procedimentos, riscos e benefícios relacionados à pesquisa, inclusive para dirimir eventuais dúvidas. Tem a liberdade de retirar seu consentimento a qualquer momento e de deixar de participar do estudo, sem que isto traga prejuízo à continuidade da assistência. Os dados serão mantidos em sigilo.

V - INFORMAÇÕES DE NOMES, ENDEREÇOS E TELEFONES DOS RESPONSÁVEIS PELO ACOMPANHAMENTO DA PESQUISA, PARA CONTATO EM CASO DE INTERCORRÊNCIAS CLÍNICAS E REAÇÕES ADVERSAS

Responsável pelo acompanhamento da pesquisa: KARINA OCHSENHOFER

Rua Itororó, 74 - Morumbi - CEP 05688-060 - São Paulo - S.P.

E-mail: karina.och@uol.com.br ou kanutri@usp.br

Telefones: 8331-4984 / 3507-4948 / 4366-9600 
VI - OBSERVAÇÕES COMPLEMENTARES

VII - CONSENTIMENTO PÓS-ESCLARECIDO

Declaro que, após convenientemente esclarecido pelo pesquisador e ter entendido o que me foi explicado, consinto em participar do presente Protocolo de Pesquisa.

São Paulo, de de 2005.

Sujeito da pesquisa Pesquisadora (carimbo ou nome legível) 
APÊNDICE 3 - Questionário de caracterização

NOME:

FICHA No.:

DATA DE NASCIMENTO: I - I $19-$

PESO (em quilos):

$-\ldots, \ldots$

ESTATURA (em metros): m

E-MAIL:

TEL 1:

TEL 2:

TEL 3:

ESCOLARIDADE: ( ) ensino fundamental incompleto

( ) completo

( ) ensino médio incompleto

( ) completo

( ) superior incompleto

( ) completo

( ) pós-graduação incompleta

( ) completa

OCUPAÇÃO:

( ) funcionário USP

( ) autônomo

( ) terceirizado

( ) aposentado

( ) estudante

ESTÁ GRÁVIDA ?

( ) $\operatorname{sim}$

( ) não

TEM ALGUMA ENFERMIDADE ?

( ) $\operatorname{sim}$

( ) não

SE "SIM", QUAL ?

( ) diabetes

( ) hipertireoidismo

( ) hipercolesterolemia

( ) hipotireoidismo

( ) hipertensão arterial

( ) outra Qual?

( ) cardiovascular 
Para responder as próximas questões lembre que:

$>$ atividades físicas MODERADAS são aquelas que precisam de ALGUM esforço físico e que fazem respirar UM POUCO mais forte que o normal

$>$ atividades físicas VIGOROSAS são aquelas que precisam de um GRANDE esforço físico e que fazem respirar MUITO mais forte que o normal

Para responder as perguntas pense somente nas atividades que você realiza por pelo menos 10 minutos contínuos de cada vez:

1a) Em quantos dias da última semana você CAMINHOU por pelo menos 10 minutos contínuos em casa ou no trabalho, como forma de transporte para ir de um lugar para outro, por lazer, por prazer ou como forma de exercício?

_ dias por SEMANA $\quad$ ( ) nenhum

1b) Nos dias em que você CAMINHOU por pelo menos 10 minutos contínuos, quanto tempo no total você gastou caminhando por dia?

_ horas e _ minutos por DIA

2a) Em quantos dias da última semana você realizou atividades MODERADAS por pelo menos 10 minutos contínuos, como por exemplo pedalar leve na bicicleta, nadar, dançar, fazer ginástica aeróbica leve, jogar vôlei recreativo, carregar pesos leves, fazer serviços domésticos na casa, no quintal ou no jardim como varrer, aspirar, cuidar do jardim, ou qualquer atividade que fez aumentar MODERADAMENTE sua respiração ou batimentos do coração? (POR FAVOR NÃO INCLUA CAMINHADA)

_ dias por SEMANA $\quad$ ( ) nenhum

2b) Nos dias em que você fez atividades MODERADAS por pelo menos 10 minutos contínuos, quanto tempo no total você gastou fazendo essas atividades por dia?

_ horas e _ minutos por DIA 
3a) Em quantos dias da última semana você realizou atividades VIGOROSAS por pelo menos 10 minutos contínuos, como por exemplo correr, fazer ginástica aeróbica, jogar futebol, pedalar rápido na bicicleta, jogar basquete, fazer serviços domésticos pesados em casa, no quintal ou cavoucar no jardim, carregar pesos elevados ou qualquer atividade que fez aumentar MUITO sua respiração ou batimentos do coração?

_ dias por SEMANA $\quad$ ( ) nenhum

3b) Nos dias em que você fez atividades VIGOROSAS por pelo menos 10 minutos contínuos, quanto tempo no total você gastou fazendo essas atividades por dia? horas e _ minutos por DIA 


\section{APÊNDICE 4 - Itens alimentares do software "Nutriquanti"}

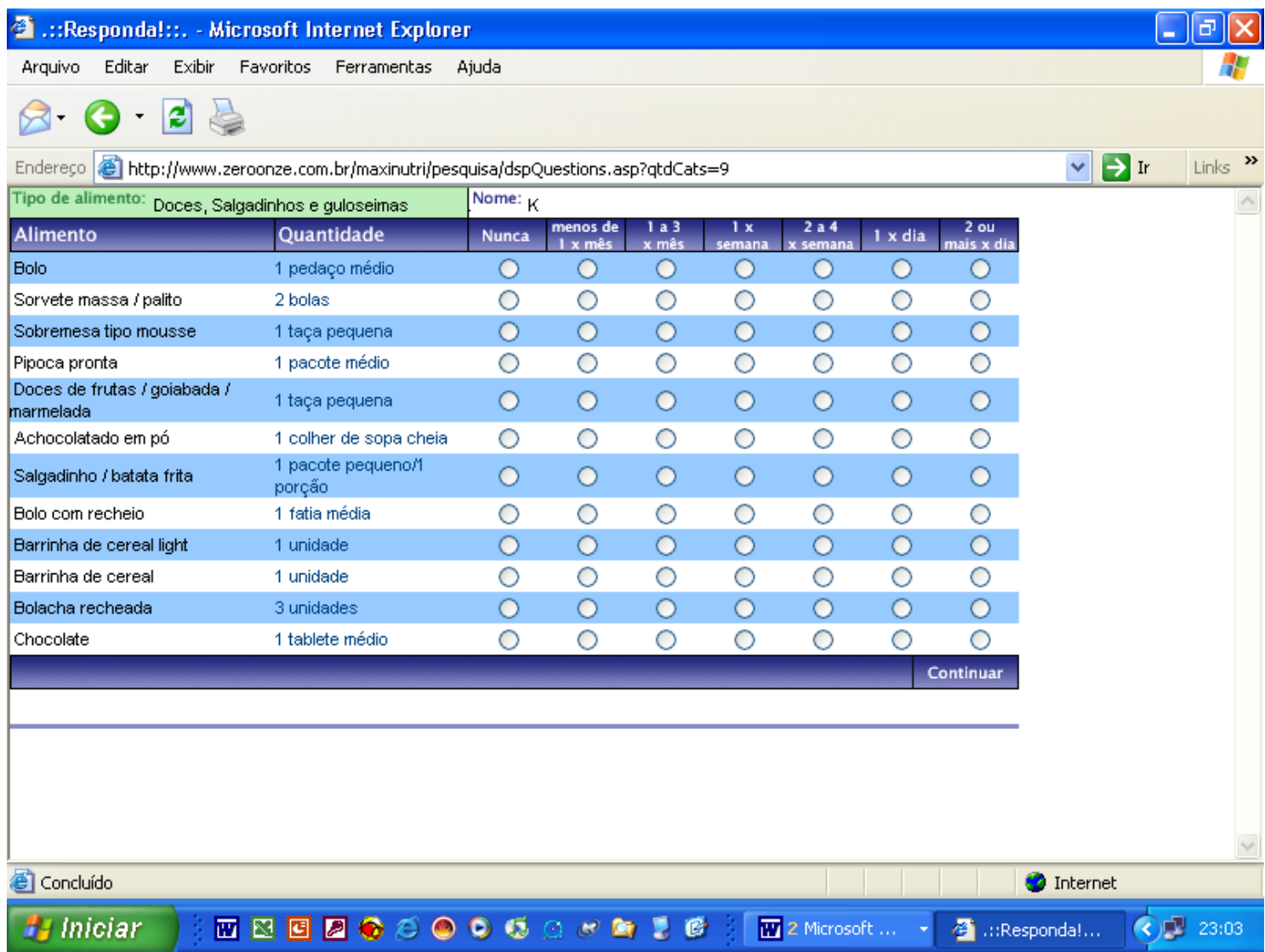

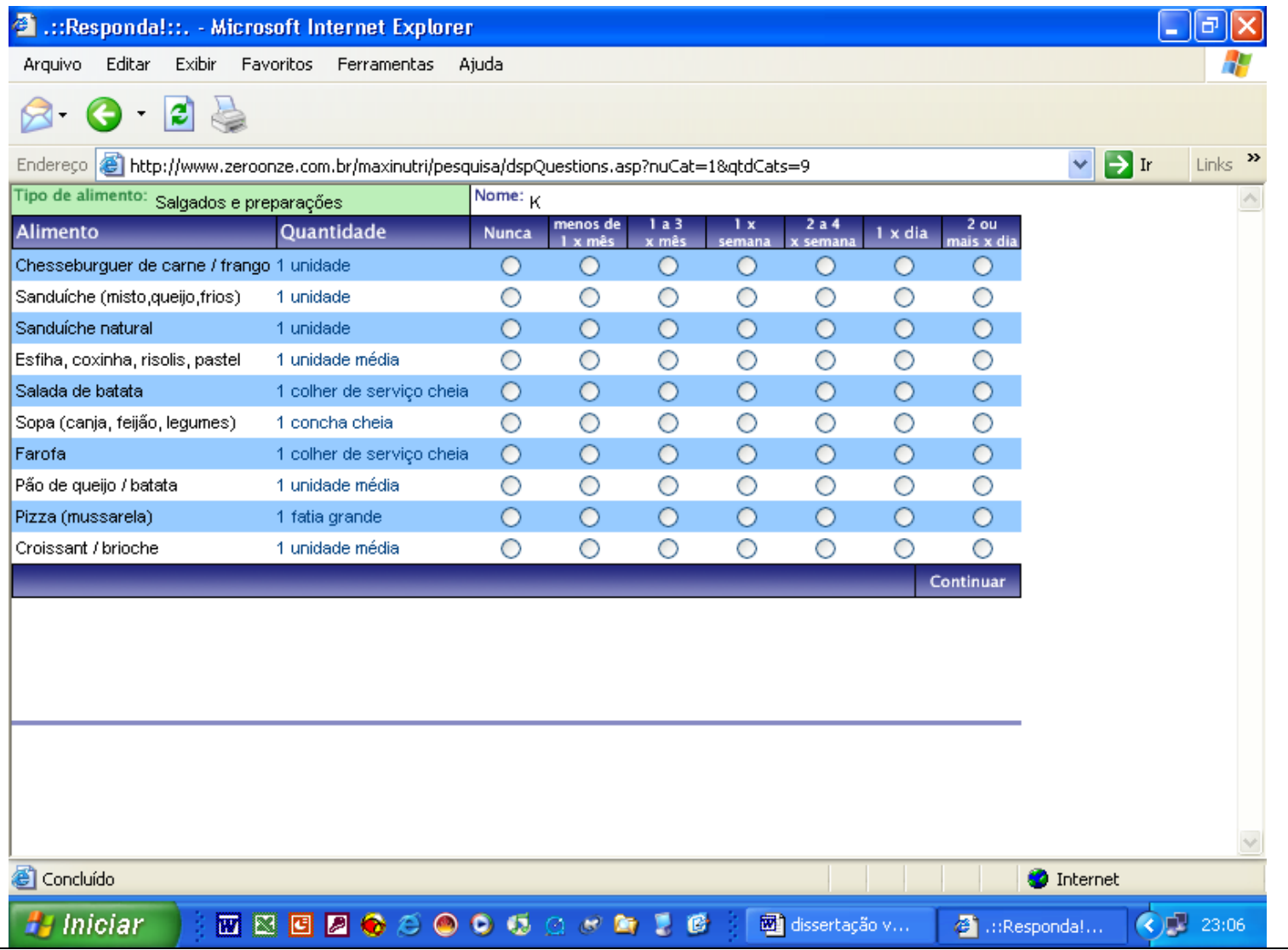




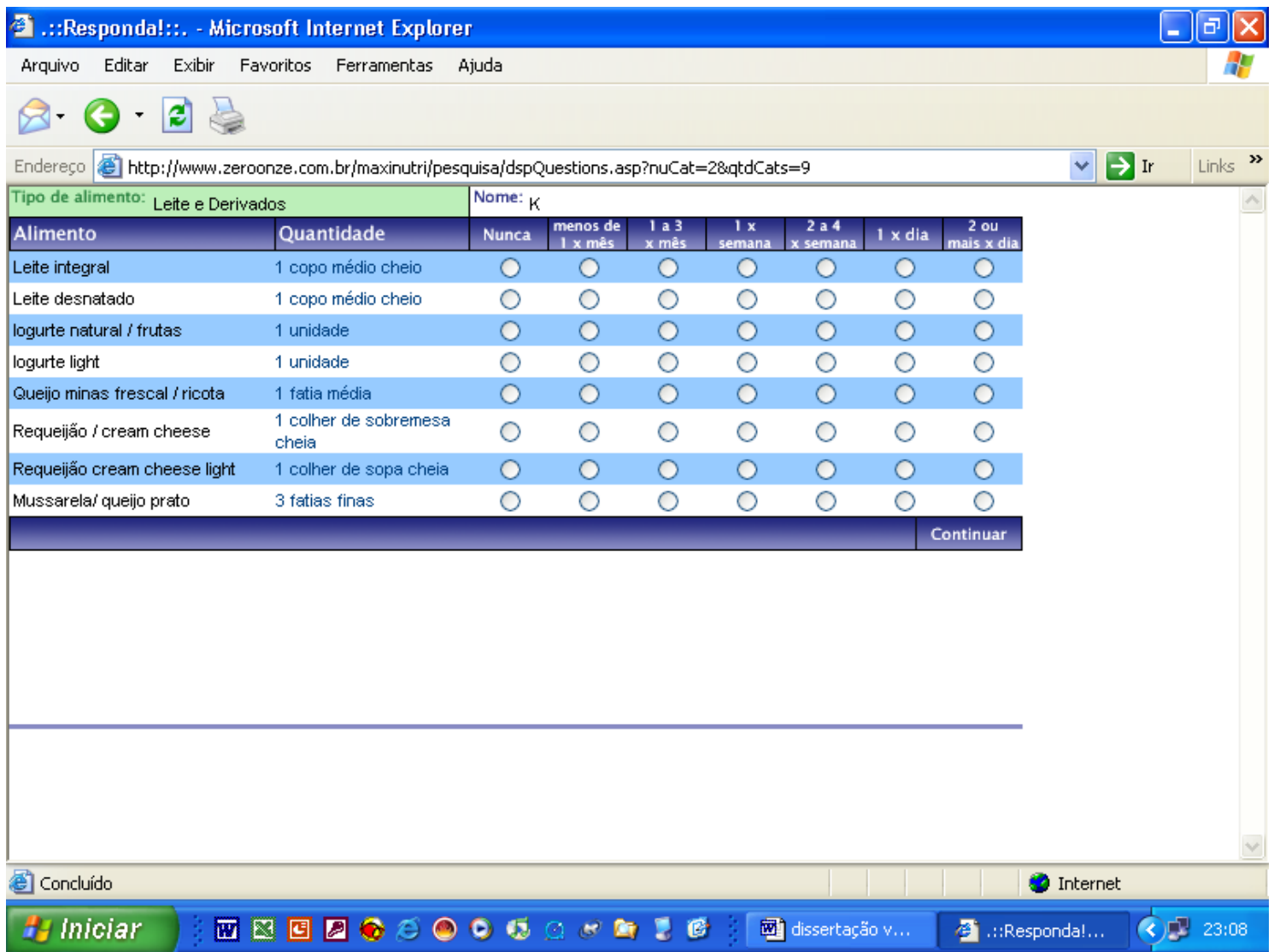

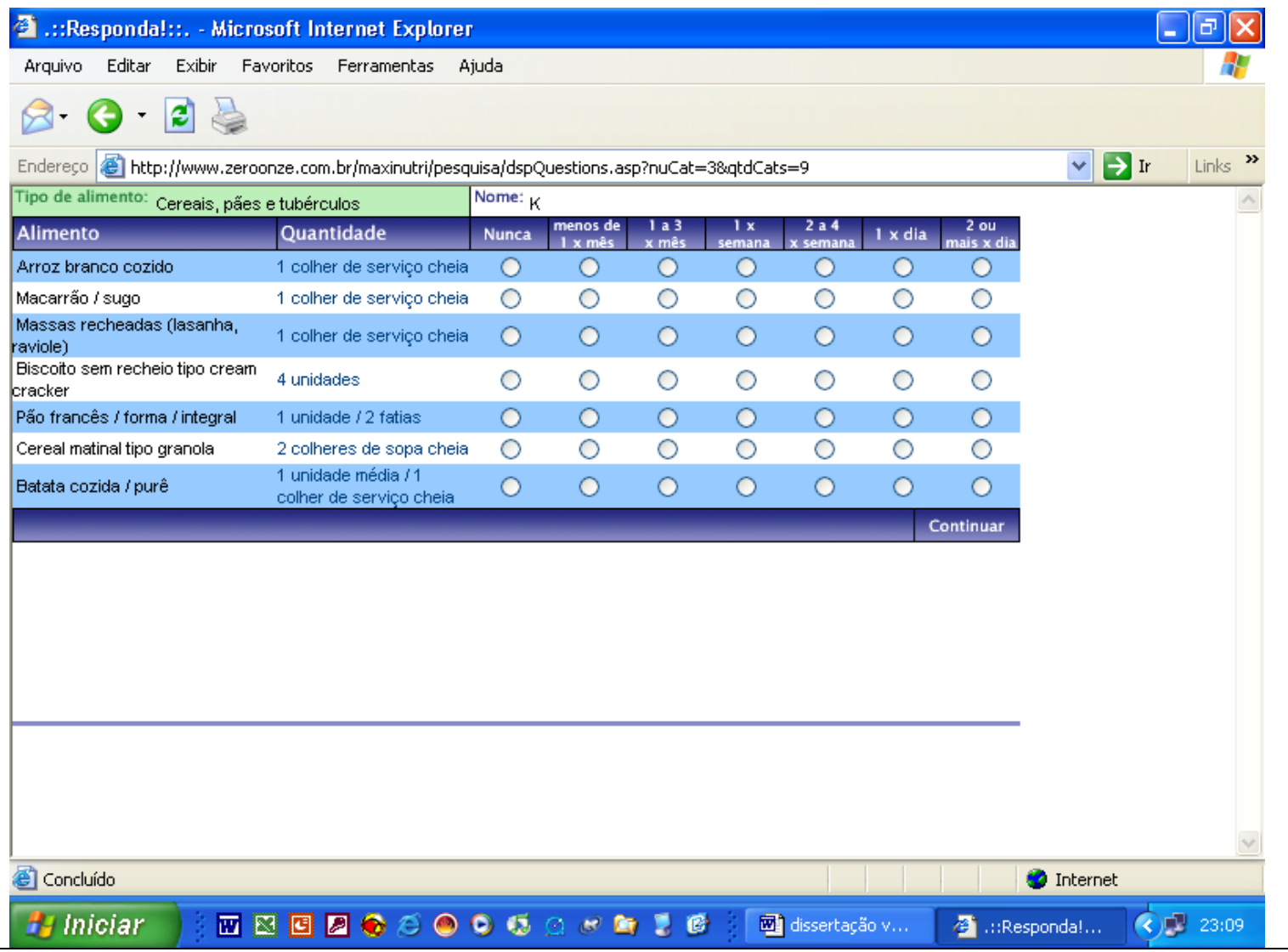


Fi .::Respondal::, - Microsoft Internet Explorer

$0 \square$

Arquivo Editar Exibir Favoritos Ferramentas Ajuda

8. $8 \cdot 20$

Endereşo hettp://wwww.zeroonze.com.brimaxinutri/pesquisa/dspQuestions.asp?nuCat=4\&:qtdCats=9

$\checkmark$ Ir Links 》

\begin{tabular}{|l|l|}
\hline Tipo de alimento: Verduras e legurnes & Nome: $K$ \\
\hline
\end{tabular}

\begin{tabular}{|c|c|c|c|c|c|c|c|c|}
\hline Alimento & Quantidade & Nunca & $\begin{array}{l}\text { menos de } \\
\mid \times m^{2} s\end{array}$ & $\begin{aligned} 1 \text { 1as } \\
x \text { mâs }\end{aligned}$ & $\begin{array}{l}\text { Ix } \\
\text { semana }\end{array}$ & 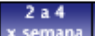 & $1 \times$ dia & 2 ou \\
\hline Alface & 1 porção média & 0 & 0 & 0 & 0 & 0 & 0 & 0 \\
\hline Acelga / repolho & 1 collher de serviço cheia & 0 & 0 & 0 & 0 & 0 & 0 & 0 \\
\hline Agriâo / rúcula & $\begin{array}{l}1 \text { pegador / } 1 \text { prato de } \\
\text { sobremesa }\end{array}$ & 0 & 0 & 0 & 0 & 0 & 0 & 0 \\
\hline Couve-flor & 2 ramos grandes & 0 & 0 & 0 & 0 & 0 & 0 & 0 \\
\hline Beterraba & 1 colher de serviço cheia & 0 & 0 & 0 & 0 & 0 & 0 & 0 \\
\hline Cenoura & 1 colher de serviço cheia & 0 & 0 & 0 & 0 & 0 & 0 & 0 \\
\hline Espinatre / couve manteiga & 1 colher de serviço cheia & 0 & 0 & 0 & 0 & 0 & 0 & 0 \\
\hline Pepino & 4 fatias médias & 0 & 0 & 0 & 0 & 0 & 0 & 0 \\
\hline Tomate & 3 fatias médias & 0 & 0 & 0 & 0 & 0 & 0 & 0 \\
\hline Abóbora & 1 colher de serviço & 0 & 0 & 0 & 0 & 0 & 0 & 0 \\
\hline
\end{tabular}

\begin{tabular}{|l|l|}
\hline & Continuar \\
\hline
\end{tabular}

C) Concluído

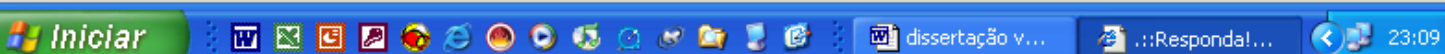

E .::Respondal:: - Microsoft Internet Explorer

Arquivo Editar Exibir Favoritos Ferramentas Ajuda

-

8. $6 \cdot \theta$

Endereço ht http://iwww. zeroonze.com.brimaxinutrijpesquisa/dspQuestions. asp?nuCat=5\&qtdCats=9

\begin{tabular}{|c|c|c|c|c|c|c|c|c|}
\hline \multicolumn{2}{|c|}{ Tipo de alimento: Frutas e Sementes } & \multicolumn{7}{|l|}{ Nome: $\mathrm{k}$} \\
\hline Alimento & Quantidade & Nunca & $\begin{array}{l}\text { menos de } \\
1 \times \text { mass }\end{array}$ & $\begin{array}{l}1 \text { a } 3 \\
x \text { mass }\end{array}$ & $\begin{array}{l}1 x \\
\text { semana }\end{array}$ & \begin{tabular}{|l|}
$2 \mathrm{a} 4$ \\
$\times \mathrm{a}$ semana \\
\end{tabular} & $1 \times d i a$ & $\begin{array}{c}2 \text { ou } \\
\text { mais } x \text { dia }\end{array}$ \\
\hline Açaí & 1 taça média & 0 & 0 & 0 & 0 & 0 & 0 & 0 \\
\hline Danasco seco & 3 unidades & 0 & 0 & 0 & 0 & 0 & 0 & 0 \\
\hline Abacaxi & 1 fatia média & 0 & 0 & 0 & 0 & 0 & 0 & 0 \\
\hline Banana & 1 unidade média & 0 & 0 & 0 & 0 & 0 & 0 & 0 \\
\hline Laranja & 1 unidade grande & 0 & 0 & 0 & 0 & 0 & 0 & 0 \\
\hline Maçẳ / pêra & 1 unidade média & 0 & 0 & 0 & 0 & 0 & 0 & 0 \\
\hline Castanha do Pará / caju & 3 unidades & 0 & 0 & 0 & 0 & 0 & 0 & 0 \\
\hline Melăo /Melancia & 1 fatia média & 0 & 0 & 0 & 0 & 0 & 0 & 0 \\
\hline Manga & 1 unidade pequena & 0 & 0 & 0 & 0 & 0 & 0 & 0 \\
\hline Morango & 1 xícara cheia & 0 & 0 & 0 & 0 & $\mathrm{O}$ & 0 & 0 \\
\hline Uva & 1 cacho médio & 0 & 0 & 0 & 0 & 0 & 0 & 0 \\
\hline Salada de frutas & 1 xicara & 0 & 0 & 0 & 0 & 0 & 0 & 0 \\
\hline Goiaba & 1 unidade média & 0 & 0 & 0 & 0 & 0 & 0 & 0 \\
\hline
\end{tabular}

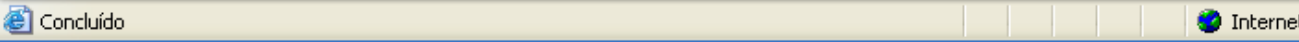

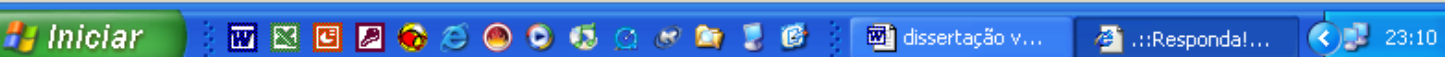




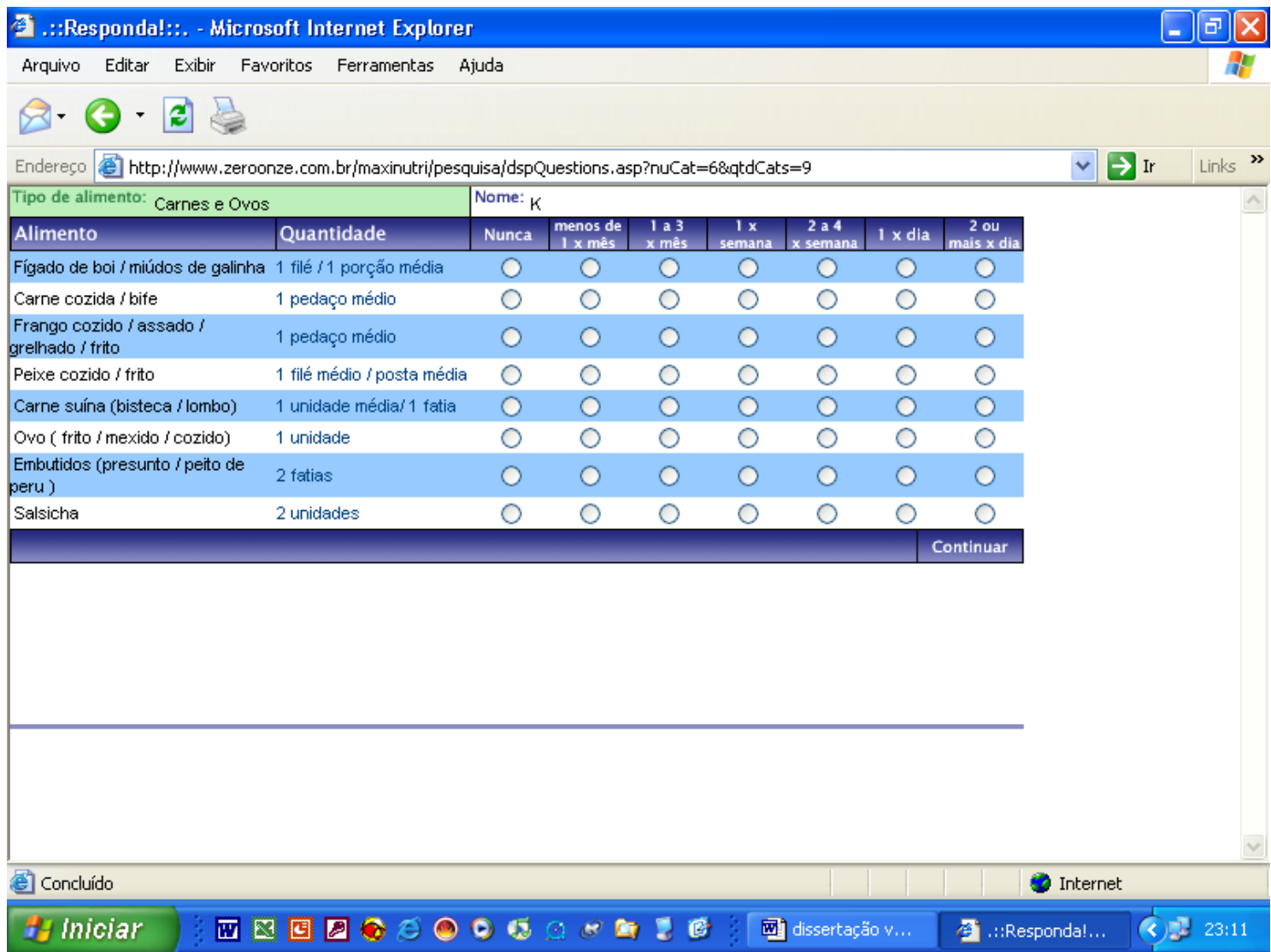

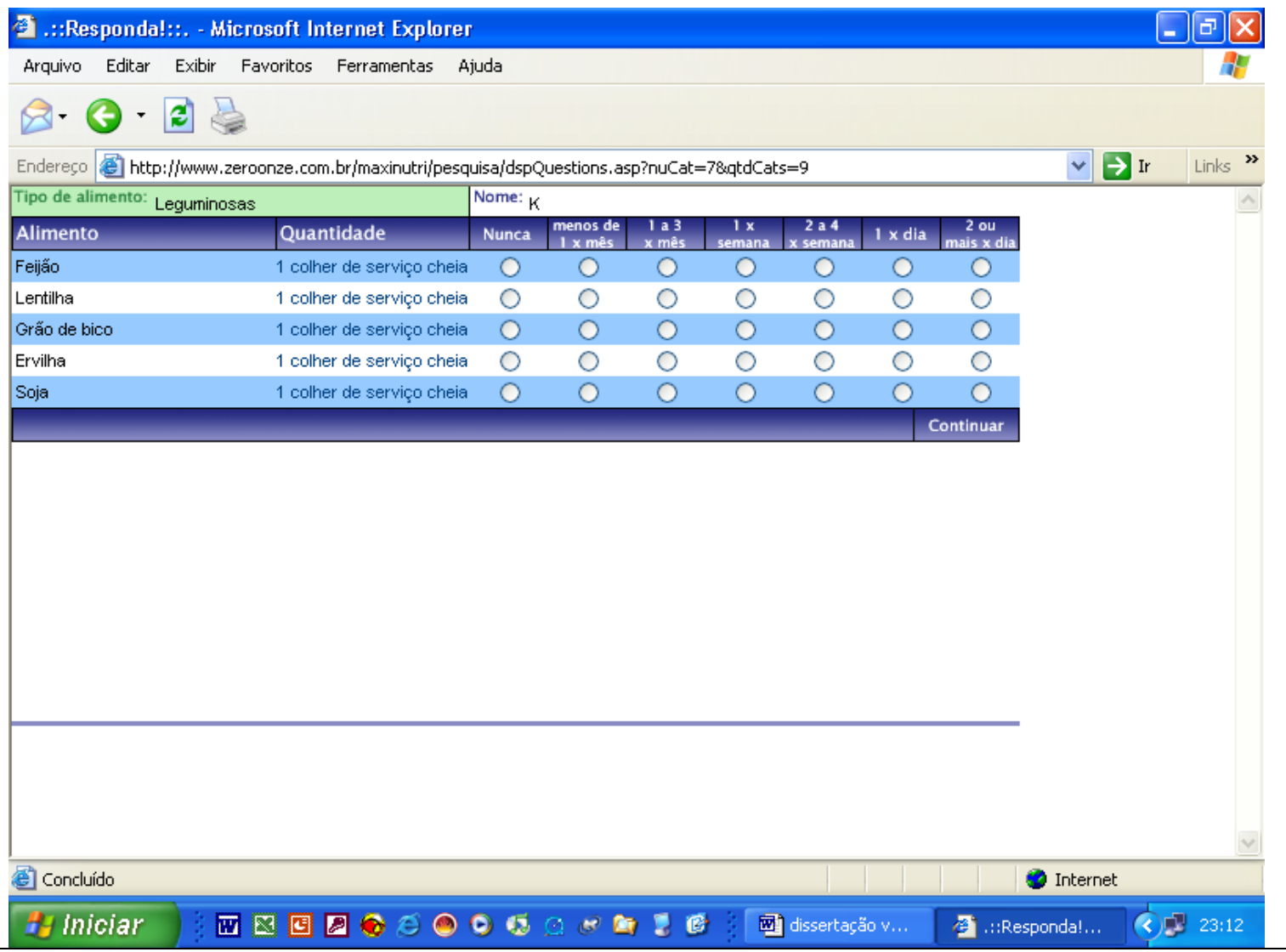




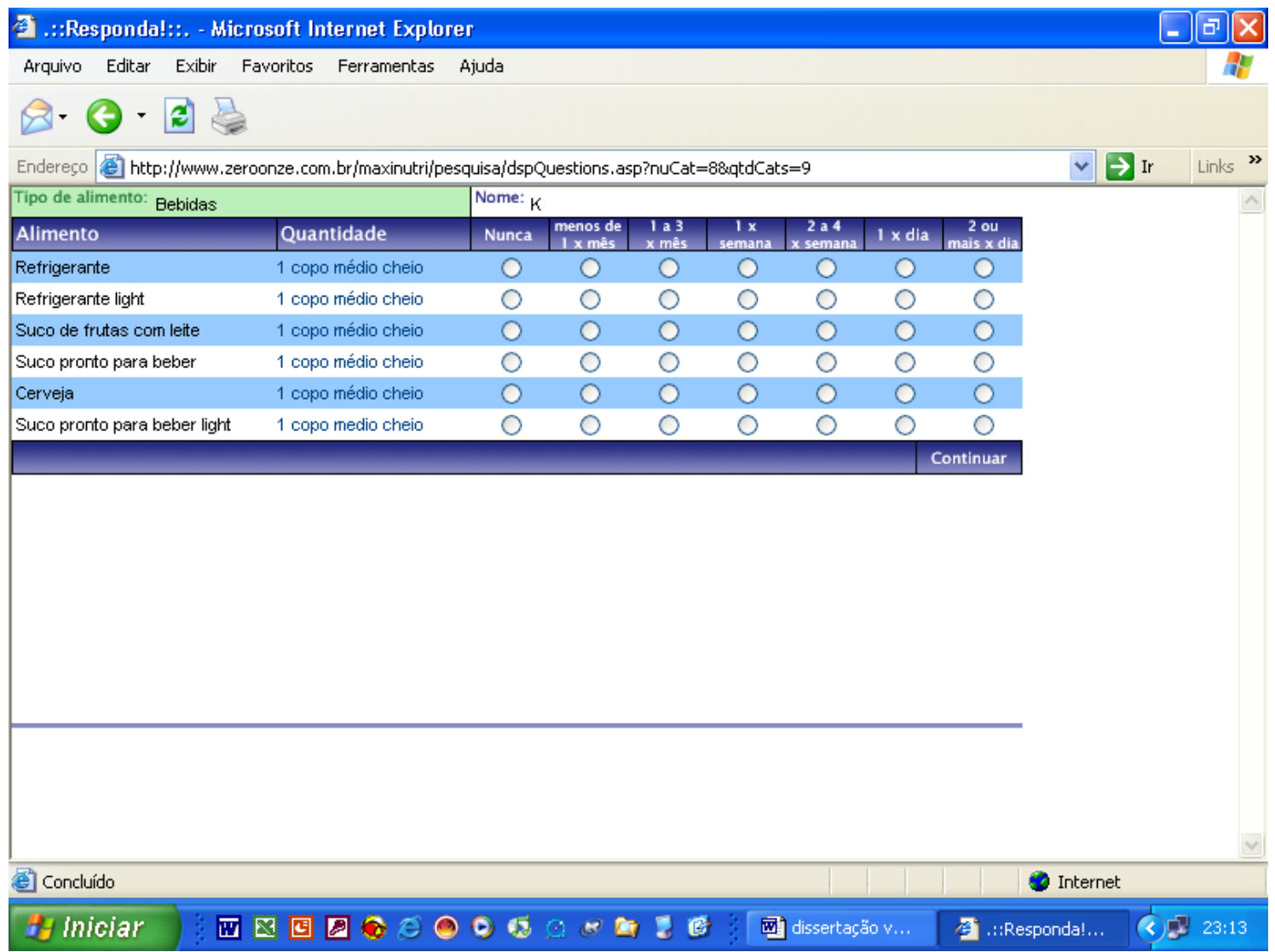


APÊNDICE 5 - Instruções para o preenchimento do QSFA online

Entre no site:

http://www.zeroonze.com.br/maxinutri/pesquisa/enquete.asp

Aparecerá a seguinte tela:

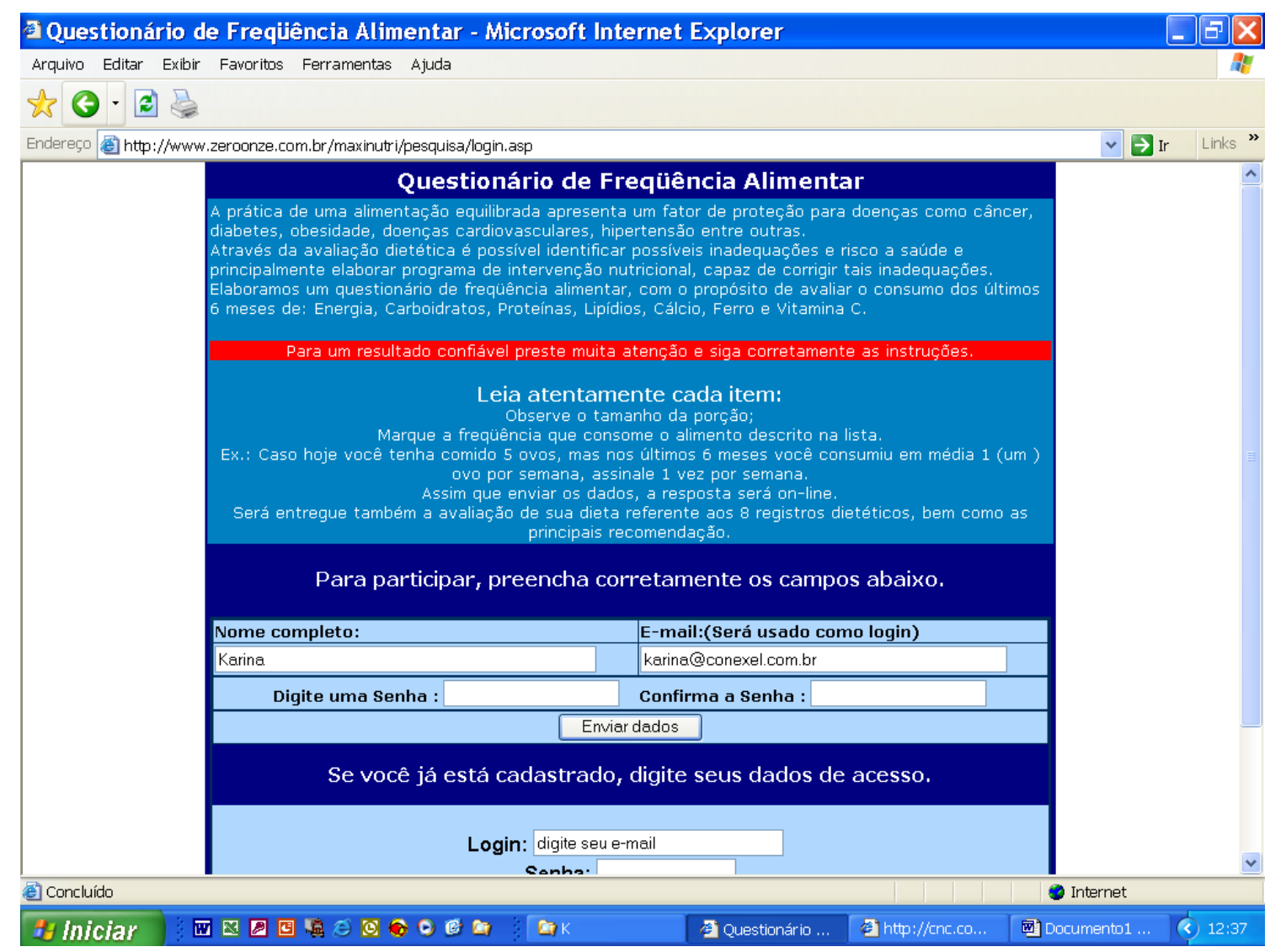

Preencha TODOS os campos corretamente e clique em "Enviar dados". 
Aparecerá a seguinte tela:

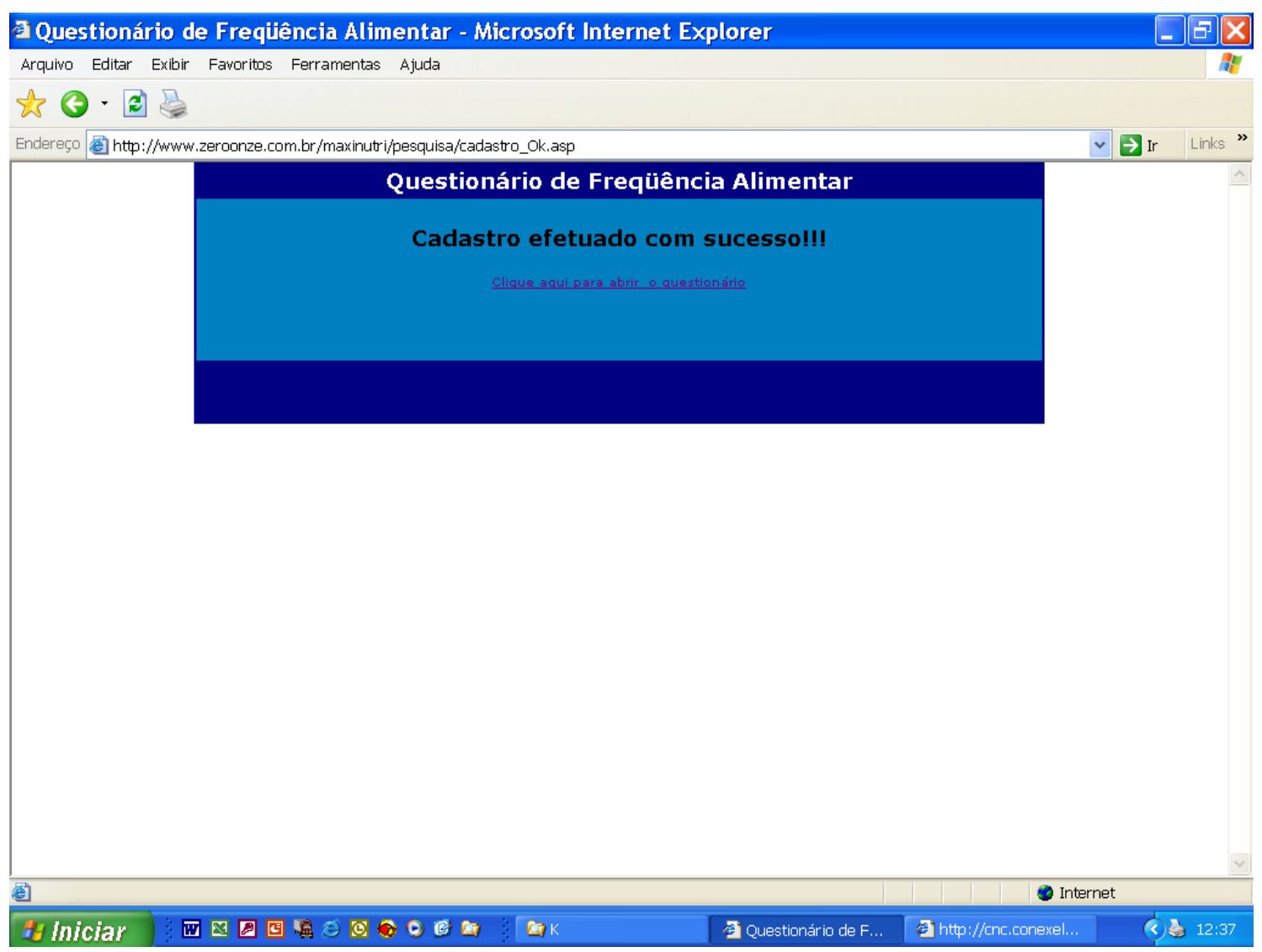

Clique em "Clique aqui para abrir o questionário". 
Aparecerá a seguinte tela:

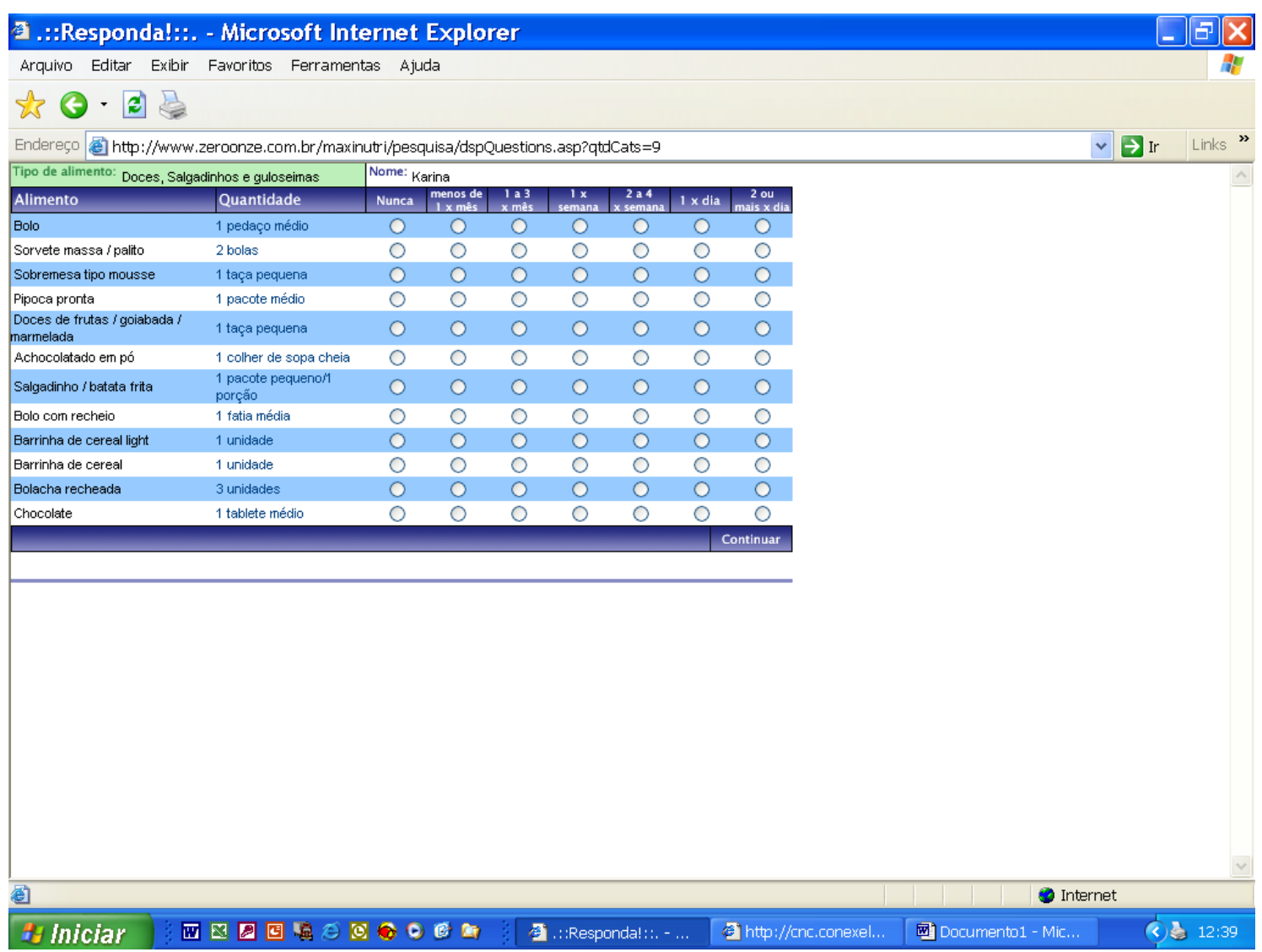

Preencha corretamente TODAS as linhas (alimentos).

Clique em "Continuar".

Siga as mesmas instruções para as telas seguintes. 
A última tela de alimentos será a seguinte:

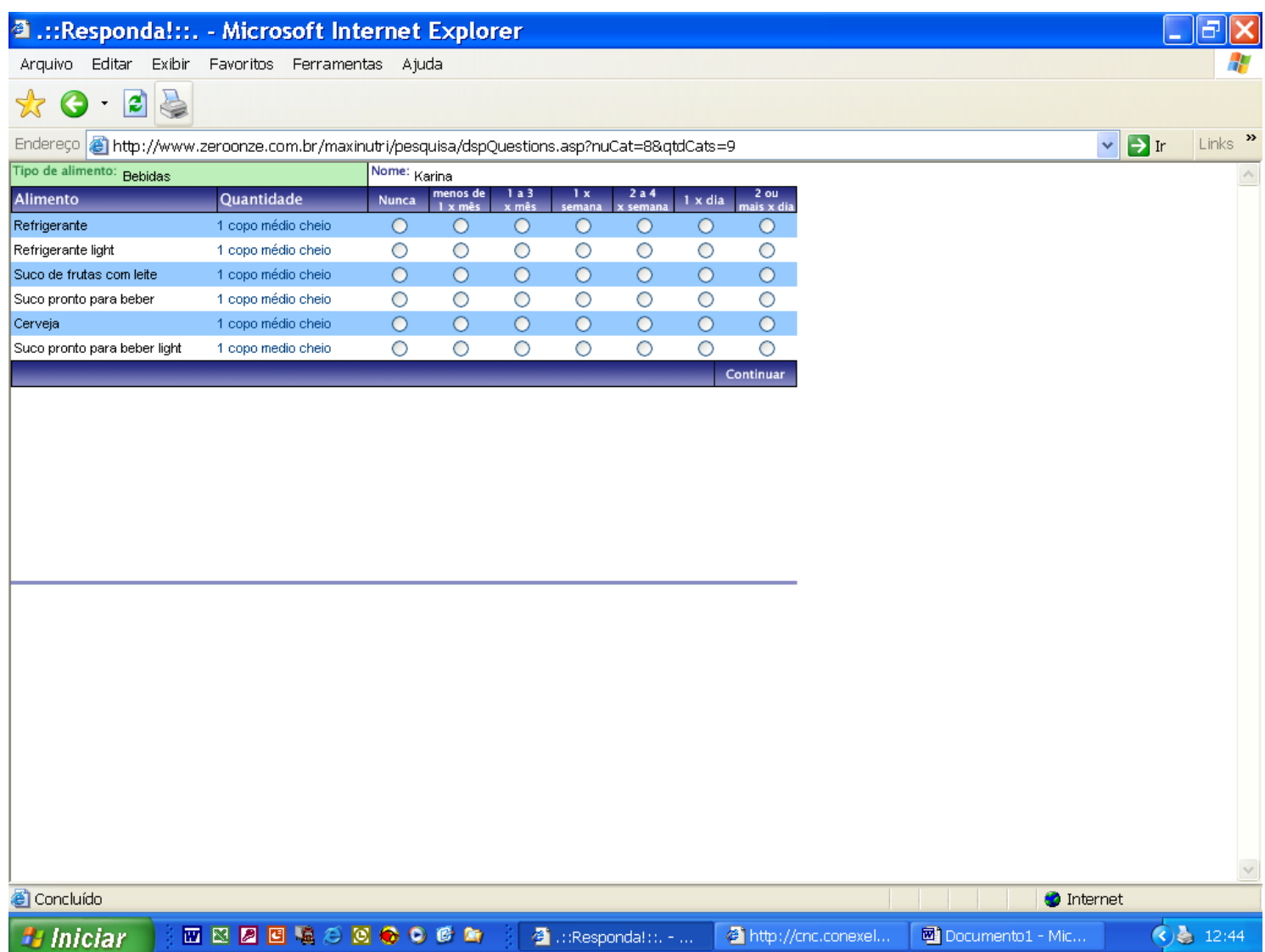

Preencha corretamente TODAS as linhas (alimentos).

Clique em "Continuar". 
No final você receberá um resumo de sua ingestão.

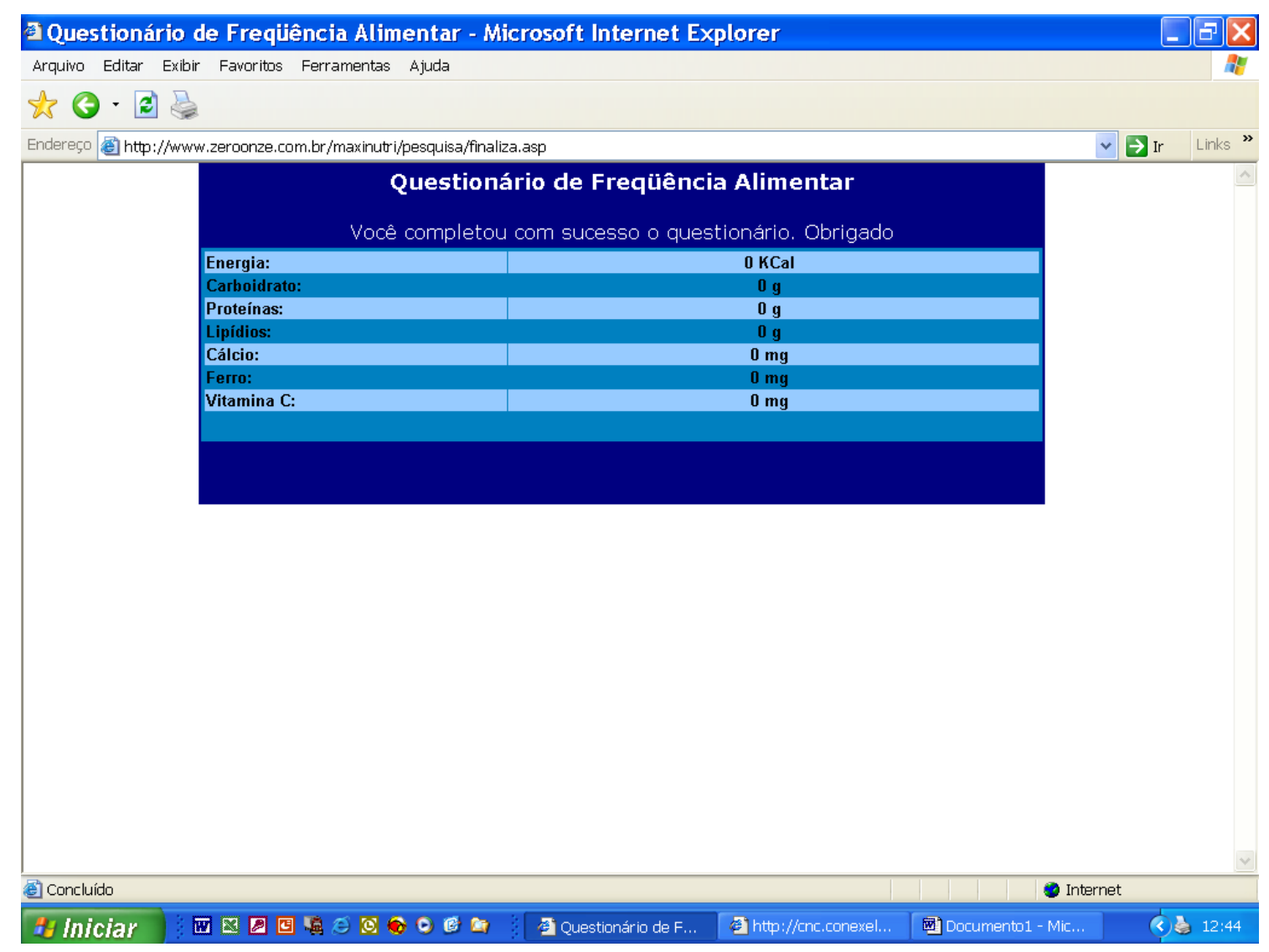

\author{
QUALQUER DÚVIDA \\ ENTRE EM CONTATO COM KARINA \\ NOS TELEFONES: \\ 8331-4984 ou 4366-9616
}

TEREI PRAZER EM AJUDAR !!! 


\section{APÊNDICE 6 - Normas para o exame de Qualificação}

\section{VII - Exame de Qualificação}

1. O exame de qualificação é obrigatório a todos os alunos nos cursos de Mestrado, Doutorado e Doutorado Direto.

2. O exame de qualificação deve ser realizado no máximo até seis meses antes da data limite do curso do aluno (conforme Resolução CoPGr 5140, de 20/09/2004), após completados os créditos mínimos obrigatórios em disciplinas.

$2.1 \mathrm{O}$ aluno que não se qualificar dentro do prazo será desligado do programa.

3. O exame de qualificação consta de:

a) avaliação do projeto de pesquisa, apresentado por escrito na forma de uma monografia.

b) avaliação do projeto de pesquisa, apresentado oralmente na forma de uma aula expositiva.

c) avaliação do currículo Lattes e do histórico escolar parcial de pós-graduação do aluno.

3.1 Seis exemplares da monografia de qualificação deverão ser apresentados junto à Secretaria de Pós-Graduação até sessenta dias antes do vencimento do prazo previsto no item 2 deste inciso VII.

3.1.1 Junto com os exemplares, poderá ser encaminhada uma lista com as sugestões de nomes para a composição da Comissão Julgadora.

3.1.2 A monografia de qualificação deve ser confeccionada de acordo com as normas da Associação Brasileira de Normas Técnicas (ABNT).

3.1.2.1 Havendo resultados e conclusões, os mesmos poderão ser incluídos no texto da monografia de qualificação.

3.1.3 A monografia deverá ter um "anexo obrigatório", no qual deverão constar:

a) cópia desta norma (inciso VII).

b) cópia da ficha do aluno (histórico escolar parcial), emitido pelo FenixWeb.

c) cópia do aval do Comitê de Ética em Pesquisa ou declaração conjunta do aluno e do orientador de que o trabalho dispensa análise do Comitê de Ética em Pesquisa.

4. Cabe à CPG indicar a Comissão Julgadora, composta por três membros titulares e dois membros suplentes, todos com titulação mínima de Doutor. No mínimo um dos membros titulares e um dos suplentes devem ser estranhos ao PRONUT.

4.1 A participação do orientador na Comissão Julgadora não é obrigatória.

5. A sessão do exame de qualificação deve ser pública, com duração máxima de cinco horas.

6. Ao aluno reprovado é dada uma segunda oportunidade para realizar outro exame desde que dentro do prazo estipulado pela Resolução CoPGr 5140, de 20/09/2004.

6.1 Nesse caso, preferencialmente, a Comissão Julgadora deverá ser composta pelos mesmos membros do primeiro exame.

$6.2 \mathrm{O}$ aluno reprovado na segunda oportunidade será desligado do programa.

7. Os casos omissos serão resolvidos pela CPG, à luz do Regimento de PósGraduação da Universidade de São Paulo

São Paulo, 10 de maio de 2005.

Profa. Dra. Silvia Maria Franciscato Cozzolino Presidente da CPG/PRONUT/USP 